\title{
CLADISTIC ANALYSIS OF THE PALEOZOIC BRYOZOAN FAMILIES MONTICULIPORIDAE AND MESOTRYPIDAE
}

\author{
Amber Diane Adamczyk
}

Submitted to the faculty of the University Graduate School in partial fulfillment of the requirements

for the degree

Master of Science

in the Department of Earth Sciences.

Indiana University

December 2010 
Accepted by the Faculty of Indiana University, in partial fulfillment of the requirements for the degree of Master of Science.

Joseph F. Pachut, Ph.D., Chair

Lenore P. Tedesco, Ph.D.

Master's Thesis

Committee

Gary D. Rosenberg, Ph.D. 


\section{DEDICATION}

To Patricia A. Roorda:

without you, I would not have known enough, cared enough, or been strong enough to want this degree.

You inspired me.

To Matt D. Adamczyk:

without you...I never would have gotten this far. You supported me.

In memory of my grandparents:

Dolores Roorda 1918 - 2009

Robert Enright Jr. 1928 - 2010 


\section{ACKNOWLEDGEMENTS}

I would like to thank several people for their help, support, and contributions to this work. First, thank you to Dr. Mirsky and the Earth Sciences Department for the fellowship that allowed me to attend IUPUI and complete this degree! Thank you to Dr. Lenore Tedesco and Dr. Gary Rosenberg for participating on my committee, and for their help in reviewing this manuscript. Thank you to my fellow students for their help and camaraderie in the classroom, office, and the field. Many thanks go to Dr. Robert Anstey for the use of his character key, and his help with finding and translating literature sources. Thank you to the Smithsonian for photographs of Aspidopora specimens. And finally, I would like to thank my adviser, Dr. Joseph Pachut, for his time spent in coding session, meetings, and draft revisions, his support during a difficult period in my life, and his patience and guidance throughout my studies at IUPUI. 


\begin{abstract}
Amber Diane Adamczyk

CLADISTIC ANALYSIS OF THE PALEOZOIC BRYOZOAN FAMILIES MONTICULIPORIDAE AND MESOTRYPIDAE
\end{abstract}

Two closely related families of Ordovician bryozoans, the Monticuliporidae and the Mesotrypidae, collectively contain 12 genera that have been reclassified repeatedly by various authors. Using published illustrations for the type specimens of each genus, character states for 267 morphological attributes were coded. Cladistic results were compared between the programs PAST and PAUP, and contrasted with phenetic methods. PAUP produced the shortest trees, with better summary index values and low homoplasy. Phenetic results varied, depending largely on the similarity measures used. Cladistic analysis produced five tree topologies, the most parsimonious of which consisted of a monophyletic crown group, representing Family Monticuliporidae, and a paraphyletic stem group that included the genera Mesotrypa and Diazipora. The crown group includes the genera Aspidopora, Atactoporella, Acantholaminatus, Peronopora, Homotrypella, Homotrypa, Gortanipora, Monticulipora, Prasopora, and Prasoporina. The paraphyletic stem group matches Astrova’s concept of Family Mesotrypidae. These results suggest the placement of all 12 genera in a single Family Monticuliporidae. Future studies that include data for additional closely related genera in might provide a clearer picture of familial assignments for these, and other, stenolaemate genera.

Joseph F. Pachut, Ph.D., Chair 


\section{TABLE OF CONTENTS}

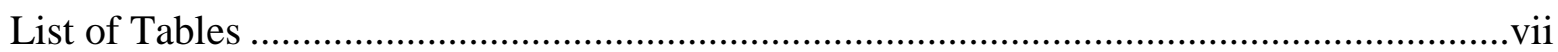

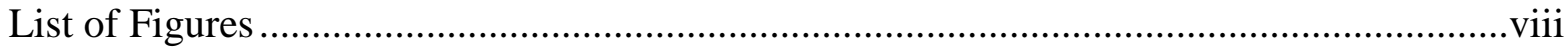

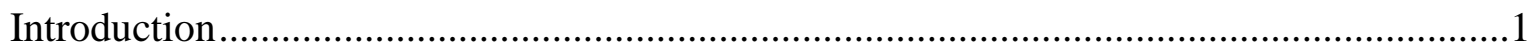

Establishment of the Families Monticuliporidae and Mesotrypidae ........................3

Taxonomic Revisions............................................................................4

Previous Cladistic Studies............................................................................ 7

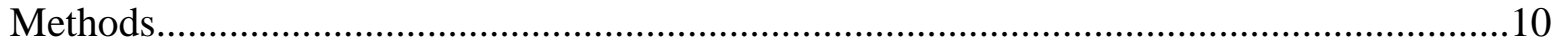

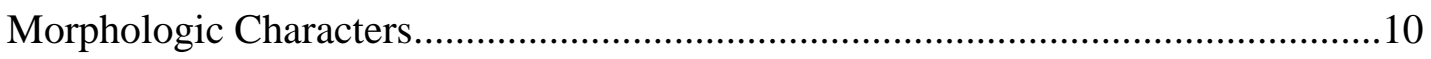

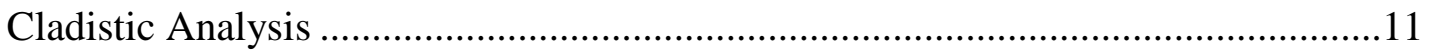

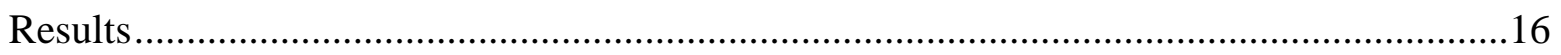

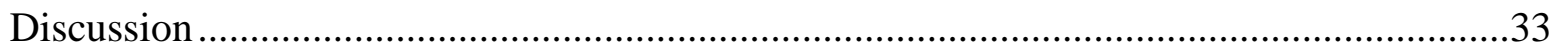

Appendices

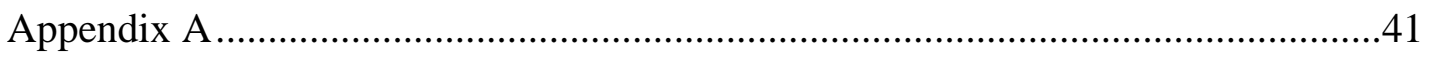

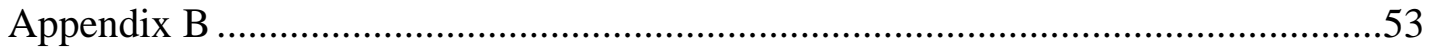

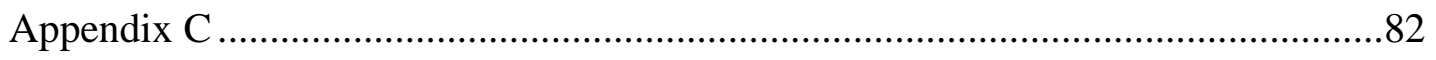

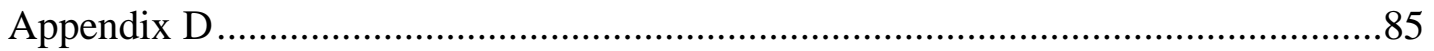

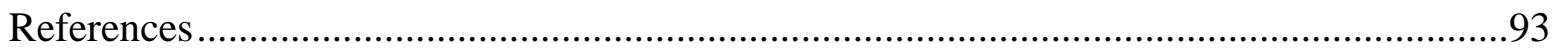

Curriculum Vitae 


\section{LIST OF TABLES}

Table 1: Assignments of genera to the Monticuliporidae and Mesotrypidae by previous

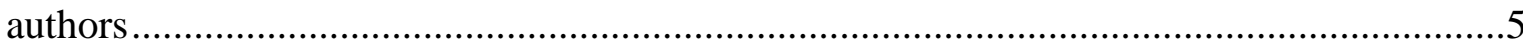

Table 2: Stratigraphic distribution of genera analyzed in this study ................................14

Table 3: Statistics associated with PAST and PAUP test results.....................................20

Table 4: Clade defining characters that have a consistency index $(\mathrm{CI})=1 \ldots \ldots \ldots \ldots \ldots \ldots \ldots . . . . .24$ 


\section{LIST OF FIGURES}

Figure 1: Cladograms based on heuristic analysis in PAST ........................................17

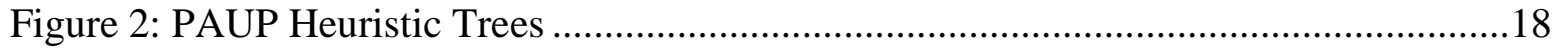

Figure 3: PAUP Bootstrap 50\% majority-rule consensus tree........................................22

Figure 4: Optimal Most Parsimonious Tree produced by reweighting of heuristic analysis by PAUP using the maximum rescaled consistency index of tree....................................23

Figure 5: Synapomorphic characters plotted on the most parsimonious tree ......................25

Figure 6: Node numbers for branching events among genera analyzed in this study ..........26

Figure 7: Cluster analysis of genera, using paired linkages and Dice similarity .................29

Figure 8: Cluster analysis of genera, using paired linkages and Euclidean similarity ..........30

Figure 9: Cluster analysis of genera using Neighbor Joining clustering and Dice

similarity.

Figure 10: Stratigraphic ranges of genera based on first (FADs) and last appearance

datums (LADs) for type species listed in Table 1 


\section{INTRODUCTION}

The Monticuliporidae and Mesotrypidae are currently recognized Ordovician and Silurian bryozoan families of stenolaemate (Class Stenolaemata) trepostome (Order Trepostomata) bryozoans. Colonies belonging to them range in maximum size from a few millimeters to a few centimeters and they may form massive or slender, cylindrically branching zoaria (stem diameter 4-8mm). Their morphology has been studied previously (Boardman 1966; Bork 1967, 1968; Pachut and Anstey 2002, etc.), providing a basis for taxonomic revisions. While there have not been many family level revisions (Anstey and Perry 1970; Anstey 1990; Anstey and Pachut 1995), several papers have re-described constituent genera (Boardman and Utgaard 1966; Astrova 1978; Boardman 1983; Brown and Daly 1985; Hickey 1988) resulting in several cases of synonymy. The validity of current definitions of the families has also been debated (Anstey and Perry 1970; Boardman 1983).

Historically, conventional taxonomic classifications have been produced using phenetics that group based on overall morphological similarity. Measurements of attributes are collected and analyzed using various forms of cluster analysis. Results reflect overall similarity between taxa, rather than delineating evolutionary relationships between taxa. For example, when applied to reptiles and birds, phenetic methods group lizards and crocodiles closer together because of greater overall similarity, with birds as a sister group. This explains the existence of separate, non-monophyletic, Classes: Reptilia and Aves. 
In cladistics, morphological measurements (or characters) are coded as discrete states that are compared to similar codings for an outgroup taxon in an attempt to determine patterns of relatedness using only shared-derived, or synapomorphic, characters. Cladistic methods reveal that crocodiles and birds share a more recent common ancestor than either does with lizards, in spite of the greater overall morphological similarity between lizards and crocodiles.

One of the strongest attributes of cladistic analysis is that characters can be weighted to reduce the effects of homoplasy, or convergent evolution. Symplesiomorphic characters (shared, primitive) can be separated from synapomorphic (shared, derived) ones that assist in delineating evolutionary relationships. Comparisons between cladistic trees and phenetic clusters can add strength to groupings that display both morphologic similarity and close genealogical descent, as well as document patterns of convergent evolution in less closely related taxa.

This study utilizes a set of 267 morphological characters to evaluate cladistic relationships among 12 genera that have been assigned to one of two families, the Monticuliporidae or Mesotrypidae. Comprehensive definitions of characters can be found in Boardman (1983), Marintsch (1998; p. 30), and/or Bock (2010). The morphology of taxa, and some of the coded characters, analyzed in this study are illustrated in Appendix A. The goal of this analysis is to compare cladistic results to existing taxonomic assignments, to determine whether cladistic results support two distinct monophyletic families, and to clarify the genus-level composition(s) of families. Results indicate that ten genera should be assigned to a Monticuliporidae crown group with the two remaining genera constituting a paraphyletic Mesotrypidae stem group. 


\section{Establishment of the Families Monticuliporidae and Mesotrypidae}

Family Monticuliporidae was created by Nicholson (1881), when bryozoans were considered species of corals rather than members of an entirely separate phylum. Nicholson assigned the genera Monticulipora, Fistulipora, Constellaria, and Dekayia to the family. Fistulipora and Constellaria were originally considered to be monticuliporids but were reassigned to families of cystoporate bryozoans by Ulrich (1882 and 1896, respectively). Dekayia is a trepostome assigned to Family Heterotrypidae. Nicholson divided Monticulipora into five sub-genera that included Heterotrypa, Diplotrypa, Monotrypa, Prasopora, and Peronopora. Heterotrypa and Monotrypa have been assigned to other families and Diplotrypa, Prasopora, and Peronopora have been placed in Family Mesotrypidae (Bock 2010). Currently, the Monticuliporidae also includes the genera Acantholaminatus (Marintsch 1998), Gortanipora (Vinassa de Regny 1921), and Aspidopora (Ulrich 1882) (Bock 2010). Boardman (1983) noted that Family Monticuliporidae is monothetic, defined by a single cystiphragm character, making its validity suspect. A polythetic approach, based on multiple characters, might produce a different and more natural family grouping (Anstey and Perry 1970; Boardman 1983).

Astrova (1965) established the Family Mesotrypidae for the placement of taxa of uncertain affinity that appear to be allied with genera assigned to the Monticuliporidae and Halloporidae. The family originally contained two genera, Mesotrypa and Diazipora, and was described as differing from the Monticuliporidae by possessing thin walls and lacking blister-like cystiphragms.

Astrova (1978) provided an overview of monticuliporids and their evolution; the family displayed trends that included decreasing zooecial sizes, increasing number of acanthostyles, and a shift from polygonal apertures to rounded and or petaloid apertures, 
the latter produced by abundant inflecting acanthostyles. This led to the suggestion that the genus Mesotrypa was ancestral to the genus Prasopora, considered at that time to be a monticuliporid, because it possessed cystiphragms. Monticulipora, which appeared in the stratigraphic record simultaneously with Prasopora, was inferred to have given rise to Homotrypa, based on a shared colony growth form and the presence of compressed zooecia. A second group of monticuliporids distinguished by abundant mesozooecia and numerous, large acanthostyles included the genera Peronopora and Atactoporella (Astrova 1978, p. 47-50).

Since the creation of Family Mesotrypidae, many revisions of component genera and of generic concepts have occurred (Table 1). This underscores the need for reanalysis of both families using cladistic methods.

\section{Taxonomic Revisions}

Boardman and Utgaard (1966, p. 1097) revised the generic concept of Peronopora to include "species differing significantly from the type species only in growth habit” based on the shared possession of hooked, offset, or segmented acanthostyles in both bifoliate (bilaminate or two-layered) and non-bifoliate species that had similar zooecial characters. That revision resulted in several authors transferring species from Atactoporella, Aspidopora, Homotrypella, Monticulipora, and Prasopora into Peronopora (Boardman and Utgaard 1966; Astrova 1978; Brown and Daly 1985).

Hickey (1988) felt that the transfer of five monticuliporid genera warranted an investigation of both generic and familial concepts. Toward that end, he performed a cladistic analysis on bifoliate forms of Peronopora to address systematic uncertainties 
Table 1: Assignments of genera to the Monticuliporidae and Mesotrypidae by previous authors. Genera in parentheses are considered synonyms with the genus listed above them.

\begin{tabular}{|c|c|c|}
\hline Source & Monticuliporidae & Mesotrypidae \\
\hline \multirow[t]{6}{*}{ Ulrich 1890} & Monticulipora & $\mathrm{n} / \mathrm{a}$ \\
\hline & Atactoporella & \\
\hline & Homotrypa & \\
\hline & Homotrypella & \\
\hline & Peronopora & \\
\hline & Prasopora & \\
\hline \multirow[t]{5}{*}{ Astrova 1978} & Monticulipora & Mesotrypa \\
\hline & $\begin{array}{l}\text { Prasopora } \\
\text { (Aspidopora, Prasoporina) }\end{array}$ & Diazipora \\
\hline & Atactoporella & \\
\hline & $\begin{array}{l}\text { Homotrypa } \\
\text { (Homotrypella) }\end{array}$ & \\
\hline & Peronopora & \\
\hline \multirow[t]{5}{*}{ Marintsch 1998} & Prasopora & n/a \\
\hline & Mesotrypa & \\
\hline & $\begin{array}{l}\text { Peronopora } \\
\text { (Homotrypella) } \\
\text { Acantholaminatus }\end{array}$ & \\
\hline & Homotrypa & \\
\hline & Monticulipora & \\
\hline \multirow[t]{8}{*}{ Bock 2010} & Acantholaminatus & Atactoporella \\
\hline & Aspidopora & Diazipora \\
\hline & Gortanipora & Homotrypa \\
\hline & Monticulipora & Homotrypella \\
\hline & & Mesotrypa \\
\hline & & Peronopora \\
\hline & & Prasopora \\
\hline & & Prasoporina \\
\hline
\end{tabular}


regarding the definitions of both the genus Peronopora and Family Monticuliporidae. Using a set of 57 characters (Hickey, 1988), the resulting clades supported a monophyletic grouping of bifoliate species of Peronopora. Conversely, removing median lamina characters from the data set produced a non-monophyletic bifoliate clade, indicating that bifoliate and unilaminate species share some homoplastic (i.e. convergent) zooecial characters and could only be considered congeneric if median lamina characters were not important taxonomically (Hickey 1988). He concluded that a discontinuous median lamina in Peronopora is characteristic of the morphology and development of bifoliate forms and is a heritable trait making the inclusion of non-bifoliate species within the genus unwarranted. Additionally, hooked acanthostyles do not occur consistently in any of the other taxa, bifoliate species of Peronopora share a unique pattern of astogeny (colony development), and the genus has a restricted geographic distribution. Pachut and Anstey (2002) have supported Hickey's restriction of bifoliate species to Peronopora. Marintsch (1998) re-described several of the genera evaluated in this study (Peronopora, Prasopora, Mesotrypa, Homotrypa and Monticulipora) and established a new genus, Acantholaminatus, all of which were placed in the Monticuliporidae. None were assigned to the Mesotrypidae, although without explanation. Marintsch disagreed with Hickey's restriction of Peronopora to bifoliate forms, adopting Boardman and Utgaard's (1966, p. 1097) concept of Peronopora that included forms “differing from type species only in growth habit.” That decision made Ulrich's original differentiation of Homotrypella invalid, and it was reassigned to Peronopora (Marintsch 1998).

This brief history of the systematics of monticuliporid bryozoans illustrates how it has been complicated by morphological uncertainties and inadequate generic descriptions 
that have resulted in a confusing number of reassignments of both species and genera. Historically, studies have considered most genera as members of the Monticuliporidae (Ulrich 1890, Astrova 1978, Anstey 1987, Pachut et al. 1994, Marintsch 1998, Pachut and Anstey 2002, etc.), leaving the Mesotrypidae with the two genera (Diazipora and Mesotrypa) that Astrova originally included in her classification. However, one current taxonomic treatment (Bock 2010) placed most traditional monticuliporids in the Mesotrypidae (Table 1).

\section{Previous Cladistic Studies}

In his analysis of the role of astogeny in the evolution of Paleozoic bryozoans, Anstey (1987, p. 33) included a previously unpublished genus-level phylogenetic tree of the Monticuliporidae developed by David R. Hickey. That tree was selected because it did not include polytomies (nodes that include three or more immediately descending branches; a non-dichotomous branching point) and was produced using Dollo parsimony that minimizes the probability of character state gains in favor of character state losses. In that tree, Mesotrypa and Diazipora were sister groups that together represented a sister group of Prasopora. In turn, all three genera represent a sister clade to one that includes Homotrypa, Gortanipora, Homotrypella, Peronopora, Atactoporella, and Monticulipora. Aspidopora was ancestral to both clades. This tree was moderately to highly congruent with trees produced by phenetic methods (Anstey and Perry, 1973; Pachut and Anstey, 1984) that utilized all characteristics without regard to their status as primitive (plesiomorphic) or advanced (apomorphic) attributes.

A cladistic study by Key (1990) resulted in the recognition of a new trepostome genus, Bimuropora. Characters involving wall structure, colony growth patterns, and 
zooecial ontogeny controlled the location of taxa in the cladogram. Specifically, four species assigned to Bimuropora shared a common ancestor with four species assigned to Champlainopora, resulting in the recognition of a new family Bimuroporidae. However, the analysis produced 19 equally parsimonious trees and a consensus cladogram that contained two large unresolved polytomies.

Anstey (1990) performed a cladistic analysis of Paleozoic bryozoan classes and orders, using 54 two-state and multistate characters. Class Stenolaemata, Paleozoic freewalled stenolaemates, Order Trepostomata, and Order Cheilostomata formed separate monophyletic, derived, clades. Class Gymnolaemata, and Orders Ctenostomata, Tubuliporata, Cryptostomata and Cystoporata, were paraphyletic taxa. Anstey concluded that extant groups of bryozoans were more plesiomorphous (primitive) than extinct freewalled stenolaemates. However, the low consistency index (CI) of 0.438 and the large number of character reversals and homoplasies suggested that the tree's topology might change if new characters were included in the analysis.

Anstey and Pachut (1995) analyzed phylogenetic relationships among 60 families of stenolaemate bryozoans using 54 characters. Initially 11 stenolaemate suborders were analyzed by coding the most frequently displayed trait in a subset of 26 characters. The Branch and Bound algorithm of PAUP produced two trees with a CI of 0.556. Trepostomes and cystoporates were sister groups, and all three major stenolaemate orders (Cystoporata, Trepostomata, and Cryptostomata) were monophyletic. A second family level analysis utilized character codings for the oldest known genus within each family and reproduced the branching patterns of the suborders from the first analysis. They concluded (fig. 8.2, p. 245) that both the Halloporina and the Trepostomata, minus the 
Esthonioporina, form ordinal-level clades. Interestingly, the Monticuliporidae and Mesotrypidae were not closely related. Anstey and Pachut (1995, p. 243) suggested that problems arise when cladistic analyses are based on the oldest genus in a family because those primitive taxa often lack the derived character states that define conventional groupings. Links between ancestral (Ordovician) and descendant (later) families will require greater resolution that can only be provided by genus level data sets. An alternate cladogram (Anstey and Pachut, 1995, fig. 8.3, p. 246), based on representative or typical genera rather than the oldest genera, indicated that the Monticuliporidae and Mesotrypidae were closely related sister clades, as were Families Halloporidae, Trematoporidae, Heterotrypidae, and Dittoporidae (Anstey and Pachut 1995).

One recent cladistic study analyzed species-level data. Pachut and Anstey (2002) recognized eight species of Peronopora. A later paper (Anstey and Pachut, 2004) extended their earlier analysis by comparing cladistically-defined species to those recognized using phenetic methods. They identified eight monophyletic crown group species, one of which (P. browni) was new, and eight non-monophyletic metaspecies. 


\section{METHODS}

\section{Morphologic Characters}

Characters useful in cladistic studies of Paleozoic stenolaemate bryozoans were developed, in part, from those used in several earlier studies (Anstey and Perry 1970, 1973; Corneliussen and Perry 1973; McKinney 1977, 2000; Anstey 1978; Prezbindowski

and Anstey 1978; Pachut and Anstey 1984; Blake and Snyder 1987; Hickey 1988; Anstey 1990; Key 1990; Cuffey and Blake 1991; Hageman 1991; Pachut, Anstey and Horowitz 1994; Anstey and Pachut 1995; Spearing 1998; Tang and Cuffey 1998; Taylor and Weedon 2000) and merged into a comprehensive listing of 317 characters that include 701 derived states (Paquette 2008; Appendix B). A subset of 267 of these characters was appropriate for coding the trepostome genera analyzed in this study.

Character state codings were determined from published photographs of thin sections, from light and SEM photomicrographs, from line drawings, and from systematic descriptions of the type species of genera included in this study. Sources for coding include (Anstey and Perry 1973; Astrova 1978; Boardman and Utgaard 1966; Bork and Perry 1968; Brown and Daly 1985; Marintsch 1998; Nickles 1902; Taylor 1996; Ross 1967; and Utgaard and Perry 1964.) It is impossible to determine the exact number of specimens utilized in defining genera because authors did not consistently list specimens that were evaluated in addition to those that they illustrated. Some generic descriptions listed large type suites, while others include only one or two specimens. Only the type species for each genus was coded, with two exceptions in which published material was inadequate to determine all character states. For those genera, a closely related species 
was used in addition to the type specimen(s). All analyses designated characters as "unordered” so that character states could change freely in either direction without penalty for reversals or skipping character states.

All ingroup genera are currently assigned to either the Mesotrypidae (eight genera) or Monticuliporidae (four genera). The genus Goryunovia (Taylor and Rozhnov 1996) was used as an outgroup. It is stratigraphically older and displays an abundance of primitive character states compared to all ingroup genera.

\section{Cladistic analysis}

Cladistic analyses were performed using PAUP, or Phylogenetic Analysis Using Parsimony, (Swofford 2007), and PAST, and PAleontological STatistics (Hammer 2003). PAUP can analyze morphometric and genetic sequence data and can perform both heuristic and exhaustive searches (see below), whereas PAST permits heuristic analyses of morphologic data only. Cladistic analyses were performed using both programs and their effectiveness compared based on the numbers and lengths of equally parsimonious trees produced by each. Cluster analysis was also performed, using PAST, to compare phenetic and cladistic results.

As mentioned above, PAUP can perform both heuristic and exhaustive searches. Heuristic searches employ a trial and error method rather than performing a comprehensive search. However, heuristic searches are faster (require fewer computer resources) and can analyze larger data sets than exhaustive searches. Described as a "hill climbing method,” heuristic searches begin with a tree consisting of three taxa. New taxa are added individually (a variety of methods are available), all possible combinations are 
evaluated, and the shortest tree is retained. The ASIS addition sequence was used, adding taxa in the order that they appeared in the data matrix. Branch swapping begins after all taxa have been added to the tree. The Tree Bisection and Reconnection (TBR) method of branch swapping bisects a tree along a branch and the resulting two "subtrees" are reconnected in every way possible. Trees are evaluated using parsimony, selecting the one(s) that reflect the fewest character state changes. The steepest descent option was used to ensure that PAUP did not abandon a search path when a shorter tree was found but continued to evaluate the entire path for the existence of shorter trees. Reconstruction of character states at internal (ancestral) nodes was accomplished by character state optimization, minimizing the amount of change required by a single character for any particular tree. In cases where character state changes could be placed at multiple nodes, the accelerated transformation criterion, or ACCTRAN, placed character state changes closer to the root of the tree rather than closer to branch tips. Initial tests runs in PAST used the heuristic search algorithm, TBR option, and Fitch (unordered character state changes) optimization.

The small data set, consisting of only 12 taxa, permitted both exhaustive and heuristic searches using PAUP. The exhaustive search, using the branch and bound algorithm, operates by starting with a tree consisting of three taxa to which taxa are added until all have been included. It then backtracks one node and evaluates all possible trees created by the addition of that taxon. This process continues until all possible trees have been evaluated.

A bootstrapping procedure was run in addition to the branch and bound search. The procedure holds taxa constant while character states are replicated with replacement, 
building a series of bootstrap replicates of the same size as the original tree. Replicates are searched using the branch and bound algorithm, and a majority rule consensus tree is constructed on which the frequency of occurrence of bootstrapped groupings in the tree is indicated, providing measures of confidence associated with each node in the cladogram. Quantitative indices from each analysis are calculated for the entire tree (ensemble value) and for individual characters (individual value). They include the consistency index, CI, which measures the fit of a character (or all characters) to the tree. CI values range from a lower bound based the number of possible states for a character, to an upper bound of one, indicative of the best possible character fit. The retention index, RI, is a function of the maximum, minimum, and actual amount of change in a character. RI equals zero when a character fits the tree as poorly as possible. The rescaled consistency index, or RC, is the product of RI and CI. With a lower bound of zero and an upper bound of one (perfect fit) the RC provides an immediate proportional indicator of a character's fit to the tree. Homoplasy is morphological similarity resulting from convergent evolution and not from genealogical descent. The degree of homoplasy is measured by the homoplasy index, HI, equaling 1-CI. Finally, the stratigraphic congruence index, SCI, measures the fit of proposed cladistic relationships to observed stratigraphic positions of the taxa being analyzed. Stratigraphic consistency indices (Table 2) were calculated using PAST (Hammer 2003) based on first and last appearance datums (FADs and LADs, respectively) for each genus, and for each type species, taken from original published reports of their stratigraphic distributions.

Stratigraphic positions were based on the International Stratigraphic Chart 2009 that uses dates from Gradstein et al. (2004) and Ogg et al. (2008). 
Table 2: Stratigraphic distribution of genera analyzed in this study. First (FAD) and Last Appearance Datums (LAD) were determined by using the endpoint ages that correspond to the currently recognized stratigraphic distribution of each genus $(G)$ and each type species (S) in the fossil record. The stages and durations were taken from the International Stratigraphic Chart (Ogg 2009).

\begin{tabular}{|c|c|c|c|c|c|}
\hline Genus & Epoch & $\begin{array}{c}\text { FAD } \\
\text { (G) }\end{array}$ & $\begin{array}{l}\text { LAD } \\
\text { (G) }\end{array}$ & $\begin{array}{r}\text { FAD } \\
\text { (S) }\end{array}$ & $\begin{array}{l}\text { LAD } \\
\text { (S) }\end{array}$ \\
\hline Monticulipora & $\begin{array}{l}\text { Upper Ordovician - } \\
\text { Late Silurian }\end{array}$ & 445.6 & 418.7 & 460.5 & 449.5 \\
\hline Gortanipora & Upper Ordovician & 445.6 & 443.7 & 460.5 & 443.7 \\
\hline Peronopora & $\begin{array}{l}\text { Upper Ordovician - } \\
\text { Early Silurian }\end{array}$ & 455.8 & 428.2 & 460.5 & 443.7 \\
\hline Aspidopora & $\begin{array}{l}\text { Upper Ordovician - } \\
\text { Early Silurian }\end{array}$ & 455.8 & 428.2 & 452.5 & 443.7 \\
\hline Acantholaminatus & Upper Ordovician & 455.8 & 445.6 & 455.8 & 445.6 \\
\hline Homotrypa & $\begin{array}{l}\text { Upper Ordovician - } \\
\text { Late Silurian }\end{array}$ & 460.9 & 418.7 & 460.5 & 449.5 \\
\hline Prasopora & $\begin{array}{l}\text { Upper Ordovician - } \\
\text { Late Silurian }\end{array}$ & 460.9 & 418.7 & 460.5 & 449 \\
\hline Prasoporina & $\begin{array}{l}\text { Upper Ordovician - } \\
\text { Late Silurian }\end{array}$ & 460.9 & 418.7 & 460.5 & 449 \\
\hline Diazipora & Upper Ordovician & 460.9 & 445.6 & 472 & 460.5 \\
\hline Mesotrypa & $\begin{array}{l}\text { Middle Ordovician - } \\
\text { Late Silurian }\end{array}$ & 471.8 & 418.7 & 460.5 & 449 \\
\hline Atactoporella & $\begin{array}{l}\text { Middle Ordovician - } \\
\text { Early Silurian }\end{array}$ & 471.8 & 422.9 & 452.5 & 443.7 \\
\hline Homotrypella & $\begin{array}{l}\text { Mid - Upper } \\
\text { Ordovician }\end{array}$ & 471.8 & 443.7 & 460.5 & 449 \\
\hline Goryunovia & Lower Ordovician & 478.6 & 471.8 & 479 & 466 \\
\hline
\end{tabular}


Initial cladistic analyses were performed using unweighted characters. However, character weights can be adjusted to de-emphasize convergences and reduce the effects of homoplasy. Second analyses reweight characters in initial heuristic searches by using the maximum (i.e., individual character) value of the RI, CI, or RC, calculated during initial unweighted PAUP analyses.

Cluster analyses of genera assigned to the Monticuliporidae and Mesotrypidae were performed using PAST so that phenetic groupings, based on overall morphologic similarity, could be compared to cladistic results. The pair group algorithm was used along with Euclidean Distance and the Dice coefficient of similarity; the neighbor joining algorithm was used with the latter. 


\section{RESULTS}

Heuristic searches using PAST identified two equally parsimonious trees (EPTs) each with lengths of 442 and ensemble Consistency Indices (CI) of 0.5463 (Figure 1). Heuristic searches using PAUP found 5 EPTs, whereas exhaustive branch and bound searches resulted in two EPTs. All reweighted searches returned a single most parsimonious tree (MPT), and the bootstrapped search produced 222 replicate trees and an associated consensus tree.

Heuristic searches using PAUP employed unordered characters and the TBR option, producing five different tree topologies. Two topologies (Figure 2) were nearly identical to those found by PAST but had better ensemble indices associated with them.

Ensemble index values for topology 2 were better than those for topology 1: tree lengths ranged between 121.45 and 124.94 , CI values between 0.6845 and 0.7085 , and RCI values between 0.4732 and 0.4989 (Table 3). Levels of homoplasy were approximately $30 \%$ for all five trees.

PAUP’s Branch and Bound algorithm generated two EPTs with topologies identical to those found using PAST's heuristic method. Tree lengths were 442 and 452 and RC values (0.232) were low. At 47\%, levels of homoplasy were higher than those for heuristic searches. These results were surprising, because exhaustive searches typically produce shorter trees than heuristic ones. This is because exhaustive methods evaluate every possible arrangement of a tree, while heuristic searches only proceed with the optimal tree at each step of addition, making it possible to miss a better configuration that occurs down a less than optimal arrangement at one step. 
Figure 1: Cladograms based on heuristic analysis in PAST. PAST found two different tree topologies, shown below. Tree length and ensemble CI for both were 442 and 0.5463 , respectively.

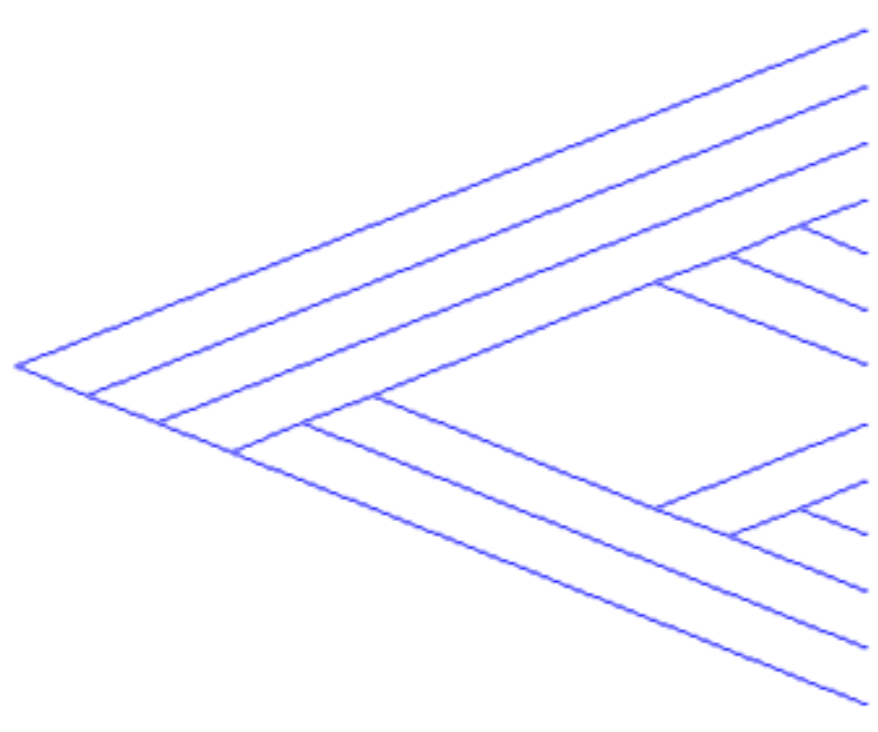

Goryunovia
Diazipora
Mesotrypa
Homotrypella
Homotrypa
Gortanipora
Monticulipora
Peronopora
Atactoporella
Acantholaminatus
Aspidopora
Prasopora
Prasoporina

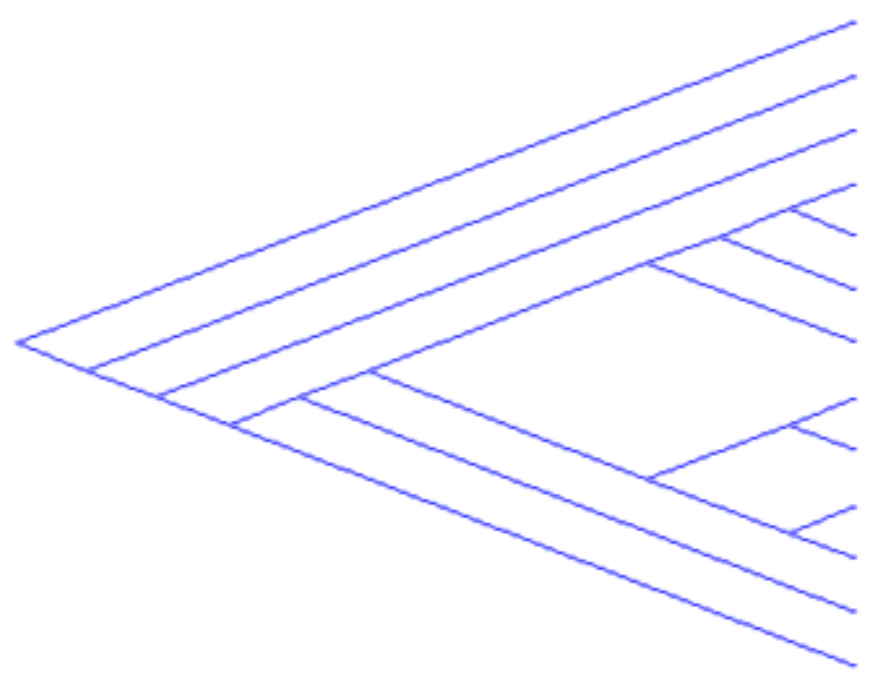

Goryunovia
Diazipora
Mesotrypa
Homotrypella
Homotrypa
Gortanipora
Monticulipora
Peronopora
Atactoporella
Acantholaminatus
Aspidopora
Prasopora
Prasoporina


Figure 2: PAUP Heuristic Trees: topology 1. This tree has a length of 123.0742. The CI was 0.6949; RC was 0.4832; and HI was 0.3051.

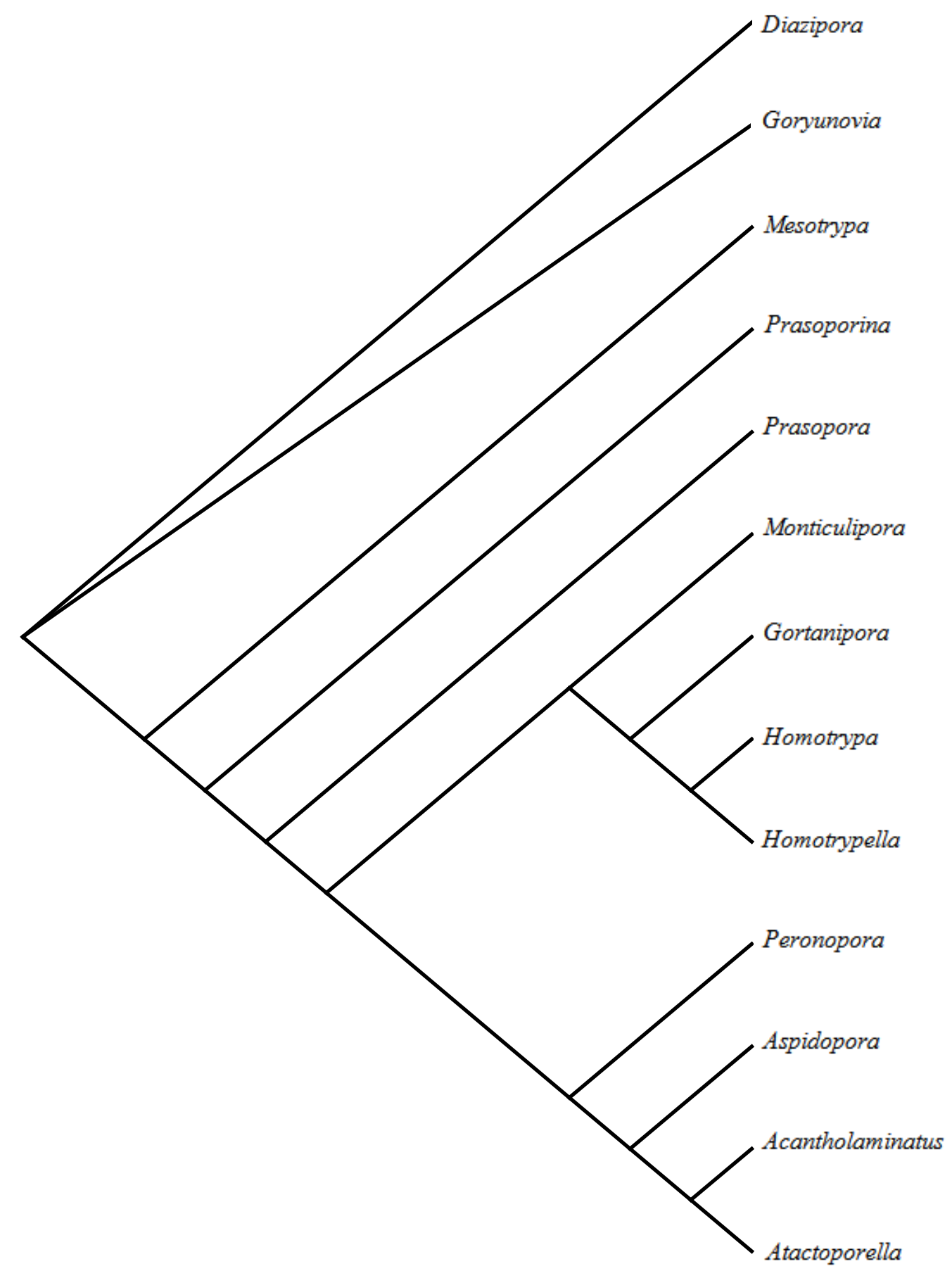


Figure 2, cont.: PAUP heuristic trees: topology 2. This tree has a length $=121.4520$, a $\mathrm{CI}=0.7042 ; \mathrm{RC}=0.4989 ;$ and $\mathrm{HI}=0.2958$.

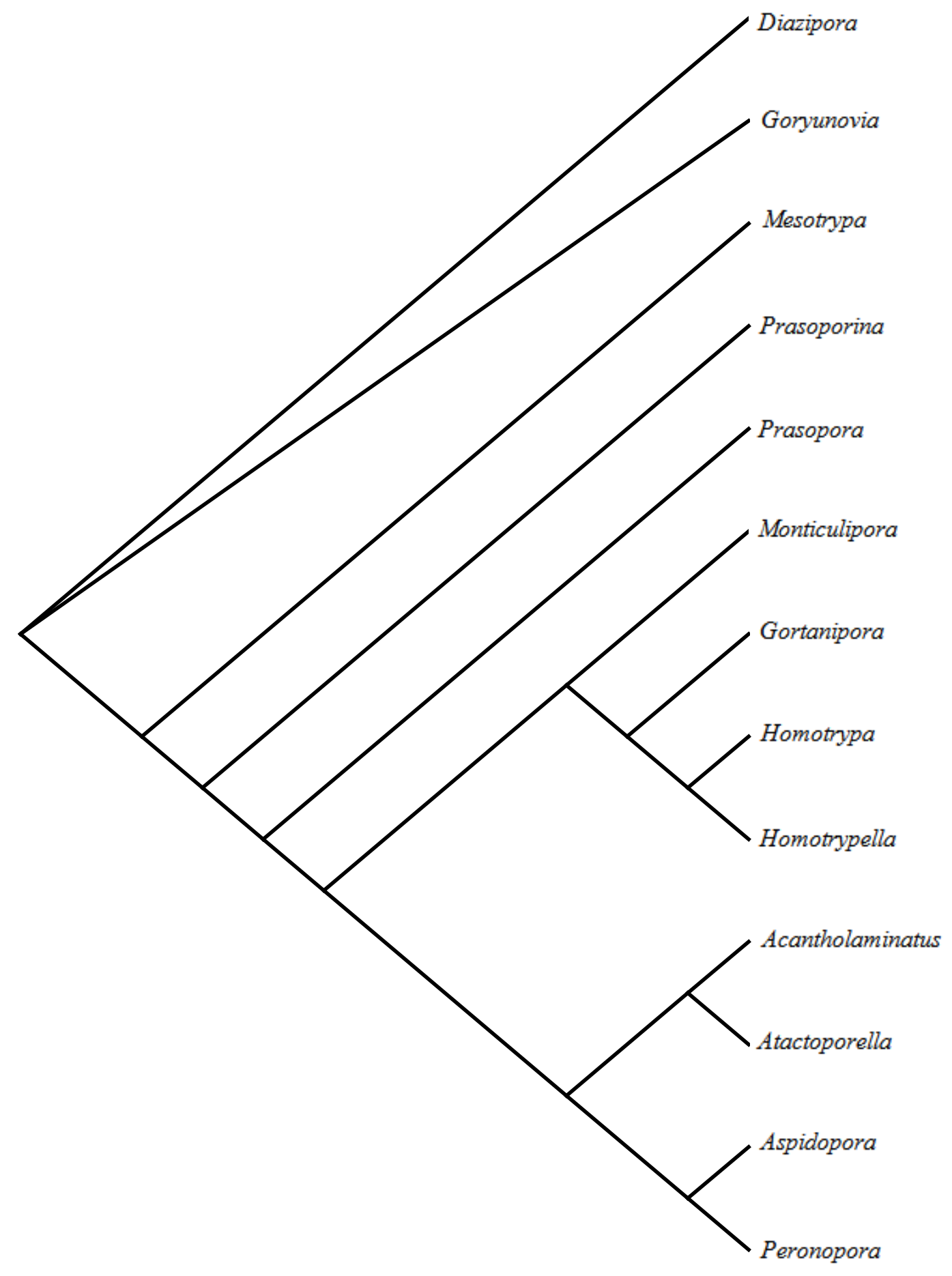


Table 3: Statistics associated with PAST and PAUP test results. Included are the consistency index (CI), rescaled consistency index (RC), retention index (RI), and the homoplasy index (HI). For PAST, the SCI is the stratigraphic consistency index. Indices are described in the text.

\begin{tabular}{lllllll} 
Type & Tree & Length & CI & RC & RI & HI \\
& Number & & & & & \\
\hline PAUP & $\mathbf{1}$ & 123.0742 & 0.6949 & 0.4832 & 0.6954 & 0.3051 \\
Heuristic & $\mathbf{2}$ & 121.4520 & 0.7042 & 0.4989 & 0.7085 & 0.2958 \\
& $\mathbf{3}$ & 124.1253 & 0.6890 & 0.4732 & 0.6868 & 0.3110 \\
& $\mathbf{4}$ & 124.9417 & 0.6845 & 0.4656 & 0.6802 & 0.3155 \\
PAUP & $\mathbf{5}$ & 123.7308 & 0.6912 & 0.4769 & 0.6900 & 0.3088 \\
B\&B Run1 & $\mathbf{1}$ & 452.0000 & 0.5288 & 0.2316 & 0.4380 & 0.4712 \\
PAUP & $\mathbf{2}$ & 452.0000 & 0.5288 & 0.2316 & 0.4380 & 0.4712 \\
B\&B Run2 & $\mathbf{2}$ & 442.0000 & 0.5249 & 0.2317 & 0.4415 & 0.4751 \\
PAUP & CI & 442.0000 & 0.5249 & 0.2317 & 0.4415 & 0.4751 \\
Reweighted & RC & 242.1167 & 0.5910 & 0.3152 & 0.5333 & 0.4176 \\
Heuristic & RI & 118.0120 & 0.6924 & 0.4892 & 0.7066 & 0.3076 \\
& Boot & 486.0500 & 0.6180 & 0.3882 & 0.6281 & 0.3820 \\
& & & 0.4774 & 0.1549 & 0.3245 & 0.5226 \\
PAST & & Length & CI & RI & SCI & \\
& $\mathbf{1}$ & 442.0000 & 0.5322 & 0.5463 & 0.4545 & \\
& $\mathbf{2}$ & 442.0000 & 0.5322 & 0.5463 & 0.3636 & \\
\hline
\end{tabular}


Bootstrapping using the Branch and Bound method produced 222 replicate trees and a consensus tree. High levels of confidence (Figure 3) were placed at nodes defining groupings common in the set of replicate trees. Individual percentages were high for all groupings indicating, for example, that a Homotrypa-Homotrypella clade occurred 65\% of the time, while a Gortanipora-Homotrypa-Homotrypella clade occurred in 93\% of all generated trees.

Exhaustive searches consistently produced longer trees than those found using the heuristic algorithm. Therefore, all subsequent analyses were computed using heuristic search methods. Initial trees were reweighted using the consistency (CI), retention (RI), and rescaled consistency (RC) indices. All three reweighting procedures produced single identical trees that matched the topology of one of the two most commonly found trees and resolved the polytomy produced using unweighted characters. The repeated appearance of one tree topology, irrespective of the algorithm used to generate it, strongly suggests that it represents an optimal solution that most accurately reflects cladistic relationships among genera (Figure 4).

Table 4 lists clade-defining apomorphies that are also plotted on the optimal MPT in Figure 5. Character state changes associated with each node in the tree are listed in Figure 6 and Appendix C. Shared derived, or synapomorphic, characters with consistency indexes (CI) of one, indicating that the state evolved only once, occur at single nodes. These characters provide the most reliable, unique (non-convergent) diagnostic traits for the identification of clades. All genera except Mesotrypa and Diazipora share monticule and cystiphragm characters. They may be important functional attributes, thought to affect water flow patterning by orienting zooid 
Figure 3: PAUP Bootstrap 50\% majority-rule consensus tree. This tree is a consensus of 222 replicate trees; numbers at the base of groups represents the percentage of replicated trees in which that group appeared. For example, the Homotrypa - Homotrypella group occurred in $65 \%$ of replicated trees.

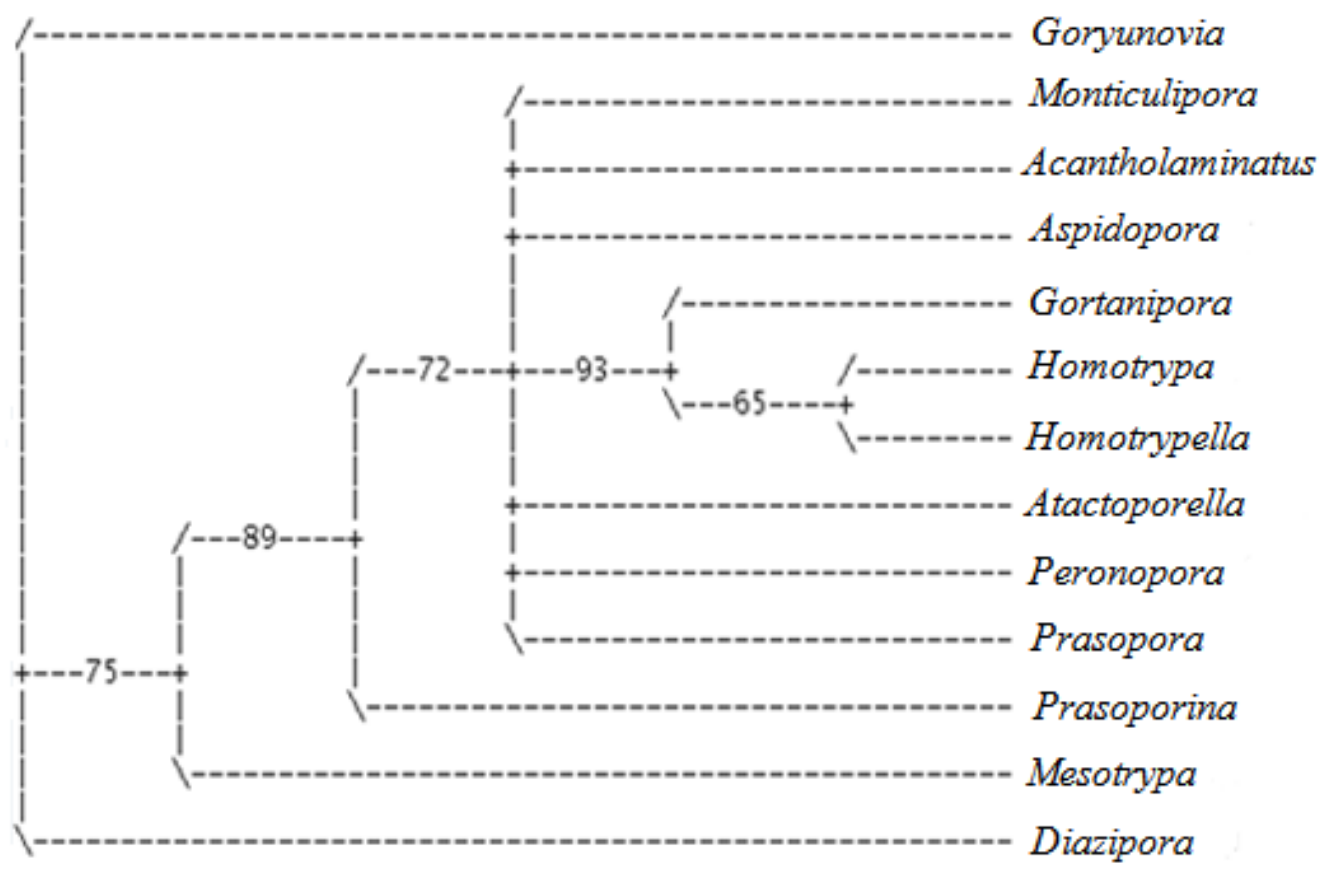


Figure 4: Optimal Most Parsimonious Tree produced by reweighting of heuristic analysis by PAUP using the maximum rescaled consistency index of tree (Figure 2).

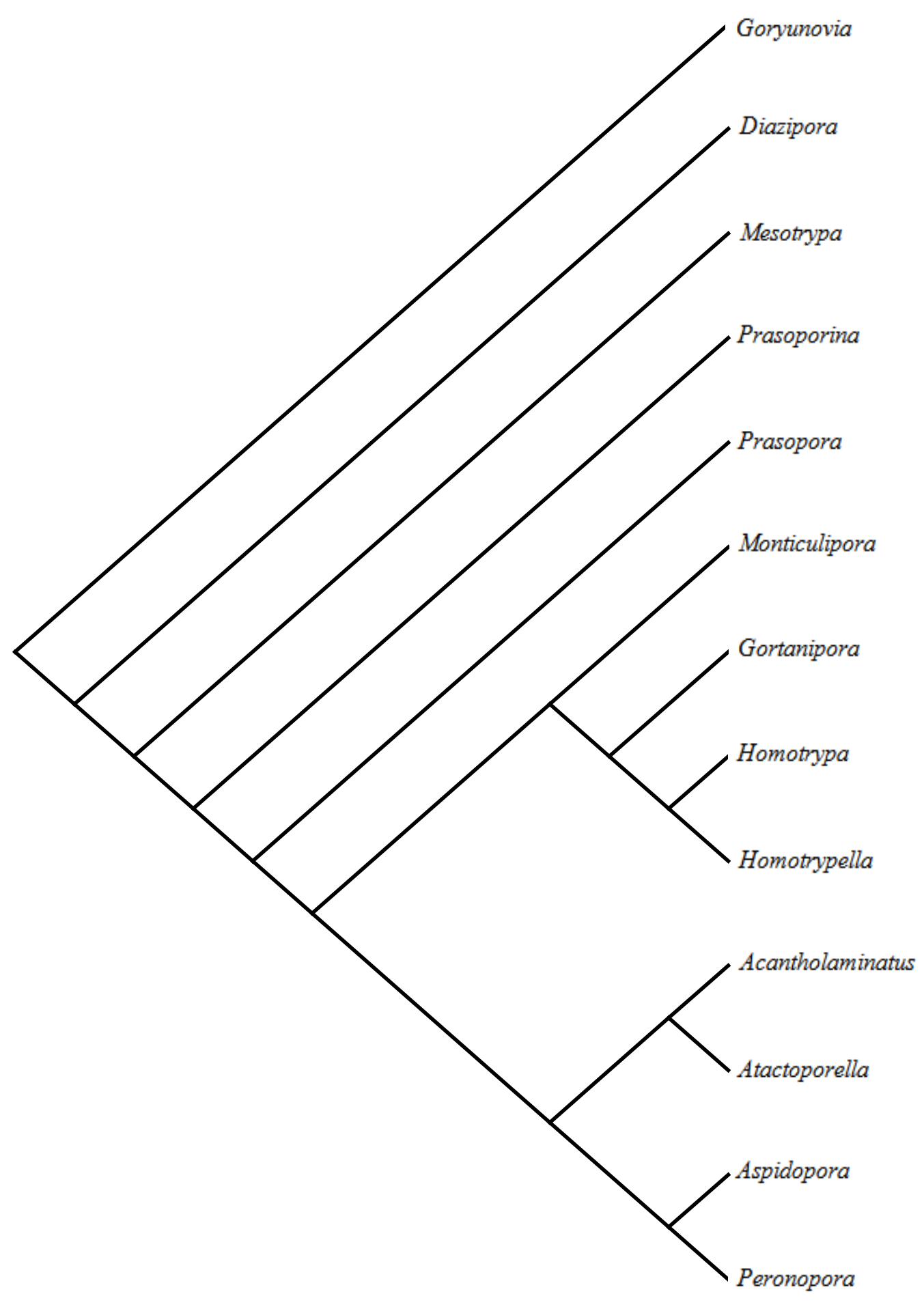


Table 4: Clade defining characters that have a consistency index $(\mathrm{CI})=1$. Characters are free of homoplasy and evolved only once. A complete character list is presented in Appendix B.

\begin{tabular}{cll}
$\begin{array}{c}\text { Character } \\
\text { Number }\end{array}$ & Type & \multicolumn{1}{c}{ Details } \\
\hline $\mathbf{6}$ & Zoarial Form & Cross section shape, cylindrical to polygonal \\
$\mathbf{7}$ & Zoarial Form & Cross section shape, type of branching \\
$\mathbf{9}$ & Zoarial Form & Diameter of branches \\
$\mathbf{1 0}$ & Zoarial Form & Cross section shape, uniform to variable diameter \\
$\mathbf{7 0}$ & Zooecia & Zooecial bend, rounded to abrupt \\
$\mathbf{7 1}$ & Endozone & Wall type, curving or linear \\
$\mathbf{8 1}$ & Budding & Axial endozone, presence of growing tips \\
$\mathbf{8 4}$ & Budding & Axial bud arrangement \\
$\mathbf{8 7}$ & Budding & Axial bundle, not present to well defined \\
$\mathbf{8 8}$ & Budding & Axial endozone without/with spiral budding \\
$\mathbf{8 9}$ & Budding & Axial endozone, non-radial to strongly radial \\
$\mathbf{9 0}$ & Budding & Axial zooecial arrangement \\
$\mathbf{9 1}$ & Budding & Axial endozone, medial rows of zooids \\
$\mathbf{9 4}$ & Basal Zooecia & Keel \\
$\mathbf{9 5}$ & Basal Zooecia & Sinus \\
$\mathbf{1 0 7}$ & Endozone & Regular to corrugated walls \\
$\mathbf{1 5 5}$ & Monticules & Size \\
$\mathbf{1 8 4}$ & Acanthostyles & Unimodal or discrete sizes \\
$\mathbf{2 0 5}$ & Diaphragms & orientation in regards to zooecial wall \\
$\mathbf{2 0 9}$ & Cystiphragms & abundance \\
$\mathbf{2 1 1}$ & Cystiphragms & present in zoarium, or only in exozone \\
$\mathbf{2 1 3}$ & Cystiphragms & degree of curvature \\
$\mathbf{2 1 5}$ & Cystiphragms & presence/absence of proximal fringe \\
$\mathbf{2 1 9}$ & Cystiphragms & single and large or small and numerous \\
\hline & &
\end{tabular}


Figure 5: Synapomorphic characters plotted on the most parsimonious tree. Cladogram is ladderized for readability. Character numbers and descriptions are listed in Appendix B.

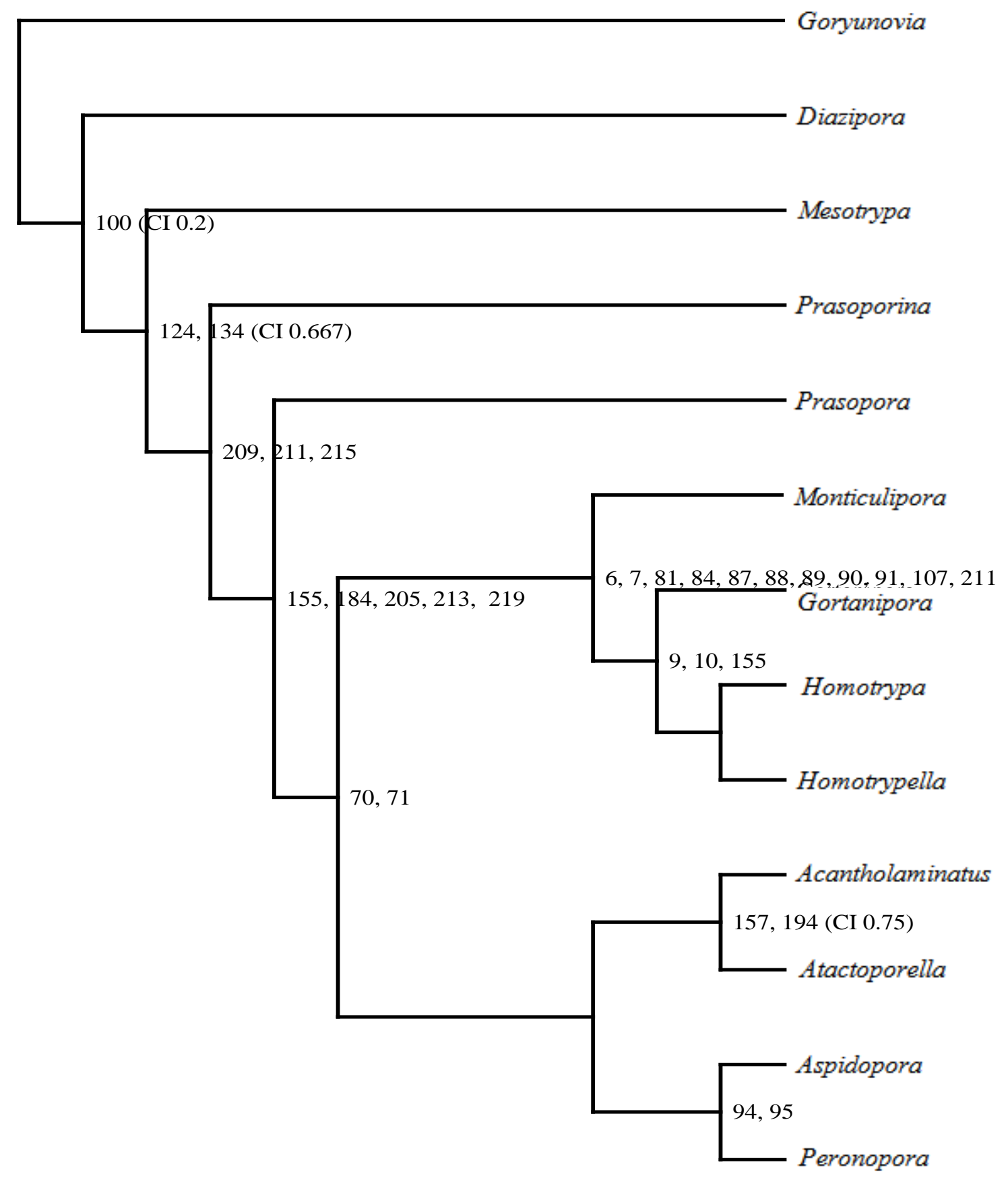


Figure 6: Node numbers for branching events among genera analyzed in this study. Nodes, and corresponding apomorphy changes at each, are listed in Table 4.

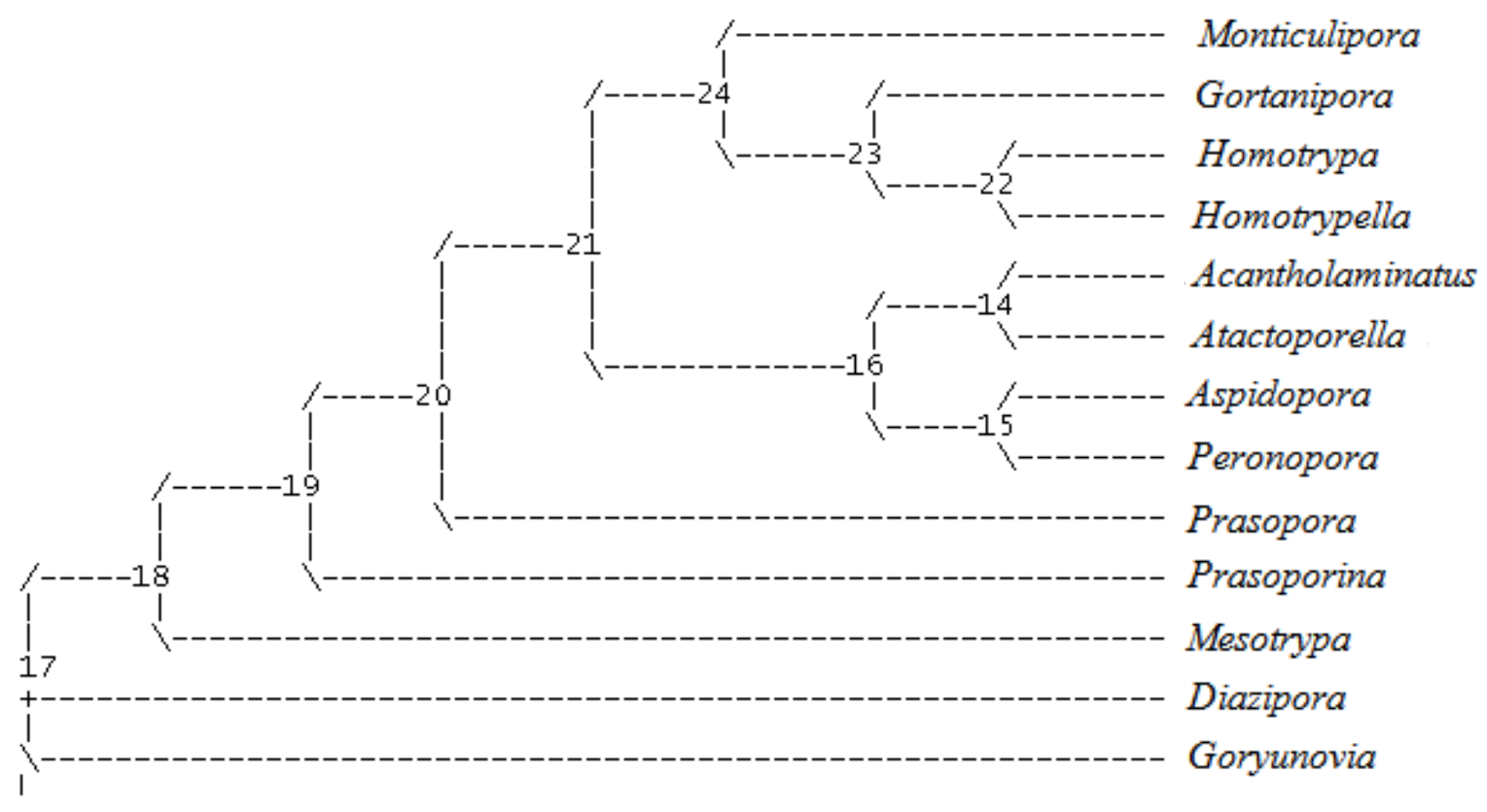


lophophore orientation, and affecting feeding currents (Anstey 1981; Anstey 1986; Banta et al. 1974; Taylor 1979). This result supports Astrova's (1965) designation of Mesotrypa and Diazipora as a family based solely on those characters. Prasopora and the remaining taxa are separated from Prasoporina by having acanthostyles of different sizes and by diaphragm orientations. The Gortanipora - Homotrypa - Homotrypella clade, with very strong bootstrap support and a presence in some phenetic analyses, is defined by a large number of characteristics including colony growth form, wall structure, and budding patterns. Aspidopora is a sister taxon to Peronopora based on the presence of keel and sinus structures in basal zooecia.

MPT 1, generated by a heuristic search in PAST, had the highest stratigraphic consistency index (SCI) of 0.4545 , providing the closest match with observed stratigraphic distributions of genera. However, neither this nor any other SCI value was statistically significant (at $\mathrm{p} \leq 0.05$ ) indicating that there is not a close correlation between stratigraphic position and the order of branching in the cladogram. The appearance datums used in this first analysis were compiled for each entire genus. Problems with insignificant correlations between the fossil record and cladistic analyses may be a common phenomenon in paleontological studies. For example, Pachut and Anstey (2007) used cladistic relationships to adjust the stratigraphic ranges of species and metaspecies of Peronopora after recognizing that sampling was incomplete, even after finding a significant correlation between observed stratigraphic position and cladistic branching pattern. Most species required no range adjustments, while one displayed a discrepancy between observed stratigraphic position and earliest cladistic first appearance spanning 3.9 MYr. Additional characters and better stratigraphic age data might resolve 
this problem, but sampled stratigraphic positions may generally provide poor matches with evolutionary sequence.

An additional reason for the stratigraphic inconsistency may be the choice of dates. The first set of FAD and LAD's were calculated based on the stratigraphic range for entire genera, resulting in an insignificant correlation of 0.4545 . While it can be assumed that species in a genus are more closely related to each other than to other genera, these groups currently lack cladistic support. The mismatch between morphologic data for single species and generic ranges that could be inflated (by related and possibly unrelated species) potentially results in poor correlations. When the ranges of coded type species were substituted for generic ranges, a highly statistically significant $(p=0.008)$ SCI of 0.9091 resulted, indicating that $90 \%$ of nodes match observed stratigraphic appearance datums. This indicates that observed first appearances in the fossil record matched cladistic relationships closely in this analysis.

As a parallel to cladistic analyses, phenetic clustering of taxa produced results that varied based on the similarity measure that was used to generate the clusters. As discussed above, phenetic methods generate groupings based on overall morphologic similarity and do not consider either the primitive or derived nature of individual characters as in cladistics studies. From the several similarity measures that were evaluated, the Dice similarity coefficient (Figure 7) generated clusters that were similar to clades produced using PAUP or PAST. They included a Diazipora-Mesotrypa cluster, an Atactoporella- Acantholaminatus cluster, and a cluster that included Homotrypella, Gortanipora, and Homotrypa. In contrast, the use of Euclidean Distance generated few clusters that matched cladistic patterns (Figure 8). 
Figure 7: Cluster analysis of genera, using paired linkages and Dice similarity.

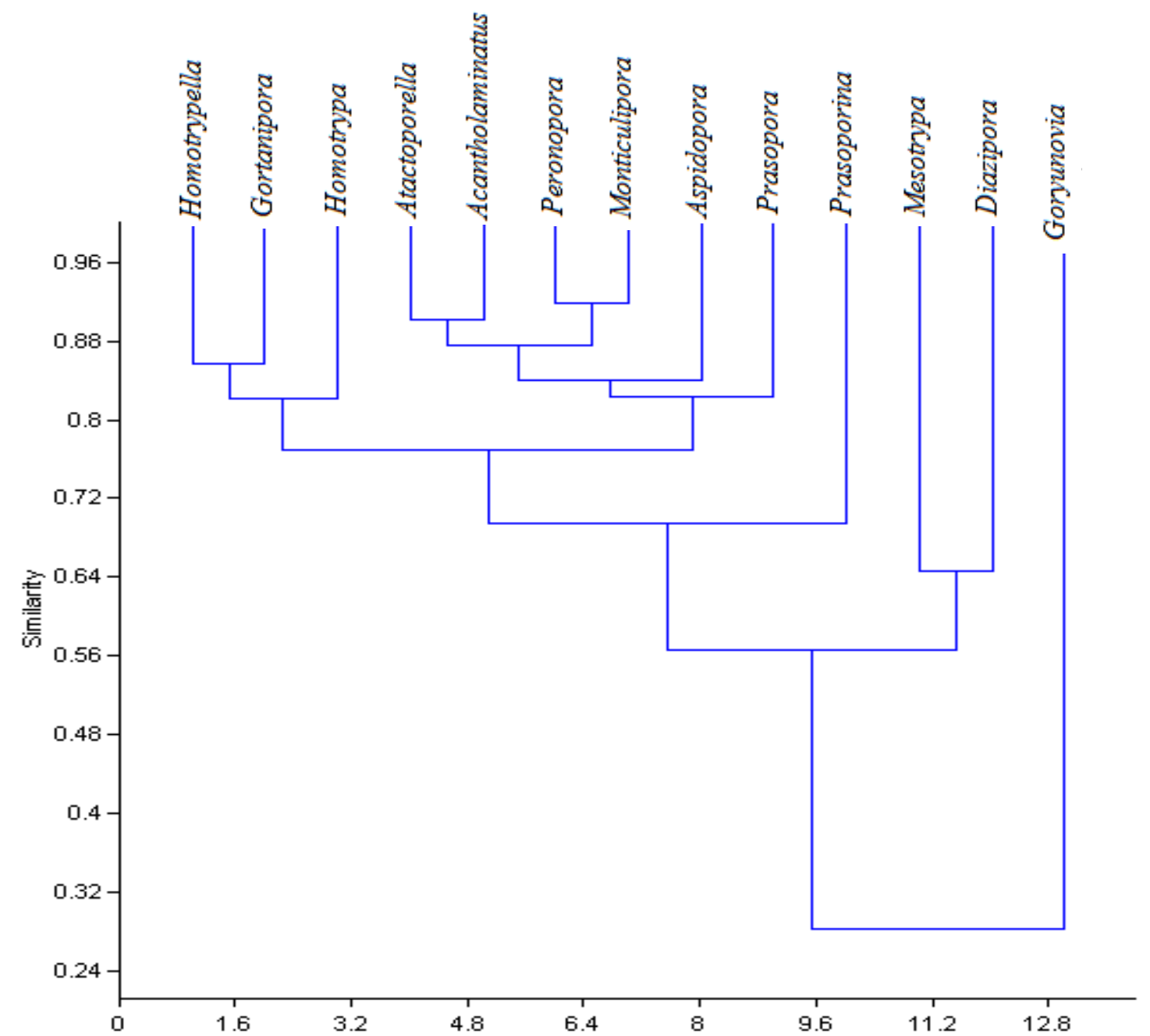


Figure 8: Cluster analysis of genera, using paired linkages and Euclidean similarity.

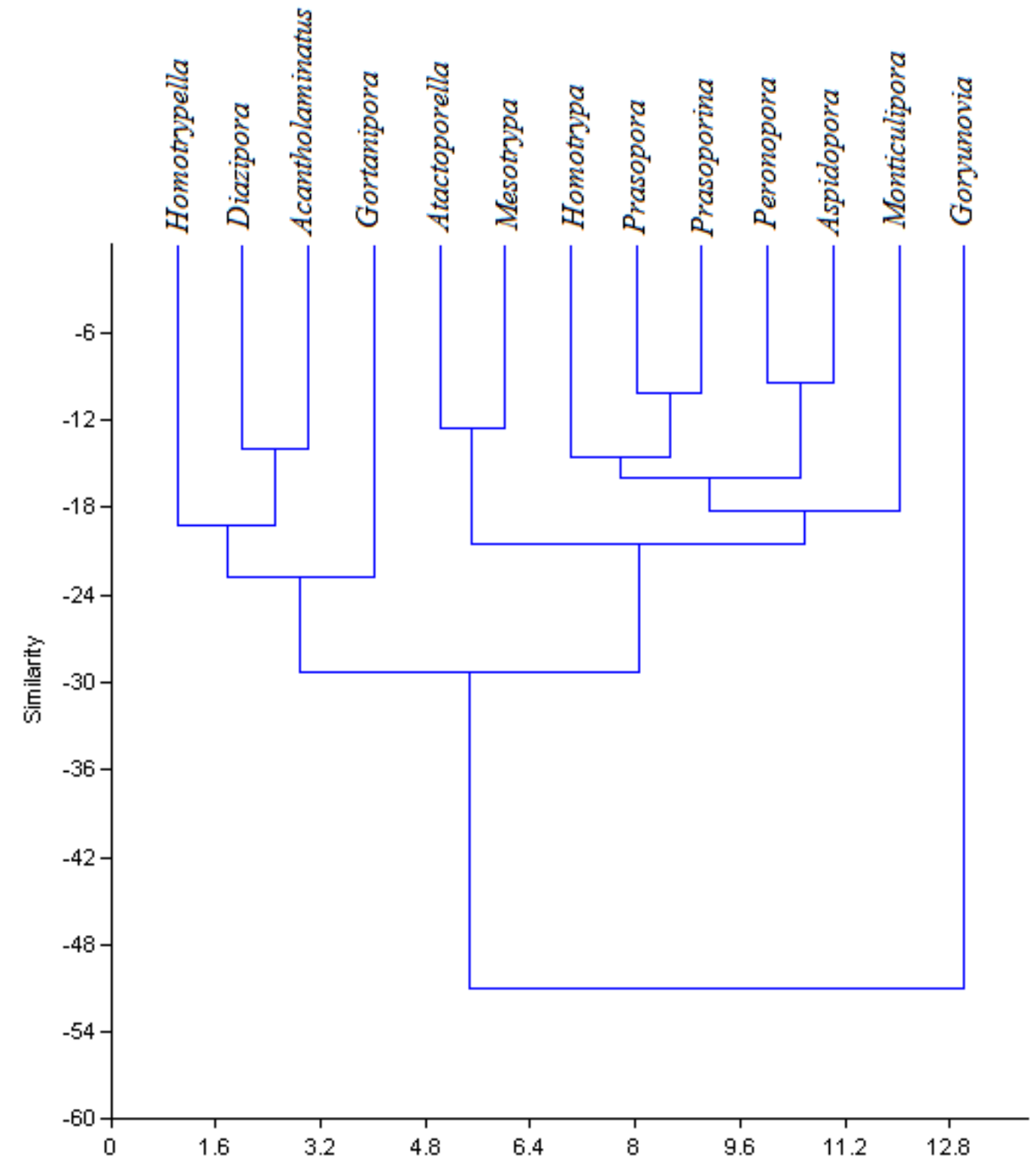


Neighbor Joining cluster analysis (Figure 9) does not require branches from the same internal node to have identical lengths (Hammer 2003) which is appropriate for data sets where taxa may have evolved at different rates. Varying the similarity measure and method of clustering produced divergent results, with the Dice coefficient producing a phenogram nearly identical in structure to the cladistic trees produced using PAUP (Figure 9). However, when the outgroup taxon (Goryunovia) was included in the analysis, phenetic groupings differed from those in the cladograms only by including Peronopora in the Monticulipora cluster, rather than in the Acantholaminatus cluster.

While the Dice similarity measure provided very similar results, the wide variability among clusters based on different similarity coefficients makes phenetic analyses more volatile and less objective. Results can be manipulated easily by changing input options. Additionally, measures of the effectiveness of phenetic methods in producing groupings currently do not exist. 
Figure 9: Cluster analysis of genera using Neighbor Joining clustering and Dice similarity. Cluster groupings parallel those found using heuristic searches in PAUP (Figure 4).

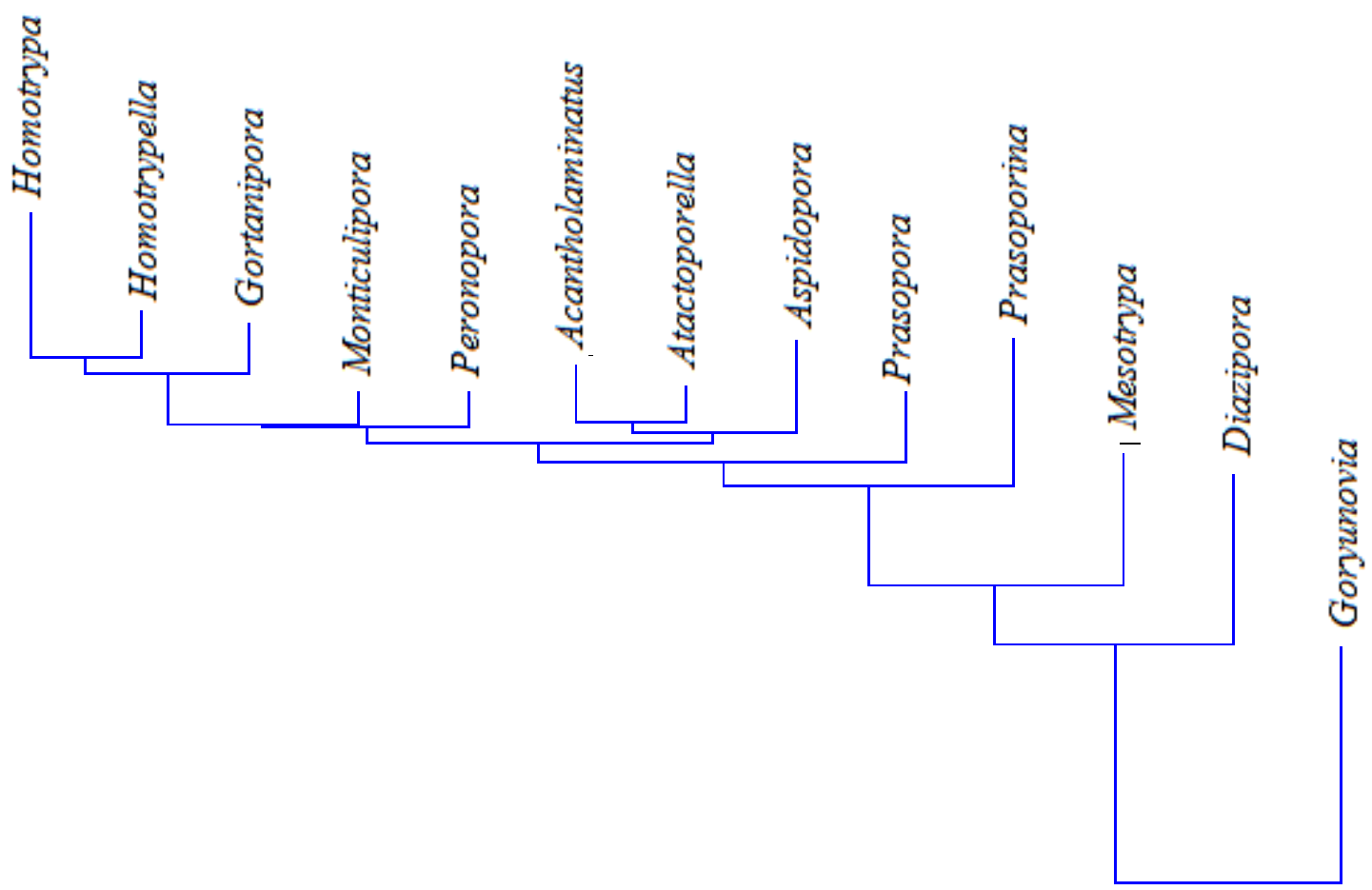




\section{DISCUSSION}

Jeffries (1979) established the concept of stem and crown groups and discussed their significance. Smith (1994) extended the concepts to cladistic classifications. Crown groups were defined as living monophyletic taxa that have all of the diagnostic characters of a taxon or have secondarily lost some of them. A total group is one that includes extinct ancestors that have one or more of the diagnostic characters of the taxon. If the crown group is removed from the total group, a paraphyletic stem group remains. Stem groups were created to avoid unnecessarily inflating designations within the taxonomic hierarchy (Smith 1994): the name and Linnaean rank of the crown group is simply extended to the stem group. The concept of crown and stem groups was applied to analyses involving only fossilized taxa at the species level by Pachut and Anstey (2002).

In this study, one crown group and one stem group are present (Figure 4) both of which represent Family Monticuliporidae. The crown group includes the genera Monticulipora, Gortanipora, Homotrypa, Homotrypella, Acantholaminatus, Atactoporella, Aspidopora, Peronopora, Prasoporina and Prasopora, and the stem group, equivalent to Astrova’s (1965) Family Mesotrypidae, consists of Diazipora and Mesotrypa. The placement of Prasoporina and Prasopora is somewhat arbitrary, based on synapomorphies involving mesozooecia and diaphragms with low CI values, possibly indicative of convergence.

Based strictly on observed first appearances (FADs), all genera appear at approximately the same time. In the crown group, almost all taxa appear nearly 
synchronously, except for Acantholaminatus, Atactoporella, and Aspidopora, which appear slightly later (approximately 5 MYr; Figure 10). This pattern appears to be consistent with the cladogram because these three genera, along with Peronopora, share a more recent common ancestor than they do with the rest of the crown group. Mesotrypa branches after Diazipora, and appears slightly later in the stratigraphic record.

Current classifications (Table 1) have defined the difference between the Monticuliporidae and the Mesotrypidae monothetically, based on the presence or absence of cystiphragms, respectively. Applying that definition to this data set would result in the inclusion of Prasoporina in Family Monticuliporidae. This would create a monophyletic grouping consisting of the crown group and two genera from the stem group. The Mesotrypidae would remain a paraphyletic stem group but would, following the recommendations of Smith (1994), be placed within the Monticuliporidae.

The results of this study agree with Astrova's (1965) original assignment of Mesotrypa and Diazipora to the Mesotrypidae and her inferred ancestor-descendent relationships which suggested that Mesotrypa gave rise to Prasopora with Prasoporina considered as a synonym of Prasopora (Astrova 1978; Figure 4). Monticulipora was viewed as ancestral to Homotrypa, based on zoarial form and the possession of compressed zooecia. Both genera are sister groups in the cladogram (Figure 4). Astrova (1978) also included a second lineage consisting of Peronopora and Atactoporella. Both occur on the second branch of the crown group.

Similarities and differences exist between the relationships depicted in Figure 4 and those in the cladogram of Anstey (1987). In the latter, Aspidopora occurred at the base of the cladogram but it is in a more derived position in Figure 4. 
Figure 10: Stratigraphic ranges of genera based on first (FADs) and last appearance datums (LADs) for type species listed in Table 1.

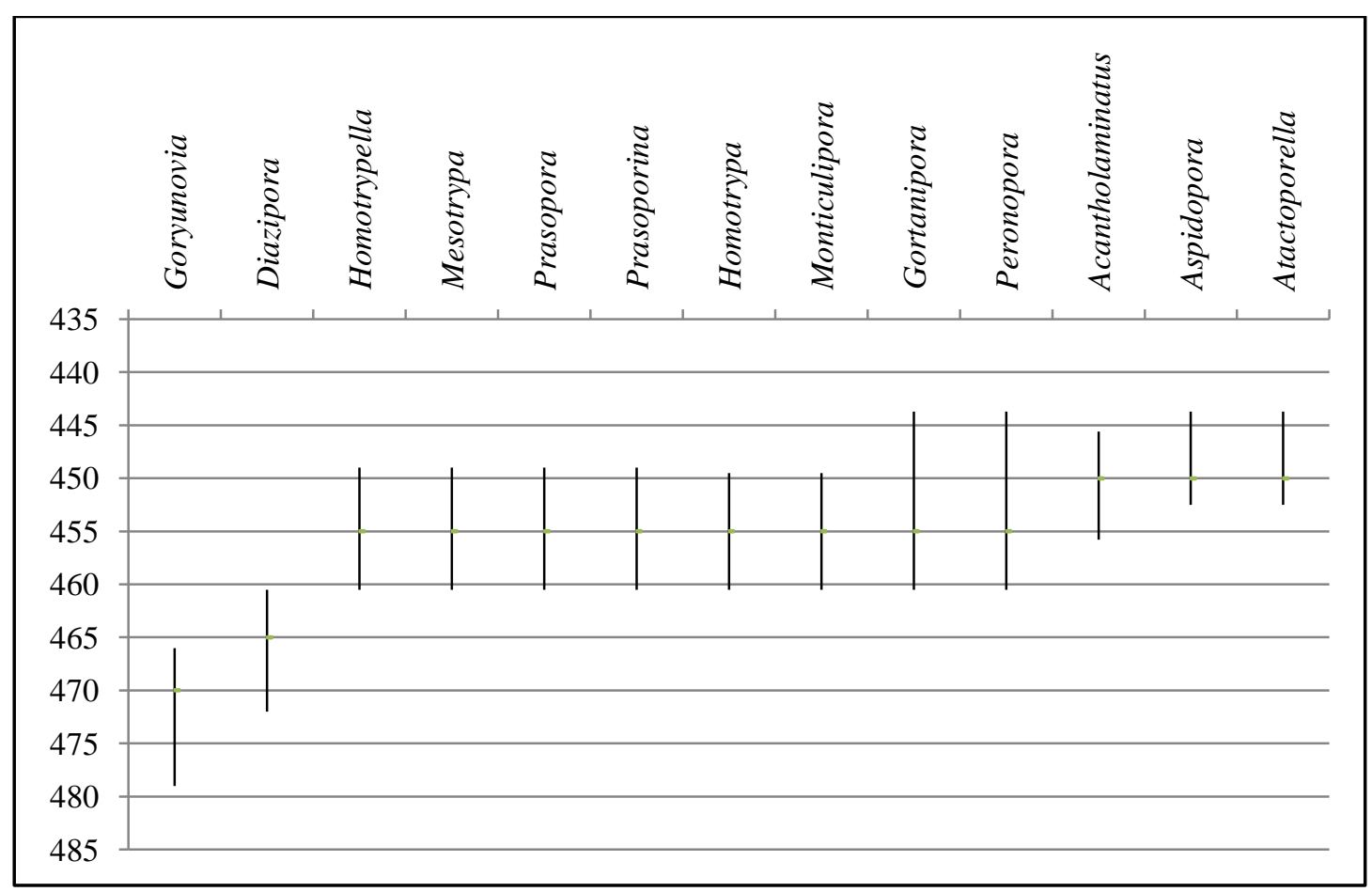


Prasopora, Mesotrypa, and Diazipora formed a sister group in Anstey’s cladogram but their branching order is reversed in Figure 4 with Mesotrypa and Diazipora branching before Prasopora. Monticulipora is followed by Atactoporella and Peronopora that branch from a common ancestor along with Monticulipora (Figure 4). Anstey (1987) indicated that Gortanipora, Homotrypa, and Homotrypella displayed homoplasies; that might explain the grouping present in both his cladogram and Figure 4. In part, differences between Anstey (1987) and this study have resulted from the very different character sets sizes used in each.

Table 4 contains a list of the most important synapomorphies (i.e., character state changes) occurring at nodes in the cladogram (Figure 6). Synapomorphies with a CI = 1 are unique states that only evolved once making them the best features with which to define taxa. Character state changes are indicated along the branches between nodes in Figures 5. Starting at the base of the cladogram, node 18 (e.g. listed in Appendix B as node 17 ----> node 18) is defined by a single character, with a low CI of 0.2 , indicating the presence of homeomorphy. Character 100 differentiates Diazipora from Goryunovia by the shape of the living chamber (becoming elongate from equidimensional).

Node 19 is defined by several characters, none of which have a CI of 1 . Characters with the highest CI of 0.667 include the presence of a constant or distally decreasing number of mesozooecia (124) and the presence of monticules in which zooecial diameters increase imperceptibly towards the center (134). Character 206, the presence of oblique diaphragms attached to proximal walls of zooids, has a CI of 0.6.

Several characters define the crown group, including Prasopora, at node 20. They include the presence of abundant cystiphragms throughout the zoarium (character 
209 with a CI of 1), large cystiphragms (220) present throughout the zoarium (211) that lack a proximal fringe (215), monticules that are flat or depressed (150), have a central macula (152) that is smaller than one zooecial diameter (153), and are regularly spaced (154), megazooecia present in monticules (146), and diaphragms that revert from convexly curved to concave or absent (203). The latter seven characters include varying degrees of homoplasy (i.e., CI between 0.250 and 0.750 ). This node occurs in $72 \%$ of bootstrapped trees (Figure 3).

The rest of the crown group (node 21) is defined by the following synapomorphies that display no homoplasy: small (<1.5 mm) monticules (155), acanthostyles with a unimodal size distribution (184), the presence of normally-curved cystiphragms (213), and large cystiphragms present in each zooecium (219).

Additionally, obliquely oriented diaphragms revert to being perpendicular to zooecial walls (205). Other synapomorphies include acanthostyles at zooecial junctions (194), cystiphragms abutted by half-diaphragms (214), and single cystiphragms present in apertures (221). Polytomies in the bootstrapped consensus tree resulted in a frequency of $72 \%$ for the clade (Figure 3).

Two non-homoplastic synapomorphies occur at node 24: the presence of a gently rounded zooecial bend (70), and the presence of a distinct endozone (71). Other synapomorphies include abundant acanthostyles (183) that have a clear core and laminations (189). All synapomorphies present defining the Monticulipora subclade are also shared by node 16, the Acantholaminatus subclade, except (in Monticulipora) completely laminated wall structure (161), acanthostyles present along the walls (192), and the presence of more than four diaphragms or cystiphragms in the endozone (197). 
Numerous synapomorphies support a very well defined subclade (93\% of bootstrapped trees) at node 23 (Figure 3). Genera include colonies that become cylindrical in cross section (6), and display branching (7); earlier genera were largely massive. They possess an axial endozone (81) with irregularly polygonal or rounded buds (84), and a well defined axial bundle (87) lacking a radial budding pattern (88) and medial rows of zooecia (91). Endozones have wavy walls (107), and cystiphragms occur only in the exozone (211).

Homotrypa and Homotrypella branch at node 22 (frequency of 65\%) (Figures 3, 6), and display synapomorphies with a CI of 1 involving branch diameter (9) and its variability (10). They are also characterized by synapomorphies displaying some homoplasy including lateral branching (8), a high zooecial reorientation angle (75), subpolygonal zooecial apertures (reversion) (41), and non-localized budding (79). CI values for these characters range between 0.400 and 0.750 .

The Acantholaminatus subclade, at node 16, is characterized by the same synapomorphies as node 24 (the Monticulipora subclade), the strongest of which are the presence of a gently rounded zooecial bend (70), and a distinct endozone (71). Node 16 also displays additional synapomorphies including a gradual change in wall thickness between the endozone and exozone (69), short overlap of recumbent zones (98) limited to the base of the zoarium (97), the presence of subcircular megazooecia (148), larger sized acanthostyles in monticules (158), and acanthostyles that predominantly inflect zooecial apertures (191). There are also a number of synapomorphies unique to this subclade that are reversals and include restricted budding reverting to non-localized budding in the exozone (79), elongate living chambers reverting to equant living chambers (100), planar 
mesozooecial tabulae reverting to concave (122), less than four diaphragms in the innermost exozone once again becoming absent or rare (198), and large cystiphragms returning to intermediate sizes (220). It is not yet clear whether the differentiation of the Monticulipora and Acantholaminatus subclades is a significant evolutionary change, or reflective of changes in environment and growth habits. This question might be resolved by additional family level cladistic analyses of Paleozoic bryozoans.

The grouping of Acantholaminatus and Atactoporella (node 14) is defined by synapomorphies that display levels of homoplasy (CI) ranging between 0.333 and 0.750 . They include intermediate length endozonal portions of zooecia (74), closed mesozooecia at the zoarial surface (115), an increased number of acanthostyles (four to seven) per zooecium in monticular areas (157), five to seven acanthostyles outside of the monticules (193), and diaphragms/cystiphragms present in the endozone (197). The loss of a central macula in monticules $(152,153)$ and non-clustered mesozooecia in monticules $(117)$ represent character state reversals.

The grouping of Aspidopora and Peronopora at node 15 is defined by two nonhomoplastic synapomorphies: the presence of keel (94) and sinus (95) structures in the endozone. Other synapomorphies, with lower CI values (0.5-0.667), are characters that were difficult to code (based on available illustrations), including budding pattern or basal zooecia characteristics $(33,93,255)$. Some characters, including the loss of diaphragms/cystiphragms in the exozone (201), reflect reversions to earlier states. 
Based on the cladistic results of this study, it is recommended that the Mesotrypidae and Monticuliporidae be merged into a single Family Monticuliporidae. The Mesotrypidae represent the paraphyletic stem group of Family Monticuliporidae. Finer scale resolution of relationships must wait for more inclusive analyses of Paleozoic genera. 


\section{APPENDIX A}

\section{Plate 1}

Acantholaminatus typicus: From Marintsch 1998 P.96 Plate 4, Figures 1a and 1c.

1a: Longitudinal section of holotype specimen x25

$1 \mathrm{~b}$ : Tangential section of holotype $\mathrm{x} 45$. Arrow AC points to cross sections of rodlike acanthostyles with hollow cores. Also note the macular megazooecia in lower right corner of figure.

Atactoporella typicalis: From Astrova 1978 Plate XV, Figures 2a and 2b.

2a: Tangential section of holotype x100. Inflecting acanthostyles produce petaloid cross sections.

2b: Longitudinal section of syntype x30. Zooecia contain flat diaphragms, curved cystiphragms, and smaller diameter mesozooecia. 

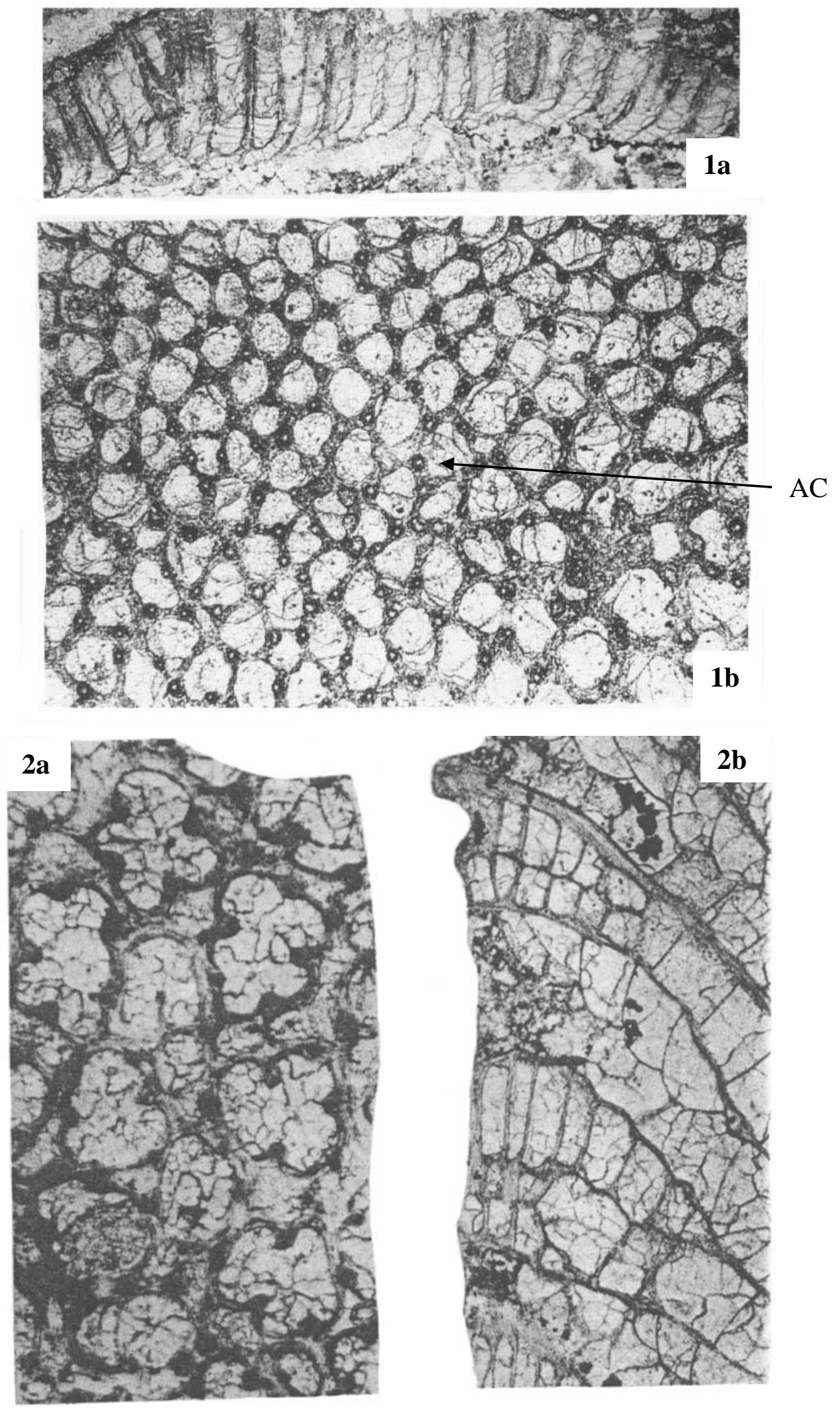


\section{Plate 2}

Aspidopora areolata: pictures provided by the USNM

1a: Two tangential and one longitudinal view of colony USNM 43632, Ulrich. Note the ovate zooecial apertures.

1b: Longitudinal section of USNM 460389 (43632-2) illustrating larger zooecia and smaller, interspersed mesozooecia rising from the encrusting surface of the colony.

Diazipora milleporacea: From Astrova 1978 Plate XVI, Figures 2a and 2b

2a: Tangential section $x 40$. Note the numerous small mesozooecia (arrow) between the large, circular zooecia.

2b: Longitudinal section x25 oriented obliquely to the direction of colony growth. Zooecia and mesozooecia remain recognizable. 

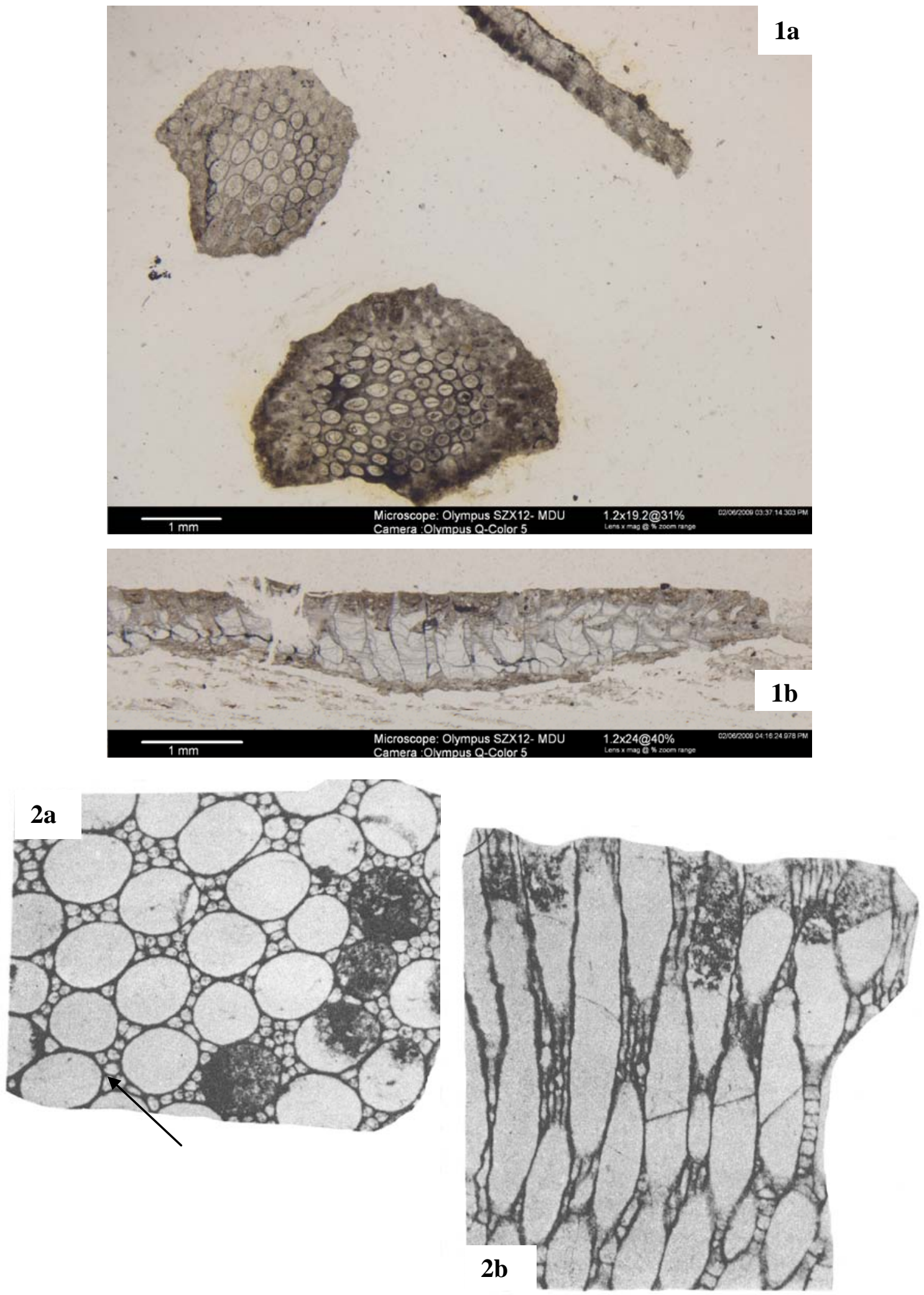


\section{Plate 3}

Gortanipora bassleri: From Nickles 1902, Figures 3, 4.

1a: Longitudinal section x20. Arrow HD points to curved, hooklike, partial diaphragms or incomplete cystiphragms.

1b: Tangential section x20. Lower arrow points to an acanthostyle. The arrow $\mathrm{Z}$ points to a zooecial aperture containing a cystiphragm.

Goryunovia hemiseptata: From Taylor 1996, Figures 3, 5.

2a: External view of a colony illustrating growth habit x11.

2b: Broken zooid containing two partial diaphragms (hemisepta) x100. 

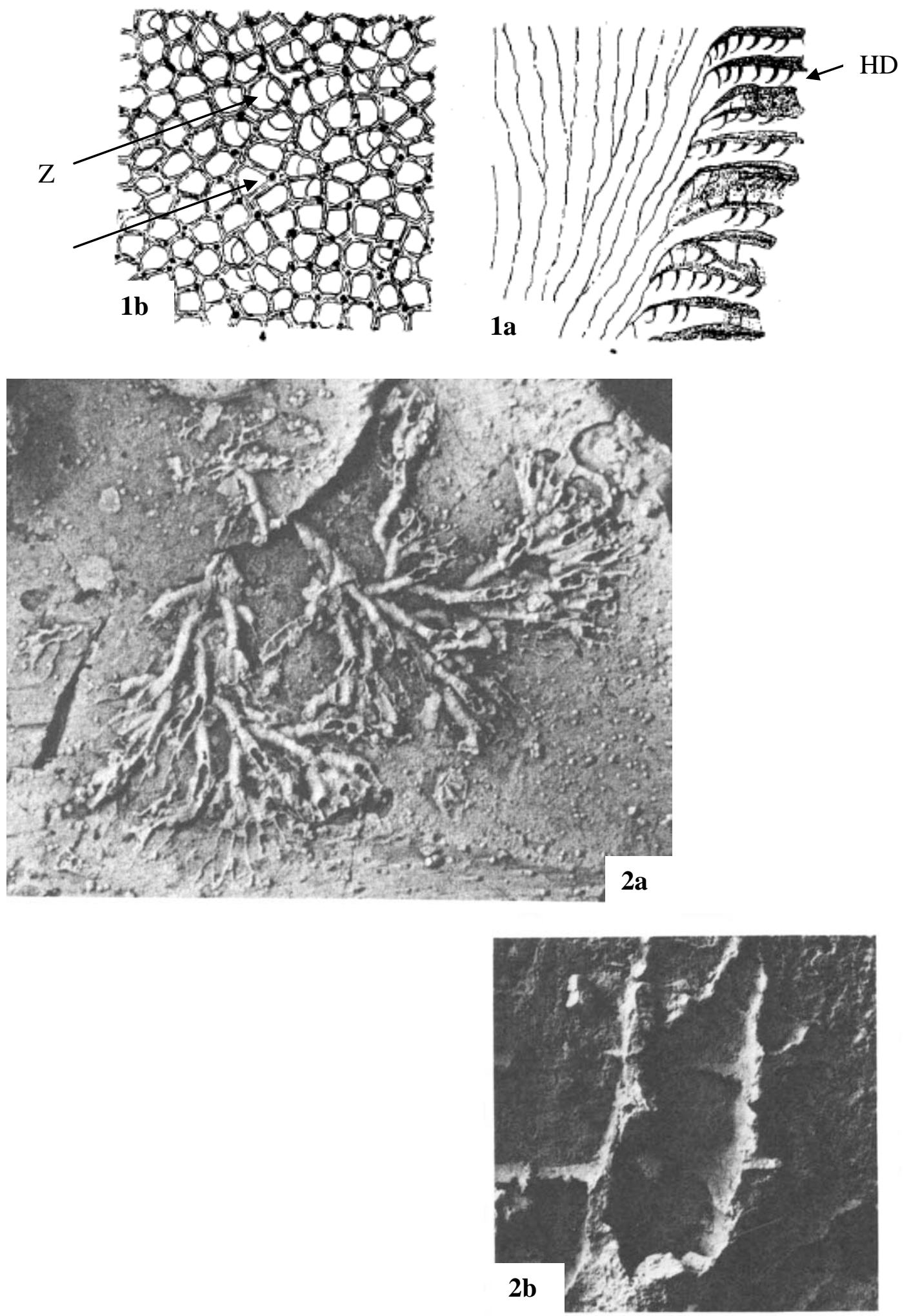


\section{Plate 4}

Homotrypa curvata: From Brown and Daly 1985, Plate 7, Figures 7, 8.

1a: Tangential section of plesiotype. Note thick walls with median line and acanthostyles.

1b: Longitudinal section of plesiotype with a short exozone containing overlapping series of cystiphragms.

Peronopora mundula (for Homotrypella instabilis): From Marintsch 1998, Plate 2, Figures 2a, 2c

2a: Longitudinal section $\mathrm{x} 25$. Note the diaphragms present in the endozone, becoming rare or absent outwards towards the surface of the colony. Cystiphragms are common and overlapping. Large mesozooecia are present with diaphragms thicker than those present in autozooecia.

2b: Tangential section $\mathrm{x} 45$. In upper right of figure, notice subpolygonal zooecial apertures, thick zooecial walls with inflecting and offset acanthostyles. In lower left, the deeper section shows subrounded apertures with thinner walls, angular mesozooecia, and smaller acanthostyles.

Mesotrypa infida: From Astrova 1978 Plate XVI, Figure 1

3a: Tangential section of syntype x30 illustrating 3-5 mesozooecia associated with each large circular zooecial aperture.

3b: Longitudinal section x30. Note zooecia becoming mesozooecia, as well as oblique and convex diaphragms. 

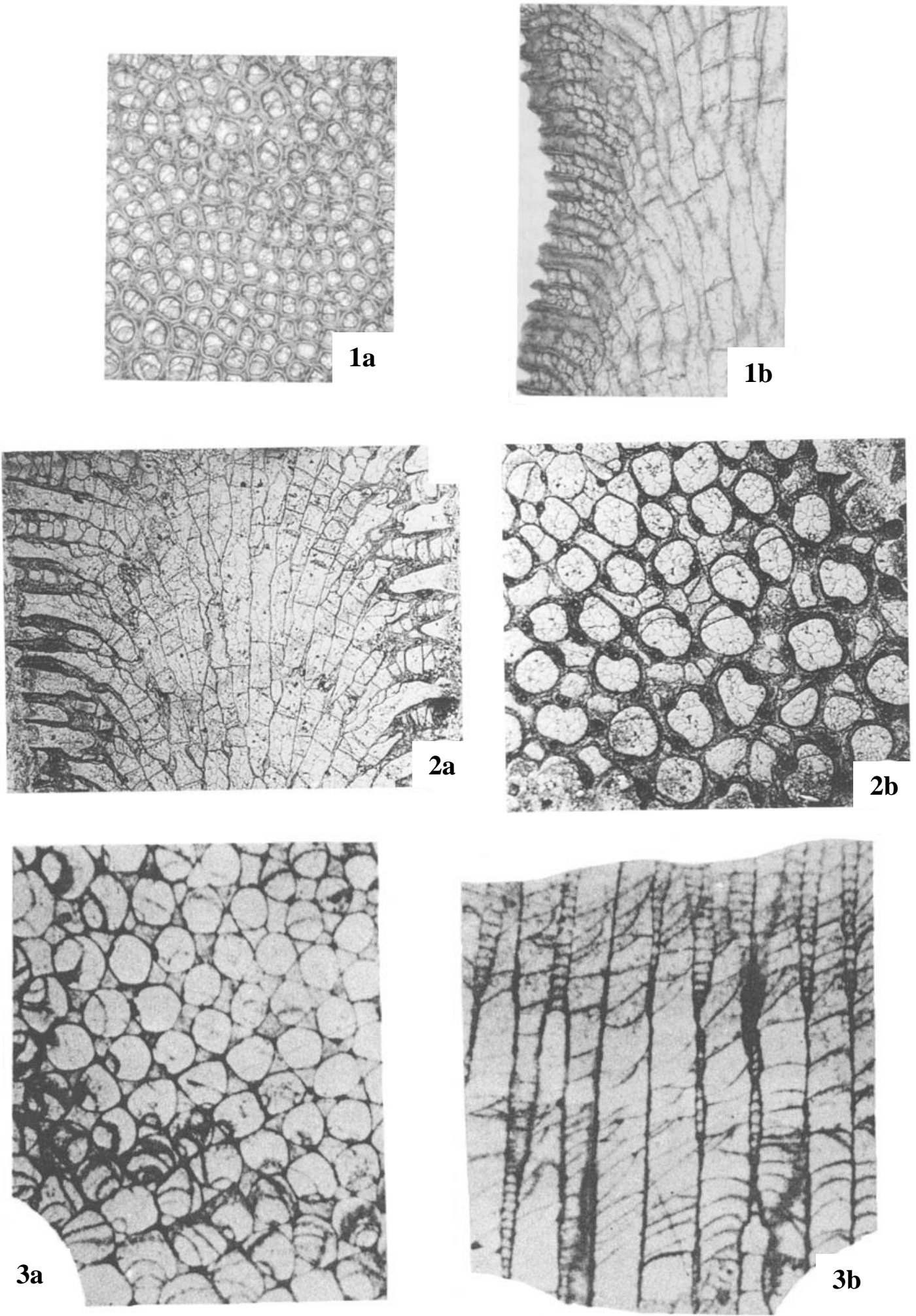


\section{Plate 5}

Monticulipora mammulata: From Boardman and Utgaard 1966, Plate 133, Figures. 1a, $1 b$.

1a: Tangential section of massive topotype x50. Central macula (M) of a monticule consisting of abundant mesozooecia. Arrow $\mathrm{C}$ points to a cystiphragm.

1b: Longitudinal section of same zoarium (colony) illustrating a monticule x30. The monticule is elevated area at the top of the image. The arrow (MZ) indicates a vertical, attenuated mesozooecium as it bends out of the plane of the section.

Peronopora decipiens: From Boardman and Utgaard Plate 135, Figures. 1c, if

2a: Tangential section of lectotype showing monticule and mesopores x50

2b: Longitudinal section of lectotype showing break in median layer x30. This is an example of a bifoliate/bilaminate species. The broken vertical line in the center is the discontinuous median lamina. Zooecia are present to the left and right of the lamina. The arrow CY indicates a row of cystiphragms within a zooecial chamber. 

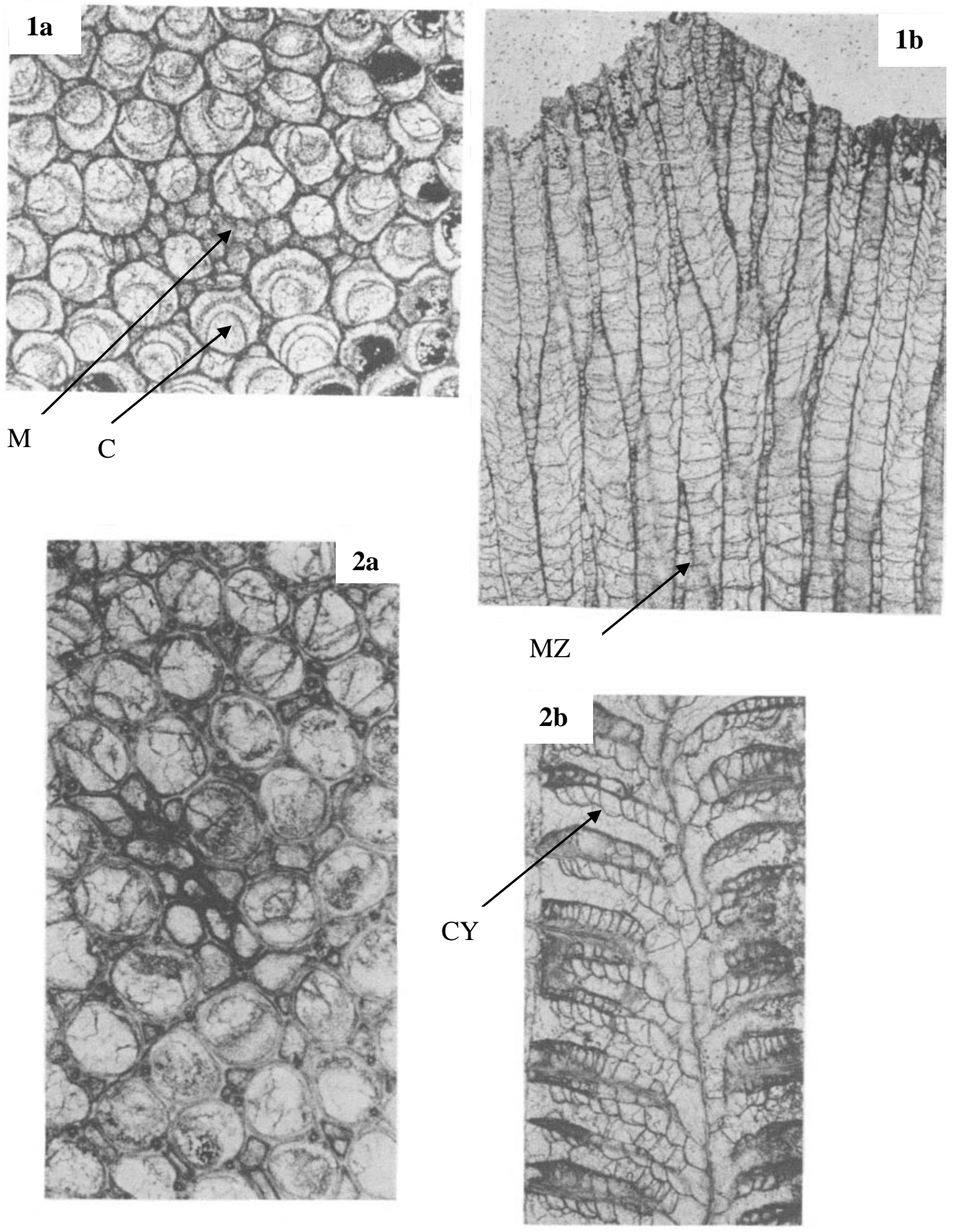


\section{Plate 6}

Prasopora falsei (for Prasopora grayae): From Marintsch 1998, Plate 1, Figures. 2a, 2c.

1a: Tangential section of hypotype x33. Figure shows rounded to subrounded zooecial apertures and small polygonal to subrounded mesozooecia associated with and sometimes isolating megazooecia in the macula (center) of monticule. Also note small acanthostyles and cystiphragms that wrap around most zooecial apertures.

1b: Longitudinal section of hypotype x25.

Prasoporina selwyniiL From Ross 1967 Plate 48, Figure 4 and Plate 49, Figure 8.

2a: Deep tangential section x20 illustrating subrounded zooecia containing cystiphragms and small, intervening, mesozooecia. A large fracture occurs on the left.

2b: Longitudinal section x20 with large, cystiphragm containing, zooecia and smaller, closely tabulated, mesozooecia passing into and out of the plane of the thin section. 

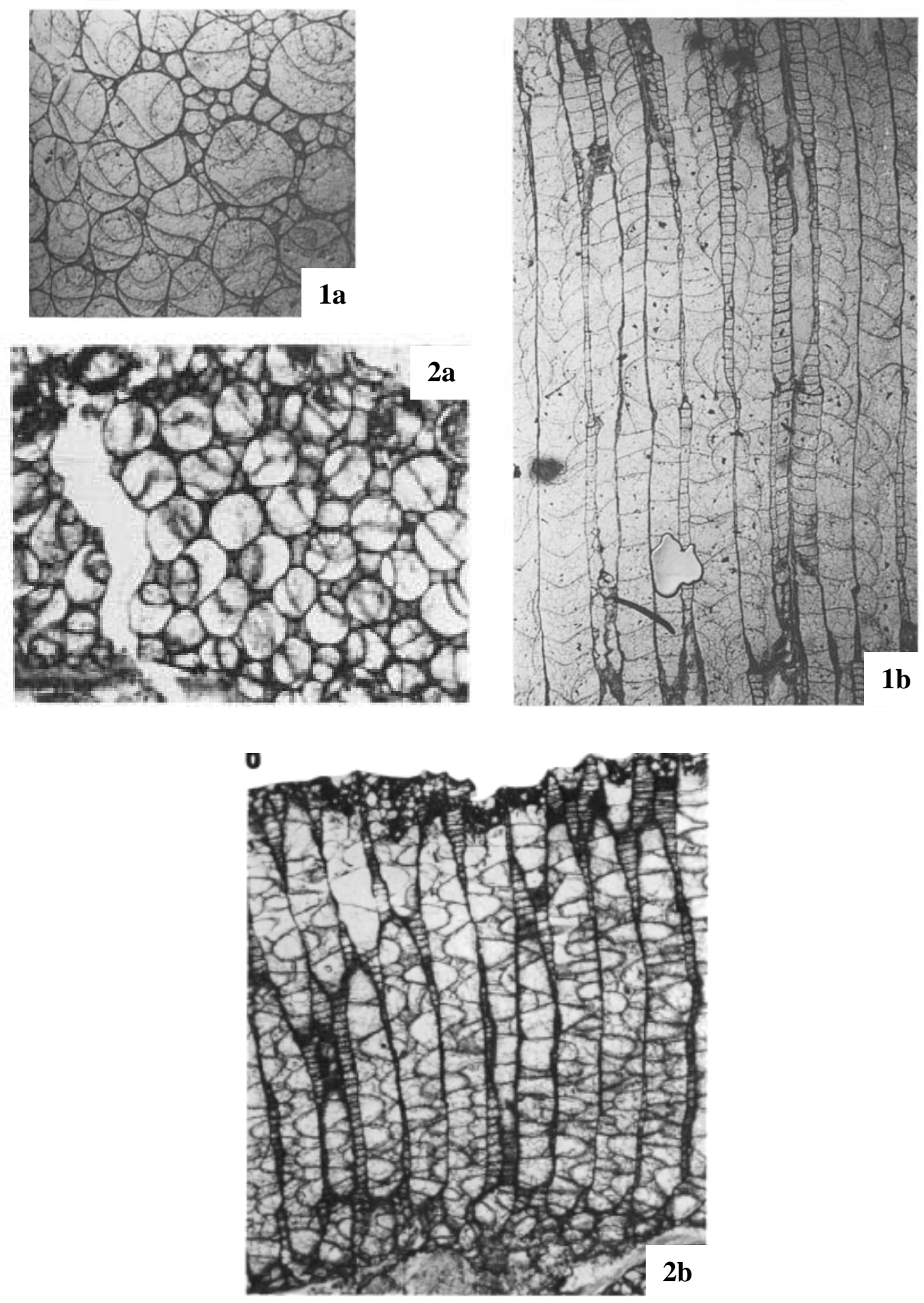


\section{APPENDIX B}

Characters of Paleozoic Stenolaemate Bryozoa

This listing includes 267 characters used in this study.

Sources used to create character listing: Anstey (1978); Anstey (1990); Anstey and Pachut 1995 (Appendix A; Appendix B); Anstey and Perry (1970, 1973); Blake and Snyder (1987); Corneliussen and Perry (1973); Cuffey and Blake (1991); Hageman (1991); Hickey (1988); Key (1990); McKinney (1977, 2000); Pachut and Anstey (1984); Pachut, Anstey and Horowitz (1994); Prezbindowski and Anstey (1978): Spearing (1998); Tang and Cuffey (1998); Taylor and Weedon (2000).

Any character may be coded as 0 to indicate that it is not applicable.

1 - Zoarial form: encrusting or erect, uniserial threads $=0$

encrusting, multiserial thin sheets $=1$

elevated as hemispheres or mounds $=2$

elevated as stalks, fronds or branches $=3$

2 - Zoarial form: colonies not multiserial or not elevated above substratum $=0$

multiserial colonies elevated above the substratum, including multilaminar, hemispherical, cylindrical, ramose, hollow ramose, or sheetlike (unilaminar, bilaminate, and radially frondescent) forms $=1$ multiserial, multilaminar, or nonlaminar amorphous elevated colonies ("massive”)=2 massive zoarium with cyclic repetitions of endozone-exozone transitions in successive laminar growth zones $=3$

3 - Zoarial form: non-multilaminar=0

multilaminar, vertical growth through successive regeneration=1

multilaminar, vertical growth through successive overgrowths $=2$

4 - Zoarial form: non-conical=0

low conical or turbinate zoaria $=1$

tall conical or helically turbinate zoaria $=2$

5 - Zoarial form: encrusting or slightly elevated (vertical growth exceeding that of a thin sheet $)=0$

hemispherical $=1$

cylindrical or flattened cylindrical stems or sheetlike expansions $=2$

cylindrical, dichotomously or laterally branching stems rounded or flattened (elliptical) in cross section $=3$ 
6 - Zoarial form: noncylindrical or nonelliptical in cross-section $=0$ cylindrical, with circular or semicircular cross-section $=1$ cylindrical, with oval or elliptical cross-section $=2$ cross-section that of a flattened or polygonal or subpolygonal branch $=3$

7 - Zoarial form: nonmultiserial or nonbranching or non-pillarlike zoarium $=0$ branching or pillarlike, cross-section circular or rounded, or flattened oval cross-section $=1$ branching or pillarlike, cross-section polygonal or subpolygonal=2 branching or pillarlike, cross-section hexagonal $=3$

8 - Zoarial form: nonmultiserial or nonbranching zoarium $=0$ dichotomous branching $=1$ lateral branching $=2$

9 - Zoarial form: nonmultiserial or noncylindrical or not having branches or stalks with a circular or subcircular cross-section $=0$ cylindrical, stem diameter greater than $8 \mathrm{~mm}=1$

cylindrical, stem diameter between 8 and $4 \mathrm{~mm}=2$ cylindrical, stem diameter 4 to $1.5 \mathrm{~mm}=3$ cylindrical, stem diameter 1.5 to $0.6 \mathrm{~mm}=4$ cylindrical, stem diameter $0.6 \mathrm{~mm}$ or smaller $=5$ cylindrical, stem diameter $0.4 \mathrm{~mm}$ or smaller $=6$ cylindrical, stem diameter $0.3 \mathrm{~mm}$ or smaller $=7$

10 - Zoarial form: nonmultiserial or noncylindrical or not having a circular or subcircular cross-section $=0$ cylindrical, uniform diameter $=1$ cylindrical, moderately variable diameter $=2$ cylindrical, highly variable diameter $=3$

11 - Zoarial form: hollow ramose: no $=0$ yes, cylindrical branches $=1$ yes, conical branches $=2$

12 - Zoarial form: pseudoramose, encrusting elongate cylindrical or branching object: no $=0$ yes $=1$

13- Zoarial form: uniserial with pyriform zooids $=0$ uniserial with cylindrical zooids $=1$ multiserial with cylindrical zooids $=2$ 
14 - Zoarial form: zoarium non-articulated $=0$

zoarium articulated at base $=1$

zoarium articulated at ends of segments $=2$

zoarium articulated at ends of segments and laterally $=3$

15 - Zoarial form: zoarium non-articulated or articulated only at base $=0$

zoarium articulated, regular joint lengths $=1$

zoarium articulated, variable joint lengths $=2$

16 - Zoarial form: zoarium non-cylindrical or cylindrical, not having a tapered base $=0$ zoarium cylindrical (unsegmented) or flattened cylindrical with a tapered base $=1$

zoarial segments cylindrical or subcylindrical with a tapered base $=2$

17 - Zoarial form: encrusting or elevated, nonunilaminate $=0$

erect unilaminate stem, bearing two or more vertical rows of zooids (with or without lateral branches) $=1$

multiple erect unilaminate free branches $=2$

unilaminate, branches anastomosing to form a cribrate zoarium $=3$

18 - Zoarial form: nonunilaminate or nonfenestrate $=0$

fenestrate lattices, non-cribrate $=1$

branches united by dissepiments bearing up to two rows of zooids $=2$

branches united by nonzooidal dissepiments $=3$

19 - Zoarial form: nonunilaminate $=0$

unilaminate, branches with more than two vertical rows of zooids $=1$

unilaminate, branches with only two vertical rows of zooids $=2$

20 - Zoarial form: nonfenestrate or noncribrate $=0$

fenestrules rhombic, square or polygonal $=1$

fenestrules oval or circular $=2$

fenestrules elliptical=3

21 - Zoarial form: nonunilaminate $=0$

unilaminate, non-pinnate $=1$

pinnately branching $=2$ 
22 - Zoarial form: nonelevated or encrusting, or nonmultiserial $=0$ multiserial encrusting or elevated, nonbilaminate $=1$ flattened cylindrical branches or explanate fronds lacking mesothecae $=2$ explanate nonbranching bilaminate fronds with mesothecae $=3$ flattened or polygonal branches or cylindrical narrow stalks with mesothecae $=4$ flattened branches or stalks with mesothecae and nonzooidal (non-autozooecial) margins $=5$

23 - Zoarial form: non-bilaminate $=0$

zoarium an undivided bilaminate frond, or a stalk/pillar, or a frond with lateral extensions $=1$ zoarium constructed of vertical, radiating bilaminate leaves ( 3 or more $)=2$

24 - Zoarial form: non-bilaminate or non-explanate or pseudo-explanate (formed by merged branches $)=0$ zoarium a single or radiating explanate frond or stalk/pillar, or a frond with short lateral extensions $=1$ explanate fronds with new fronds developing at right angles, forming a boxwork structure $=2$

25 - Zoarial form: zoarial base with open autozooecial apertures (or base not observable) $=0$

zoarial base heavily calcified, lacking apertures $=1$

26 - Zoarial form: reticulate meshwork superstructure absent $=0$ reticulate meshwork superstructure present $=1$

27 - Mesotheca: absent $=0$ present with continuous microgranular or hyaline core $=1$ present with discontinuous or indistinct microgranular or hyaline core $=2$ present, completely laminated $=3$

28 - Mesotheca: absent $=0$

present but discontinuous $=1$

present and continuous $=2$

29 - Mesotheca: absent $=0$

present as a median wall or plate, not extending to zoarial edges (or confined to endozone) $=1$ present, extending to zoarial edges $=2$ present, emerging as a ridge on the zoarial surface $=3$ 
30 - Mesotheca: absent $=0$

present, median styles or stylets absent or rare $=1$

present, median styles or stylets scattered to common $=2$

present, median styles or stylets ovate in cross-section $=3$

31 - Basal epitheca: absent or not observable $=0$

present, thinly developed $=1$

present, thick and wrinkled $=2$

32 - Basal epitheca: absent or not observable $=0$

present, not projecting beyond zooecial limits $=1$

present, projecting beyond outer edges of zooecia $=2$

33 - Locus of budding: linear, or one-dimensional, or nonmultiserial $=0$

planar, or two-dimensional $=1$

not confined to a single line or plane, or three-dimensional $=2$

34 - Budding: zoaria nonmultiserial, or nonerect, or lack localized budding centers (i.e., disordered budding) within branches, fronds, or stems $=0$

localized along a linear endozonal axis, style, plate or other surface $=1$

originating from an axial zooid (basilozooid) $=2$

originating from a localized zooid cluster $=3$

35 - Budding: endozone absent, or present in a laminate or bilaminate zoarium, or lacking central styles $=0$

endozone present in a ramose zoarium, arising from a large central style $=1$ endozone present, stellate clusters of autozooecial buds around endozonal acanthostyles $=2$

36 - Budding: mesozooecia absent in exozone, or do not transform into autozooecia=0 mesozooecia in exozone transform into autozooecia, length of transition less than $0.1 \mathrm{~mm}=1$

mesozooecia in exozone transform into autozooecia, length of transition greater than $0.1 \mathrm{~mm}=2$

37 - Budding: zoaria not multiserial $=0$

irregular in multiserial zoaria $=1$

semi-regular in multiserial zoaria $=2$

highly geometric in multiserial zoaria $=3$

38 - Budding: zoarium non-hemispherical=0

zoarium hemispherical, all zooecia perpendicular to basal layer=1

zoarium hemispherical, zooecia radially oriented from a single point of origin $=2$ 
39 - Budding: exozone absent, or exozonal zooecia close-packed, unaligned or irregular $=0$

aligned in non-curving rows $=1$

aligned into curving rows or series $=2$

intersecting spiral rows form a Fibonacci or sunflower pattern $=3$

40 - Wall boundaries: separate (fixed-walled) $=0$

fused (free-walled) $=1$

41 - Zooecial boundaries (defined by edge of zooecial wall if neighboring zooecia are not in contact, or by midpoint of wall or dark line in wall if neighboring zooecia are in contact):

polygonal or rectangular $=0$

subpolygonal or subrectangular $=1$

subcircular or subelliptical $=2$

circular or elliptical $=3$

42 - Zooecial apertures: uniserial zoaria $=0$

polygonal (with angular corners) in multiserial zoaria $=1$

subpolygonal (with rounded corners) in multiserial zoaria $=2$

rounded subcircular or subelliptical in multiserial zoaria $=3$

rounded circular or elliptical in multiserial zoaria $=4$

43 - Zooecial apertures: polygonal in endozone (or equivalent) and remaining polygonal in exozone, or no differentiation between endozone and exozone $=0$ polygonal in endozone (or equivalent) and becoming subpolygonal in exozone $=1$

polygonal or subpolygonal in endozone (or equivalent) and becoming subcircular (or subelliptical) to circular in exozone $=2$

44 - Zooecial apertures: equidimensional $=0$

elongate $=1$

45 - Zooecial apertures: not wedge-shaped or triangular $=0$

wedge-shaped or subtriangular $=1$

46 - Zooecial apertures (in exozone): elliptical, circular, or subpolygonal, or exozone absent $=0$

pentagonal (or subpentagonal) to hexagonal (or subhexagonal) (in

exozone $)=1$

rhombic (or subrhombic) or quadrate (or subquadrate) (in exozone) $=2$ 
47 - Zooecial apertures (in exozone): circular, elliptical, subelliptical or otherwise nonpolygonal $=0$

irregularly polygonal or subpolygonal $=1$

regularly polygonal or subpolygonal $=2$

48 - Zooecial apertures: margins non-reentrant $=0$

margins invaginated with one or two reentrants, having a kidney, peanut, or dumbbell

shape $=1$

margins petaloid with three or four inflecting acanthostyles $=3$

margins petaloid with five or more inflecting acanthostyles $=4$

49 - Zooecial apertures: lacking a sharply differentiated peristome or cingulum=0 having a weakly differentiated peristome or cingulum $=1$

having a sharply differentiated peristome or cingulum $=2$

50 - Mesozooecial, exilazooecial or metapore apertures: absent, or lacking a secondary lining $=0$

having a secondary lining=1

51 - Zooecial apertures: peristome or cingulum absent or weakly differentiated $=0$

thin peristome or cingulum, less than $0.04 \mathrm{~mm}$ thick $=1$

thick peristome or cingulum, more than $0.04 \mathrm{~mm}$ thick=2

52 - Zooecial apertures: peristomes or equivalent structures absent $=0$

peristomes not touching (non-connate) $=1$

peristomes of adjacent apertures touching (connate) $=2$

peristomes connate, grouped into bundles or fascicles $=3$

53 - Zooecial apertures: peristomes or equivalent structures absent $=0$

peristomes present, lack distal prolongation $=1$

peristomes present, with distal prolongation $=2$

54 - Zooecial apertures: similar size to polygons formed by zooecial boundaries $=0$ markedly smaller than polygon formed by zooecial boundaries $=1$

55 - Zooecial apertures: dark lines (or lines of contiguous stylets) defining zooecial boundaries absent around zooecial apertures $=0$

incomplete polygon of dark lines or stylets around each aperture $=1$ unbroken polygon of dark lines or stylets around each aperture $=2$

56 - Zooecial apertures: short, dark, radial lines or dark spots (pustules) absent around zooecial aperture $=0$

short, dark lines or spots (pustules) radially arranged in walls perpendicular to zooecial apertures $=1$ 
57 - Zooecial apertures: mural tubules, stenostyles or numerous very small styles of any kind absent around apertures $=0$

present, not curving or bifurcating (in longitudinal view) $=1$

present, curving and/or bifurcating $=2$

58 - Autozooecial apertures: minimum diameter greater than $0.25 \mathrm{~mm}=0$

minimum diameter between 0.18 and $0.25 \mathrm{~mm}=1$

minimum diameter between 0.12 and $0.18 \mathrm{~mm}=2$

minimum diameter between 0.07 and $0.12 \mathrm{~mm}=3$

minimum diameter less than $0.07 \mathrm{~mm}=4$

59 - Autozooecial apertural separation: less than one zooecial diameter $=0$

more than one zooecial diameter $=1$

60 - Peristomial ridges: absent $=0$

present $=1$

61 - Longitudinal extrazooidal ridges (keels): absent between rows of zooids=0

dividing rows of zooids $=1$

extending into zoarial superstructure $=2$

62 - Range boundaries (dark divisional line or equivalent structure in wall): absent between rows of zooids $=0$

present between rows of zooids $=1$

parallel pair or series of dark lines separating long rows of zooids $=2$

63 - Range boundaries (dark divisional line or equivalent structure in wall): absent between rows of zooids or lacking tubules, styles, or pustules $=0$ mural tubules, stenostyles, acanthostyles or pustules present along range boundaries $=1$

64 - Zooecial rows: absent, zooecia not strongly aligned in long rows along (parallel to) branch length, or zoarium not branching $=0$

14 or more rows per branch $=1$

$5-13$ rows $=2$

$3-4$ rows $=3$

2 rows $=4$

1 row $=5$

65 - Zooecial rows: absent, zooecia not strongly aligned in long rows (parallel to branch length) or zoarium not branching $=0$

variable number of zooecial rows per branch $=1$

constant number of zooecial rows per branch $=2$

66 - Polygonal extrazooidal ridges: absent $=0$

present $=1$ 
67 - Autozooecia: contiguous, on all sides in multiserial zoaria, or along a chain of zooids in uniserial zoaria $=0$

partially isolated by small polymorphs, vesicles, or stereom in multiserial zoaria $=1$

completely isolated $=2$

68 - Endozone-exozone: no distinction present $=0$

somewhat distinct $=1$

markedly distinct, abrupt transition=2

69 - Change in wall thickness between endozone and exozone: no transition=0 very gradual $=1$

moderately gradual (as in most trepostomes) $=2$

abrupt (as in most cryptostomes) $=3$

70 - Zooecial bend: absent $=0$

rounded zooecial bend $=1$

abrupt zooecial bend $=2$

abrupt deflection, deflecting both distal and proximal walls $=3$

abrupt deflection, visible in proximal wall only $=4$

71 - Endozone: undifferentiated or absent $=0$

present, with gently curving zooecial walls $=1$

present, with straight linear zooecial walls $=2$

72 - Endozone: absent or highly variable in thickness $=0$

thin, less than $4 \mathrm{~mm}$ in diameter or thickness $=1$

intermediate, between 4 and $10 \mathrm{~mm}$ in diameter or thickness $=2$

thick, greater than $10 \mathrm{~mm}$ in diameter or thickness $=3$

73 - Exozone (of mature colony): not differentiated or poorly developed $=0$

well-developed, intermediate to thick $=1$

well-developed, extremely short $=2$

74 - Length of endozonal portion of zooecium: not distinguishable $=0$

short (confined to recumbent portions of zooecia, or shorter than one zooecial diameter $)=1$

intermediate (extending 1-3 zooecial diameters) $=2$

long (extending more than 3 zooecial diameters) $=3$

75 - Autozooecial orientation: no change from major axis of colony growth $=0$

reorientation angle low, 10-30 degrees $=1$

reorientation angle moderate, $30-60$ degrees $=2$

reorientation angle high, $60-90$ degrees $=3$ 
76 - Budding: limited to encrusting base of colony $=0$

present above colony base $=1$

77 - Budding: intercalated budding absent in vicinity of endozone-exozone boundary $=0$ intercalated budding prominent in vicinity of endozone-exozone boundary $=1$

intercalated budding prominent above endozone-exozone boundary $=2$

78 - Budding: endozone absent, or accessory (=secondary) budding absent in endozone $=0$ accessory (secondary) budding present in endozone $=1$

79 - Budding: none in exozone, or exozone absent $=0$

non-localized in exozone $=1$

restricted to monticules or annuli in exozone $=2$

80 - Budding: no endozone-exozone differentiation, or not cyclic within endozone $=0$ cyclic within endozone $=1$

81 - Budding: axial endozone absent $=0$

axial endozone present, remnant growing tips absent $=1$

axial endozone present, remnant growing tips present $=2$

82 - Budding: endozone absent, or budding outside of pre-existing autozooecia in endozone $=0$

within pre-existing autozooecia in endozone, not on distal sides of diaphragms $=1$

within pre-existing autozooecia in endozone, by fission on distal surfaces of diaphragms $=2$

83 - Budding: endozone absent $=0$

endozone present, with new buds having flat walls with pre-existing autozooecia $=1$

endozone present, with new buds having curved walls with pre-existing autozooecia $=2$

84 - Budding: axial endozone absent $=0$

new buds irregularly polygonal or rounded, or radially arranged around a linear axis $=1$

triangular buds at corners of hexagonal autozooecia $=2$

quadrate buds at corners of quadrate zooecia $=3$

85 - Budding: axial endozone absent, or budding outside of pre-existing autozooecia $=0$ budding within endozonal autozooecia $=1$

three-sided endozonal autozooecia, internally divided by budding $=2$ 
86 - Budding: axial endozone absent, or interzooecial budding $=0$

budding within endozonal autozooecia $=1$

autozooecia decrease in diameter toward periphery of endozone (as a result of intra-autozooecial budding) $=2$

very concentrated budding in periphery of endozone nearest to the exozone boundary $=3$

87 - Axial zooecia: axial endozone absent or no axial zooecia $=0$

a few zooecia follow axis for short distances $=1$

axial bundle weakly defined $=2$

axial bundle well defined $=3$

axial bundle large (10+ axial zooecia) and well defined $=4$

88 - Budding: axial endozone absent $=0$

endozone present, without spiral budding pattern $=1$

endozone present, with spiral budding pattern $=2$

89 - Budding: axial endozone absent $=0$

present, non-radial pattern in endozonal cross-section $=1$

present, radial pattern in endozonal cross-section $=2$

present, strongly radial spoke-like structure $=3$

90 - Budding: axial endozone absent $=0$

axial zooecia polygonal or subpolygonal, lacking strongly geometric arrangement $=1$

axial zooecia with strongly geometric budding pattern $=2$

91 - Budding: axial endozone absent $=0$

present, medial rows of zooids absent in endozonal cross-section $=1$

present, medial rows of zooids present in endozonal cross-section $=2$

92 - Zooecial orientation: nearly perpendicular to zoarial surface (79-90 degrees) $=0$ oblique to zoarial surface ( $71-78$ degrees $)=1$

oblique to zoarial surface ( 70 degrees or less $)=2$

93 - Basal zooecium (at colony base, or along mesotheca, or other budding surface): attenuated, smaller than distal portions of zooecia $=0$

same diameter as distal portions of zooecia $=1$

weakly inflated base $=2$

strongly inflated or hemispherical $=3$

94 - Basal zooecium: zoarium nonmultiserial, or no flat base (keel) in recumbent portion $=0$

flat base (keel) present in recumbent portion=1 
95 - Basal zooecium: zoarium nonmultiserial, or no sinuses (indentations) in cross section of recumbent portion $=0$

sinuses (indentations) present in cross-section of recumbent portion $=1$

96 - Basal zooecium: overgrowth layers absent, or present with no recumbent zone $=0$

overgrowth layers present with short recumbent endozone at base $=1$

97 - Basal zooecium: recumbent zones absent $=0$

recumbent zones limited to zoarial base $=1$

recumbent zones present above zoarial base $=2$

98 - Basal zooecium: zoarium nonmultiserial, or recumbent zone absent=0 recumbent zone present, length of zooecial overlap short, less than one zooecial diameter $=1$

recumbent zone present, length of zooecial overlap long, more than one zooecial diameter $=2$

99 - Depth of living chamber: less than two zooecial diameters=0

between two and four zooecial diameters $=1$

greater than four zooecial diameters (or diaphragms absent) $=2$

100 - Shape of living chamber: equant, depth approximating width=0

elongate, depth much greater than width=1

101 - Exozonal zooecia: uniform diameter throughout exozone, or exozone absent=0 increasing diameter into exozone $=1$

102 - Length of autozooecia (including segments below terminal diaphragms): short, 1-2 zooecial diameters $=0$

intermediate, 2-4 zooecial diameters $=1$

long, 4 or more zooecial diameters $=2$

103 - Walls thickness variation: uniform or uniformly increasing thickness $=0$ unevenly thickened or undulating but not distinctly beaded $=1$ distinctly beaded (moniliform) $=2$

104 - Monilae: absent $=0$

present, spacing between successive beads greater than zooecial diameter $=1$

present, spacing between successive beads less than zooecial diameter $=2$

105 - Interzooecial exozonal wall thickness: less than $0.01 \mathrm{~mm}$, or exozone absent $=0$ between 0.01 and $0.04 \mathrm{~mm}=1$

greater than $0.04 \mathrm{~mm}=2$ 
106 - Interzooecial endozonal wall thickness: endozone absent $=0$

less than $0.01 \mathrm{~mm}=1$

between 0.01 and $0.03 \mathrm{~mm}=2$

greater than $0.03 \mathrm{~mm}=3$

107 - Zooecial walls in endozone: regular, or endozone absent $=0$

wavy $=1$

crenulated $=2$

corrugated (fluted) $=3$

108 - Zooecial walls in exozone: regular, or exozone absent $=0$

wavy $=1$

crenulated $=2$

109 - Mesozooecia: absent $=0$

sparse $=1$

abundant $=2$

110 - Mesozooecia: absent $=0$

present at autozooecial junctions $=1$

present at junctions and along wall $=2$

111 - Mesozooecia: absent $=0$

fewer than two associated with each zooecial aperture $=1$

more than two associated with each zooecial aperture $=2$

completely surrounding each zooecial aperture $=3$

112 - Mesozooecia: absent $=0$

present in exozone, small, less than $0.05 \mathrm{~mm}$ in diameter $=1$

present in exozone, between 0.05 and $0.10 \mathrm{~mm}$ in diameter $=2$

present in exozone, large, greater than $0.10 \mathrm{~mm}$ in diameter $=3$

113 - Mesozooecia (cross-sections): absent $=0$

present, thin-walled, polygonal or subpolygonal=1

present, thick-walled, rounded $=2$

114 - Mesozooecial boundaries (defined by midpoint of wall with neighboring mesozooecia or autozooecia): mesozooecia absent $=0$

polygonal $=1$

subpolygonal $=2$

subcircular or subelliptical $=3$

circular or elliptical $=4$

115 - Mesozooecia or cystopores: absent $=0$

open at surface $=1$

closed over at surface $=2$ 
116 - Mesozooecia: absent $=0$

present only in exozone $=1$

present, originate near endozone-exozone boundary $=2$

present in outer endozone $=3$

117 - Mesozooecia: absent $=0$

present, not clustered $=1$

present in clusters in maculae $=2$

clustered mesozooecia have a vesicular or imbricate cystose structure $=3$

118 - Mesozooecia: absent $=0$

present, not clustered $=1$

present in small clusters between adjacent zooecial apertures $=2$

119 - Mesozooecia or cystopores: absent $=0$

present, adjacent structures lack a zigzag boundary $=1$

present, adjacent structures have a zigzag boundary caused by indentations

of flat tabulate $=2$

120 - Mesozooecia or exilazooecia: absent $=0$

present, most not beaded or moniliform $=1$

present, most beaded or moniliform $=2$

beaded or moniliform small polymorphs or incipient zooecia only in

lowermost portion of exozone $=3$

121 - Mesozooecia or cystopores: absent or not tabulate $=0$

tabulae or vesicle plates widely spaced, spacing greater than lateral

diameter $=1$

tabulae or vesicle plates closely spaced, spacing less than lateral

diameter $=2$

122 - Mesozooecial tabulae: mesozooecia absent or not tabulate $=0$

slightly curved, distally concave $=1$

planar $=2$

slightly curved, distally convex $=3$

123 - Mesozooecial tabulae: mesozooecia absent or not tabulate $=0$

most perpendicular to wall $=1$

most oblique to wall $=2$

124 - Mesozooecia or cystopores: absent $=0$

number between adjacent zooecia nearly constant, or decreases distally $=1$

number between adjacent zooecia increases distally, or characterizes overgrowth layers $=2$ 
125 - Metapores: absent in endozone (or endozone absent) $=0$

present in endozone $=1$

126 - Metapores: absent in exozone (or exozone absent) $=0$

present in exozone, fewer than 2 per zooecium $=1$

present in exozone, numerous but not in fields $=2$

present in exozone, numerous and in fields $=3$

127 - Fenestrules: absent, or zoarium not unilaminate,fenestrate $=0$

small, length less than $0.4 \mathrm{~mm}$, width less than $0.24 \mathrm{~mm}=1$

intermediate, length $0.4-0.9 \mathrm{~mm}$, width $0.24-0.34 \mathrm{~mm}=2$

large, length greater than $0.9 \mathrm{~mm}$, width greater than $0.34 \mathrm{~mm}=3$

128 - Exilazooecia or "kenozooecia” (=nanozooecia): absent or very rare $=0$

rare to sparse $=1$

numerous $=2$

129 - Cystopores (vesicles): absent $=0$

present but sparse $=1$

abundant $=2$

130 - Cystopores (vesicles): absent $=0$

present in endozone $=1$

concentrated in exozone $=2$

131 - Cystopores (vesicles): absent $=0$

irregularly shaped $=1$

boxlike or quadrate $=2$

bubble-like or rounded $=3$

132 - Cystopores (vesicles): absent, or with indistinct roof plates $=0$

present, roofed by flat tabulae $=1$

present, roofed by arched, imbricate plates $=2$

133 - Monticules: absent or rare $=0$

irregular in shape $=1$

circular or oval $=2$

radial to stellate $=3$

134 - Monticules: absent or rare $=0$

present, zooecial diameter grades imperceptibly into intermonticular region $=1$

present, zooecial diameters change abruptly at edge of monticule $=2$ 
135 - Monticules: absent or non-stellate $=0$ radiating rows of bundled zooecia $=1$

radiating distinct rows of aligned zooecia $=2$

136 - Monticules: absent or nonstellate $=0$ radiating rows of zooecia lack a mid-ray partition $=1$ radiating rows of zooecia have a mid-ray partition $=2$

137 - Monticules: absent or nonstellate $=0$ inter-ray zooecia present $=1$ inter-ray zooecia absent $=2$

138 - Monticules: absent or nonstellate $=0$ zooecia present outside radiating structure $=1$ zooecia absent outside radiating structure $=2$

139 - Monticules: absent or non-stellate $=0$ zoarium composed of numerous radial disk subcolonies $=1$ entire zoarium a single radial disk $=2$

140 - Monticules: absent on non-stellate $=0$ fewer than 8 rays per stellate monticule $=1$ approximately 9-11 rays per stellate monticule $=2$ more than 12 rays per stellate monticule $=3$

141 - Monticules: absent or non-stellate $=0$ stellate, rays do not bifurcate or give rise to secondary rays $=1$ stellate, rays bifurcate or give rise to secondary rays $=2$

142 - Monticules: absent or non-stellate $=0$ radiating rows of mesozooecia or cystopores $=1$

143 - Monticules or annuli: absent or rare or irregularly shaped $=0$ circular or oval $=1$ elongate to bar-like $=2$ forming extensive ridges $=3$

144 - Monticules or annuli: absent or non-rugose $=0$ rugose ridges perpendicular to long axis of zoarium $=1$ rugose ridges oblique to long axis of zoarium $=2$

145 - Monticules: absent or more circular than elongate in outline $=0$ present, more elongate in outline than circular $=1$ present, elongate, tapered at proximal end $=2$ 
146 - Monticules: absent or lack megazooecia $=0$ megazooecia present in monticules $=1$ central macula ringed by megazooecia $=2$

147 - Megazooecia or amplozooecia: absent $=0$ present in exozone $=1$ present in exozone extending from endozone-exozone boundary $=2$ present in exozone and outer endozone $=3$

148 - Megazooecia or amplozooecia apertural cross-section: absent $=0$ polygonal $=1$ subpolygonal $=2$ subcircular or subelliptical=3 circular or elliptical $=4$

149 - Monticules: absent, or lack megazooecia, or megazooecia all of subequal size $=0$ prominent single monarchozooid present in each monticule $=1$

150 - Monticules: absent or rare $=0$ flat or depressed $=1$ elevated $=2$ highly elevated and sharply conical $=3$

151 - Monticules: absent or lack central macula formed by stereom=0 have central macula formed by stereom $=1$

152 - Monticules: absent or lack central macula formed by a cluster of small polymorphs $=0$ have central macula formed by a cluster of small polymorphs or vesicles $=1$

central macula of small polymorphs or vesicles stellate $=2$

153 - Monticules: absent or lacking central macula $=0$ central macula smaller than one zooecial diameter $=1$ central macula larger than one zooecial diameter $=2$

154 - Monticules: absent or rare $=0$ present, but irregularly spaced $=1$ present, regularly spaced $=2$

155 - Monticules: absent or rare $=0$ small, less than $1.5 \mathrm{~mm}=1$ large, greater than $1.5 \mathrm{~mm}=2$ 
156 - Monticules: absent or rare $=0$

widely spaced, centers more than $3 \mathrm{~mm}$ apart $=1$

closely spaced, centers less than $3 \mathrm{~mm}$ apart $=2$

157 - Monticules: acanthostyles (sensu lato) absent $=0$

acanthostyles present, fewer than one per zooecium $=1$

acanthostyles present, one to three per zooecium $=2$

acanthostyles present, four to seven per zooecium $=3$

acanthostyles present, more than seven per zooecium $=4$

158 - Monticules: acanthostyles (sensu lato) absent $=0$

present, less than $0.03 \mathrm{~mm}$ in diameter $=1$

present, greater than $0.03 \mathrm{~mm}$ in diameter $=2$

159 - Coordinated extrazooidal feeding currents: unknown, or not reflected in zoarial structure $=0$

reflected in zoarial structure $=1$

160 - Extrazooidal calcification: absent $=0$

limited to basal portions of zoarium $=1$

present above basal portions of zoarium $=2$

161 - Wall microgranular: entirely (or laminae indistinct) or recystallized $=0$ microgranular core and laminated outer portions, or bulk of wall microgranular or recrystallized with some distinct laminae $=1$ no microgranular wall material (entirely laminated) $=2$

162 - Wall laminated (in exozone if present): no, or laminations indistinct $=0$

yes, laminations longitudinal $=1$

yes, laminations V-shaped, with dark divisional line $=2$

yes, laminations U-shaped (amalgamate), posteriorly flexed laminae

greatly dominant over transverse laminae $=3$

yes, laminations transverse across broad regions $=4$

163 - Wall laminated (in exozone if present): no or wall amalgamate $=0$

wall weakly integrate, discontinuous or faint dark divisional line $=1$

wall strongly integrate, continuous and prominent dark line, straight $=2$

wall strongly integrate, prominent dark line, crinkled=3 
164 - Wall strongly laminated (in exozone if present): no, or laminations indistinct $=0$ yes, with continuous succession of laminae $=1$

yes, with unconformities or cessation surfaces that extend across several zooecia or mesozooecia $=2$

yes, with zones of wall laminae separated wall units defined distally and proximally by cessation surfaces, the laminae within each unit not extending into any diaphragms $=3$

165 - Diaphragms (or cystiphragms or hemiphragms or hemisepta): absent $=0$ granular microstructure $=1$

laminated microstructure, laminae merge inconspicuously into zooecial wall $=2$

laminated microstructure, laminae extend into zooecial wall beneath cessation surfaces dividing the wall into units resembling a stack of nested tumblers $=3$

166 - Diaphragm wall units: absent $=0$ thicken walls more on proximal sides of zooecia $=1$ thicken walls equally on both sides of zooecia $=2$ thicken walls more on distal sides of zooecia $=3$

167 - Diaphragm thickness: absent $=0$ present, thinner than $0.02 \mathrm{~mm}=1$ present, thicker than $0.02 \mathrm{~mm}=2$

168 - Laminated stereom: absent in zoarium, or absent in intermonticular exozone or in nonzooidal regions $=0$ present in intermonticular (or equivalent regions of) exozone or in nonzooidal regions $=1$ thickly developed in exozone or in nonzooidal regions $=2$ with crinkled laminae in exozone or in nonzooidal regions $=3$

169 - Extensive nonzooidal surfaces: absent $=0$ smooth or pitted $=1$ marked by longitudinal ridges or striations $=2$ marked by ridges, ridges converge distally $=3$

170 - Interzooecial pores: solid walls $=0$ mural pores rare or few $=1$ walls regularly perforated $=2$

171 - Interzooecial pores: absent $=0$ straight-sided, wall laminae not flexed into pores $=1$ double-funnel shaped pores, with wall laminae flexed into them $=2$ 
172 - Interzooecial passageways: absent $=0$

large passageway connected to proximal zooid $=1$

173 - Lunaria: absent $=0$

present, slight outcurving of wall, not prominent $=1$

present, moderately curved $=2$

present, highly curved, prominent $=3$

174 - Lunaria: absent $=0$

granular-prismatic or variable $=1$

hyaline or laminated $=2$

175 - Lunaria: absent $=0$

present, inner side lacking a thin, dark colored zone $=1$

present, inner side lined by a thin, dark colored zone continuous with the zooecial wall $=2$

176 - Lunaria: absent $=0$

present, lunaria wall identical to zooecial wall $=1$

present, lunarial wall sharply differentiated from laminae of zooecial

walls $=2$

177 - Lunaria: absent $=0$

present, without longitudinal median ridge (carina) $=1$

present, with longitudinal median ridge (carina) $=2$

178 - Lunaria: absent or lacking rodlike cores $=0$

present with longitudinal, rodlike cores $=1$

present, cores having tabulations $=2$

179 - Lunaria: absent $=0$

present, without spurs (pseudosepta) $=1$

present, with spurs (pseudosepta) $=2$

180 - Lunaria: absent $=0$

present, margins lack knoblike or spinelike projections $=1$

present, margins with knoblike or spinelike projections $=2$

181 - Lunaria: absent, or monticules absent $=0$

present, aligned in rows parallel to monticular margins $=1$

present, aligned in a semiradial or funnel pattern centered on monticules $=2$

present, aligned radially around monticules $=3$ 
182 - Lunaria: absent, or monticules absent $=0$

present, radially arranged on sides of zooecia nearest to a monticule $=1$ present, radially arranged on sides of zooecia away from a monticular center $=2$

183 - Acanthostyles (sensu lato) : absent or rare $=0$

sparse $=1$

abundant $=2$

184 - Acanthostyles (sensu lato): absent or rare $=0$ unimodal size distribution in zoarium $=1$

simultaneously present as two or more discrete size classes $=2$

185 - Acanthostyles (sensu lato): absent $=0$

present, maximum diameter (in zoarium) less than $0.03 \mathrm{~mm}=1$

present, maximum diameter (in zoarium) greater than $0.03 \mathrm{~mm}=2$

186 - Endacanthostyles (long acanthostyles originating in endozone): absent $=0$ present $=1$

187 - Exacanthostyles (sensu lato, long or short acanthostyles originating in exozone): absent $=0$

present $=1$

188 - Acanthostyles (sensu lato): absent $=0$

incipient acanthostyles present as small, dark spots at zooecial junction angles $=1$

acanthostyles fully developed $=2$

189 - Acanthostyles (sensu lato): absent $=0$

present, crossed by laminations, clear core absent $=1$

present, with clear core flanked by cone-in-cone laminations $=2$

present, with clear core flanked by cone-in-cone laminations, width of core (lumen) predominates over laminated margin $=3$

190 - Acanthostyles (sensu lato): absent or lacking clear core $=0$

clear core throughout acanthostyle $=1$

clear core present toward endozone, completely laminated in outer

exozone $=2$

191 - Acanthostyles (sensu lato): absent or most noninflecting $=0$

most offset but not inflecting apertures $=1$

most inflecting apertures $=2$

most producing petaloid apertures $=3$ 
192 - Acanthostyles (sensu lato): absent or off-center=0

centered acanthostyles present along walls $=1$

centered acanthostyles common along walls $=2$

193 - Acanthostyles (sensu lato): absent $=0$

present, but fewer than two acanthostyles around each zooecial apertures $=1$

present, with two to four acanthostyles around each zooecial aperture $=2$

present, with five to seven acanthostyles around each zooecial aperture $=3$

present, forming rings or bands around zooecial apertures $=4$

194 - Acanthostyles (sensu lato): absent or absent at zooecial junction angles $=0$

present at some of the junction angles between zooecial apertures $=1$

present at most or all junction angles between zooecial apertures $=2$

present at most or all junction angles between zooecial apertures, and

commonly present in the wall between the junction angles as well $=3$

195 - Acanthostyles (sensu lato): absent $=0$

present, lacking growth discontinuities or rejuvenation $=1$

present, with growth discontinuities or rejuvenation=2

196 - Complete planar (non-perforated) diaphragms: absent or rare $=0$

sparse $=1$

abundant $=2$

197 - Diaphragms, hemiphragms, ring septa, or cystiphragms: absent or rare in endozone or endozone absent $=0$

fewer than four in endozone $=1$

more than four in endozone $=2$

198 - Diaphragms, hemiphragms, ring septa, or cystiphragms: absent or rare in innermost $0.5 \mathrm{~mm}$ of exozone $=0$

fewer than four in innermost $0.5 \mathrm{~mm}$ of exozone $=1$

more than four in innermost $0.5 \mathrm{~mm}$ of exozone $=2$

199 - Complete planar (non-perforated) diaphragms: absent or rare, or exozone absent or weakly developed or diaphragms absent in exozone $=0$

present in exozone $=1$

present in exozone and endozone $=2$ 
200 - Complete planar (non-perforated) diaphragms: absent or rare in endozone, or endozone absent or weakly developed, or limited to basal diaphragm present at scattered levels in endozone $=1$

present at a single level in endozone that passes laterally into the exozone $=2$

201 - Diaphragms, ring septa, cystiphragms, and hemiphragms: absent or rare, or present as single structures in exozone $=0$

widely spaced in exozone, spacing greater than one zooecial diameter $=1$

closely spaced in exozone, spacing less than one zooecial diameter $=2$

202 - Curved diaphragms: absent or rare $=0$

sparse $=1$

abundant, may appear as crescentic bands in zooecia $=2$

203 - Curved diaphragms: absent, rare, or slightly curved, concave outward=0 slightly curved, convex outward $=1$

strongly curved, semi-cystiphragms $=2$

fully developed cystiphragms $=3$

204 - Curved diaphragms: absent, rare, or slightly curved, convex outward=0 slightly curved, concave outward $=1$ line of concave diaphragms extending over numerous zooecia $=2$

205 - Orientation of diaphragms, hemiphragms, or ring septa: diaphragms absent or rare $=0$ most diaphragms perpendicular to zooecial wall $=1$ most diaphragms oblique to zooecial wall=2

206 - Oblique diaphragms: absent or sparse $=0$

high edge attached to proximal walls of zooids $=1$

high edge attached to both proximal and distal walls $=2$

high edge attached to distal walls of zooids $=3$

207 - Infundibular (funnel-shaped) diaphragms: absent=0

present $=1$

208 - Sigmoid diaphragms: absent $=0$

present $=1$

209 - Cystiphragms: absent $=0$

sparse $=1$

abundant $=2$ 
210 - Cystiphragms: absent, or present in an overlapping series $=0$ present as single closed cystiphragms on top of a planar diaphragm=1

211 - Cystiphragms: absent $=0$ present throughout zoarium $=1$ present only in exozone $=2$

212 - Cystiphragms: absent $=0$ present in a vertical, non-overlapping series $=1$ present in a vertical, overlapping series $=2$

213 - Cystiphragms: absent $=0$ present, with low curvature $=1$ present with normal curvature $=2$ hemispherical, completely recurved to zooecial wall $=3$

214 - Cystiphragms: absent $=0$ present, not joined to a half-diaphragm or diaphragm $=1$ present, abutted by horizontal half-diaphragms $=2$ present, V-shaped or U-shaped, and linked by inclined or oblique semidiaphragms $=3$

215 - Cystiphragms and/or hemiphragms: absent $=0$ present, without proximal fringe $=1$ present, with proximal-directed fringes $=2$

216 - Cystiphragms: absent or monticules absent or not oriented with respect to monticules $=0$ arranged in linear rows parallel to monticules $=1$ arranged in a semiradial or funnel pattern leading into a monticule $=2$ radially arranged around monticules $=3$

217 - Cystiphragms: absent or not radially arranged around monticules $=0$ preferentially located on the sides of zooecia nearest a monticular center $=1$ preferentially arranged on the sides of zooecia away from a monticular center $=2$

218 - Cystiphragms: absent or absent in apertures $=0$ present, restricted zooecial aperture rounded or elliptical $=1$ present, restricted zooecial aperture $\mathrm{V}$-shaped or U-shaped $=2$

219 - Cystiphragms: absent, or not present in all zooecia $=0$ single or multiple large cystiphragms present in each zooecium $=1$ small, numerous, blisterlike cystiphragms present in each zooecium $=2$ 
220 - Cystiphragms: absent or absent in apertures $=0$

single cystiphragms small, restricting less than one third of the apertural area $=1$

single cystiphragms intermediate, restricting from one third to one half of the apertural area $=2$

single cystiphragms large, restricting more than one half of the apertural area $=3$

221 - Cystiphragms: absent or absent in apertures $=0$

present as single, non-nested structures within each zooecium (as seen in tangential sections) $=1$

present as multiple, nested structures within each zooecium (as seen in tangential sections $)=2$

222 - Heterophragms (variant or irregularly shaped diaphragms, hemiphragms or

hemisepta): absent $=0$

planar $=1$

hooked or curved $=2$

223 - Hemiphragms (incomplete diaphragms): absent $=0$

sparse $=1$

at least one per zooecium $=2$

more than one in most zooecia $=3$

224 - Hemiphragms (or hemisepta): absent $=0$

present in endozone, but may also be present in exozone $=1$

present only in exozone $=2$

225 - Hemiphragms (or hemisepta): absent $=0$

present, irregularly spaced $=1$

present in a regularly spaced vertical series $=2$

226 - Hemiphragms (or hemisepta): absent $=0$

present, projecting from both sides of zooecia $=1$

present, projecting from only one side of zooecia $=2$

227 - Hemiphragms: absent on convex side of zooecial bend $=0$

present on convex side of zooecial bend $=1$

228 - Hemiphragms: absent $=0$

present, not abutted by thinner semidiaphragms $=1$

present, abutted by thinner semidiaphragms $=2$ 
229 - Perforate diaphragms (ring septa): absent $=0$

present in exozone, centrally perforate $=1$

present in exozone, foramina increasingly off center distally=2

230 - Ring septa or perforate tabulae: absent $=0$

present only in mesozooecia or small incipient zooecia $=1$

present in autozooecia $=2$

231 - Ring septa: absent $=0$

foramen circular $=1$

foramen kidney-shaped $=2$

232 - Intrazooecial tubes: absent $=0$

present in exozone $=1$

233 - Zooecial operculum (terminal diaphragm): absent=0

present, imperforate $=1$

present, perforate or incompletely calcified $=2$

234 - Inferior (on distal wall) hemisepta: absent or rare $=0$

sparse $=1$

abundant $=2$

235 - Superior (on proximal wall) hemisepta: absent $=0$

sparse $=1$

abundant $=2$

236 - Ovicells: absent $=0$

present $=1$

237 - Skeletal growth cycles (regularly spaced cessation surfaces): absent=0 present $=1$

238 - Budding: uniserial zoaria $=0$

multiserial, irregular apertural arrangement $=1$

multiserial zoaria, zooids hexagonally packed=2

rhombic or rhombic-linear alignment $=3$

longitudinal rows of zooids $=4$

strongly linear alignment, with longitudinal range boundaries $=5$

239 - Stenostyles (“capillaries, tubules, or minutopores”) or mural styles: absent=0

present but sparse in exozone, stereom, or vesicle roofs $=1$

abundant $=2$

organized into stellate clusters around a central axis (stellatopores)=3 
240 - Paurostyles (thin mural styles with transverse laminae regularly crossing the clear calcite core, and with very thin sheaths): absent $=0$

present $=1$

241 - Aktinotostyles (with laminated cores and "Christmas-tree” lateral projections): absent $=0$

present $=1$

242 - Heterostyles (strongly segmented styles with nonlaminated core segments separated by bands of sheath laminae): absent $=0$

present $=1$

243 - Pustules (mural lacunae; granules; dark spots; small patches of crinkled wall laminae): absent $=0$ present in exozone $=1$ present in exozone as distinctly spherical voids $=2$

244 - Carinal styles: absent $=0$ present in longitudinal rows between zooecial ranges $=1$ embedded within a carinal layer $=2$

245 - Pseudopores: absent in uniserial or multiserial zoaria=0 present in uniserial zoaria $=1$ present in multiserial zoaria $=2$

246 - Intrazooecial spines: absent or rare $=0$ present, thin and delicate $=1$ present, thick and blunt $=2$

247 - Intrazooecial spines: absent or rare $=0$ present on both proximal and distal sides of zooecia $=1$ present on only one side of zooecial wall=2

248 - Intrazooecial spines: absent or rare $=0$ most numerous in exozone $=1$ present only near endozone-exozone boundary, or abundant in endozone $=2$

249 - Intrazooecial spines: absent or rare $=0$ present, non-lobate $=1$ present with lobate extremities $=2$ 
250 - Intrazooecial spines: absent or rare, or not in a vertical series $=0$

present in a vertical series but widely spaced $=1$

present in a vertical series, spacing less than one zooecial diameter $=2$

251 - Septa (vertical plates radiating into apertures): absent=0

present $=1$

252 - Apertural styles, stylets or spines: absent $=0$

present $=1$

253 - Rhizoids: no=0

yes $=1$

254 - Mesotheca: absent, or no increase in thickness towards zoarial margin (in transverse section) $=0$

becomes thicker and internally laminated towards zoarial margin=1

255 - Budding surface: nonplanar (including linear) $=0$

planar or radiating-planar $=1$

transversely curved $=2$

cylindrical $=3$

256 - Budding: no axial endozone, or endozone with interzooecial budding=0

intrazooecial budding, no keel and sinus pattern $=1$

intrazooecial budding, with keel and sinus pattern in which autozooecial have concave walls towards the branch axis, and convex walls away from $\mathrm{it}=2$

257 - Budding: no axial endozone, or endozone lacking mesozooecia=0

endozonal mesozooecial develop into autozooecial=1

258 - Superior (proximal) hemiseptum: absent, or normally developed=0

present only as a thickened bulge in proximal wall $=1$

259 - Mesotheca: absent $=0$

straight or slightly curved $=1$

sinuous, highly curved, or crenulated $=2$

260 - Acanthostyles (sensu lato): absent in entire zoarium $=0$

well developed in autozooidal walls, and possibly extrazooidal regions $=1$ absent or less well developed in autozooidal walls, but more abundantly developed in nonzooidal regions of stereom $=2$ 
261 - Fossazooecia: absent $=0$

present $=1$

262 - Stenostyles: absent $=0$

present $=1$

present with distally extending lateral projections $=2$

263 - Mesotheca: absent $=0$

present in interior or center of frond or branch $=1$

absent in interior or center of frond or branch, but present in peripheral region extending to zoarial margin $=2$

264 - Zoarial margins: lack non-zooidal regions of stereom $=0$

have non-zooidal regions of stereom $=1$

have non-zooidal regions of stereom developed as annular curved reentrants $=2$

265 - Stenostyles: absent $=0$ present in autozooidal regions $=1$

concentrated in or around zooecial peristomes $=2$

266 - Amplozooecia: absent $=0$

present $=1$

267 - Mesotheca: absent or non-zigzag=0

present with zigzag development $=1$ 


\section{APPENDIX C}

Apomorphy listing, by node, for the heuristic analysis reweighted by maximum value of RC performed using PAUP. A double line arrow means that the change occurs in all possible reconstructions. A single lined arrow means that the change differs when other input parameters were used.

\begin{tabular}{|c|c|c|c|c|}
\hline Branch & Character & Steps & S CI & Change \\
\hline node_17 - - > node_18 & 100 & 1 & 0.200 & $0-->1$ \\
\hline node_18 - - > node_19 & $\begin{array}{l}1 \\
39 \\
58 \\
83 \\
110 \\
116 \\
118 \\
121 \\
124 \\
134 \\
165 \\
196 \\
198 \\
199 \\
200 \\
206\end{array}$ & $\begin{array}{l}1 \\
1 \\
1 \\
1 \\
1 \\
1 \\
1 \\
1 \\
1 \\
1 \\
1 \\
1 \\
1 \\
1 \\
1 \\
1\end{array}$ & $\begin{array}{l}0.500 \\
0.200 \\
0.333 \\
0.400 \\
0.286 \\
0.500 \\
0.500 \\
0.500 \\
0.667 \\
0.667 \\
0.400 \\
0.400 \\
0.500 \\
0.400 \\
0.500 \\
0.600\end{array}$ & $\begin{array}{l}0-->2 \\
0-->1 \\
0-->2 \\
0-->1 \\
0-->2 \\
0-->3 \\
0-->1 \\
0-->2 \\
0-->1 \\
0-->1 \\
0-->2 \\
0-->1 \\
1-->2 \\
0-->2 \\
0-->1 \\
0-->2\end{array}$ \\
\hline node_19 - - > node_20 & $\begin{array}{l}37 \\
43 \\
79 \\
112 \\
117 \\
133 \\
146 \\
147 \\
150 \\
152 \\
153 \\
154 \\
202 \\
203 \\
209 \\
211 \\
215 \\
220\end{array}$ & $\begin{array}{l}1 \\
1 \\
1 \\
1 \\
1 \\
1 \\
1 \\
1 \\
1 \\
1 \\
1 \\
1 \\
1 \\
1 \\
1 \\
1 \\
1 \\
1\end{array}$ & $\begin{array}{l}0.250 \\
0.333 \\
0.400 \\
0.286 \\
0.500 \\
0.500 \\
0.667 \\
0.500 \\
0.750 \\
0.333 \\
0.400 \\
0.500 \\
0.400 \\
0.667 \\
1.000 \\
1.000 \\
1.000 \\
0.667\end{array}$ & $\begin{array}{ll}1 & ->3 \\
0 & ->2 \\
1 & ->>2 \\
1 & ->>2 \\
1 & -->2 \\
0 & ->>2 \\
0 & ->1 \\
0 & ->>1 \\
0 & ->>1 \\
0 & ->>1 \\
0 & ->>1 \\
0 & ->>2 \\
2 & ->>0 \\
1 & ->>0 \\
0 & ->>2 \\
0 & ->>1 \\
0 & ->>1 \\
0-->3\end{array}$ \\
\hline node_20 --> node_21 & $\begin{array}{l}31 \\
32 \\
39 \\
155 \\
184 \\
187 \\
188 \\
194 \\
195 \\
196 \\
205 \\
206 \\
212 \\
213\end{array}$ & $\begin{array}{l}1 \\
1 \\
1 \\
1 \\
1 \\
1 \\
1 \\
1 \\
1 \\
1 \\
1 \\
1 \\
1 \\
1\end{array}$ & $\begin{array}{l}0.500 \\
0.500 \\
0.200 \\
1.000 \\
1.000 \\
0.500 \\
0.500 \\
0.750 \\
0.500 \\
0.400 \\
1.000 \\
0.600 \\
0.667 \\
1.000\end{array}$ & $\begin{array}{l}2-->0 \\
1->0 \\
1-->0 \\
0-->1 \\
0-->1 \\
0->>1 \\
0->>2 \\
0-->1 \\
0->>1 \\
1->>2 \\
2->>1 \\
2->>0 \\
0-->2 \\
0->>2\end{array}$ \\
\hline
\end{tabular}




\begin{tabular}{|c|c|c|c|c|}
\hline & $\begin{array}{l}214 \\
218 \\
219 \\
221 \\
260\end{array}$ & $\begin{array}{l}1 \\
1 \\
1 \\
1 \\
1\end{array}$ & $\begin{array}{l}0.750 \\
0.500 \\
1.000 \\
0.667 \\
0.333\end{array}$ & $\begin{array}{lll}0 & -->2 \\
0 & -->1 \\
0 & -->1 \\
0 & -->1 \\
0 & -->1\end{array}$ \\
\hline node_21 - - > node_24 & $\begin{array}{l}37 \\
68 \\
70 \\
71 \\
72 \\
74 \\
75 \\
116 \\
156 \\
157 \\
161 \\
183 \\
185 \\
189 \\
190 \\
192 \\
193 \\
197\end{array}$ & $\begin{array}{l}1 \\
1 \\
1 \\
1 \\
1 \\
1 \\
1 \\
1 \\
1 \\
1 \\
1 \\
1 \\
1 \\
1 \\
1 \\
1 \\
1 \\
1\end{array}$ & $\begin{array}{l}0.250 \\
0.500 \\
1.000 \\
1.000 \\
0.400 \\
0.600 \\
0.750 \\
0.500 \\
0.667 \\
0.750 \\
0.333 \\
0.667 \\
0.500 \\
0.667 \\
0.500 \\
0.400 \\
0.600 \\
0.500\end{array}$ & $\begin{array}{ll}3 & -->1 \\
0 & ->>1 \\
0 & -->1 \\
0 & -->1 \\
0 & -->1 \\
0 & -->3 \\
0 & ->>2 \\
3 & ->>2 \\
0 & ->>1 \\
0 & -->2 \\
0 & -->2 \\
0 & -->2 \\
0 & -->1 \\
0 & ->>2 \\
0 & ->>1 \\
0 & -->1 \\
0 & -->2 \\
1-->2\end{array}$ \\
\hline node_24 - - > node_23 & $\begin{array}{l}1 \\
5 \\
6 \\
7 \\
8 \\
22 \\
39 \\
42 \\
43 \\
47 \\
58 \\
69 \\
77 \\
81 \\
84 \\
87 \\
88 \\
89 \\
90 \\
91 \\
105 \\
106 \\
107 \\
111 \\
153 \\
162 \\
163 \\
164 \\
202 \\
211 \\
255 \\
256\end{array}$ & $\begin{array}{l}1 \\
1 \\
1 \\
1 \\
1 \\
1 \\
1 \\
1 \\
1 \\
1 \\
1 \\
1 \\
1 \\
1 \\
1 \\
1 \\
1 \\
1 \\
1 \\
1 \\
1 \\
1 \\
1 \\
1 \\
1 \\
1 \\
1 \\
1 \\
1 \\
1 \\
1 \\
1\end{array}$ & $\begin{array}{l}0.500 \\
0.600 \\
1.000 \\
1.000 \\
0.667 \\
0.600 \\
0.200 \\
0.500 \\
0.333 \\
0.667 \\
0.333 \\
0.500 \\
0.400 \\
1.000 \\
1.000 \\
1.000 \\
1.000 \\
1.000 \\
1.000 \\
1.000 \\
0.286 \\
0.286 \\
1.000 \\
0.500 \\
0.400 \\
0.500 \\
0.429 \\
0.250 \\
0.400 \\
1.000 \\
0.667 \\
0.500\end{array}$ & 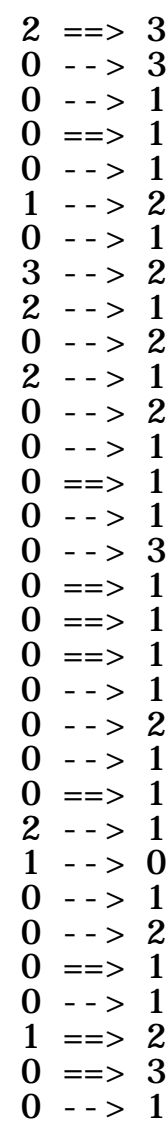 \\
\hline node_23 --> node_22 & $\begin{array}{l}8 \\
9 \\
10 \\
41 \\
75 \\
79\end{array}$ & $\begin{array}{l}1 \\
1 \\
1 \\
1 \\
1 \\
1\end{array}$ & $\begin{array}{l}0.667 \\
1.000 \\
1.000 \\
0.600 \\
0.750 \\
0.400\end{array}$ & $\begin{array}{l}1->2 \\
0 \Longrightarrow 2 \\
0-->2 \\
2 \Longrightarrow 1 \\
2 \Longrightarrow 3 \\
2 \Longrightarrow 1\end{array}$ \\
\hline
\end{tabular}




\begin{tabular}{|c|c|c|c|c|}
\hline & $\begin{array}{l}152 \\
155\end{array}$ & $\begin{array}{l}1 \\
1\end{array}$ & $\begin{array}{l}0.333 \\
1.000\end{array}$ & $\begin{array}{l}1 \Longrightarrow 0 \\
1->3\end{array}$ \\
\hline node_21 - > node_16 & $\begin{array}{l}1 \\
34 \\
37 \\
68 \\
69 \\
70 \\
71 \\
72 \\
74 \\
75 \\
79 \\
97 \\
98 \\
100 \\
116 \\
122 \\
143 \\
148 \\
156 \\
157 \\
158 \\
183 \\
185 \\
189 \\
190 \\
191 \\
193 \\
198 \\
220\end{array}$ & $\begin{array}{l}1 \\
1 \\
1 \\
1 \\
1 \\
1 \\
1 \\
1 \\
1 \\
1 \\
1 \\
1 \\
1 \\
1 \\
1 \\
1 \\
1 \\
1 \\
1 \\
1 \\
1 \\
1 \\
1 \\
1 \\
1 \\
1 \\
1 \\
1 \\
1\end{array}$ & $\begin{array}{l}0.500 \\
0.500 \\
0.250 \\
0.500 \\
0.500 \\
1.000 \\
1.000 \\
0.400 \\
0.600 \\
0.750 \\
0.400 \\
0.667 \\
0.667 \\
0.200 \\
0.500 \\
0.500 \\
0.250 \\
0.667 \\
0.667 \\
0.750 \\
0.500 \\
0.667 \\
0.500 \\
0.667 \\
0.500 \\
0.500 \\
0.600 \\
0.500 \\
0.667\end{array}$ & 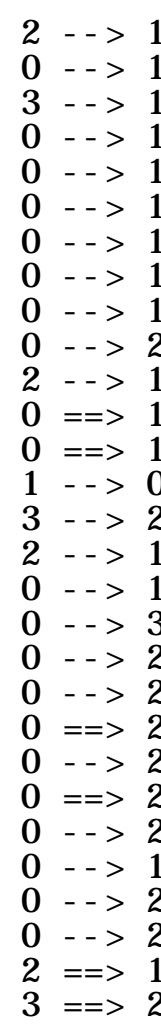 \\
\hline node_16 - - > node_14 & $\begin{array}{l}74 \\
115 \\
117 \\
152 \\
153 \\
157 \\
161 \\
193 \\
194 \\
197\end{array}$ & $\begin{array}{l}1 \\
1 \\
1 \\
1 \\
1 \\
1 \\
1 \\
1 \\
1 \\
1\end{array}$ & $\begin{array}{l}0.600 \\
0.500 \\
0.500 \\
0.333 \\
0.400 \\
0.750 \\
0.333 \\
0.600 \\
0.750 \\
0.500\end{array}$ & $\begin{array}{l}1-> \\
1-> \\
2 \Longrightarrow \\
1 \Longrightarrow \\
1 \Longrightarrow \\
2 \Longrightarrow \\
0 \Rightarrow> \\
2 \Longrightarrow \\
1-> \\
1->\end{array}$ \\
\hline node_16 - - > node_15 & $\begin{array}{l}33 \\
83 \\
93 \\
94 \\
95 \\
106 \\
192 \\
199 \\
201 \\
238 \\
255\end{array}$ & $\begin{array}{l}1 \\
1 \\
1 \\
1 \\
1 \\
1 \\
1 \\
1 \\
1 \\
1 \\
1\end{array}$ & $\begin{array}{l}0.500 \\
0.400 \\
0.500 \\
1.000 \\
1.000 \\
0.286 \\
0.400 \\
0.400 \\
0.667 \\
0.429 \\
0.667\end{array}$ & $\begin{array}{l}2 \Longrightarrow 1 \\
1 \Longrightarrow 1 \\
0 \Longrightarrow 1 \\
0 \Longrightarrow 1 \\
0 \Longrightarrow 1 \\
0-->1 \\
0-->1 \\
2-->0 \\
2-->0 \\
1-->0 \\
0-->1\end{array}$ \\
\hline
\end{tabular}


APPENDIX D

\begin{tabular}{|c|c|c|c|c|c|c|c|c|c|c|c|c|c|}
\hline 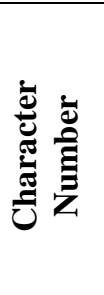 & 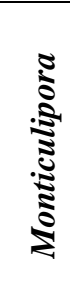 & 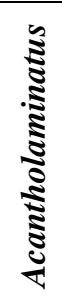 & $\begin{array}{l}\frac{2}{2} \\
\frac{0}{2} \\
\frac{2}{2} \\
\frac{\pi}{2}\end{array}$ & 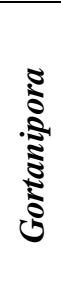 & 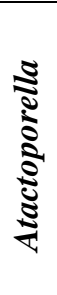 & 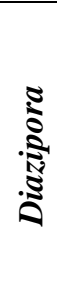 & 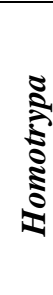 & 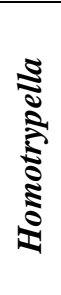 & 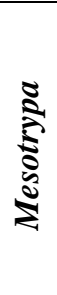 & 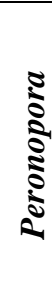 & 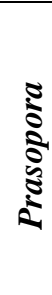 & 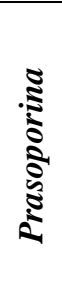 & 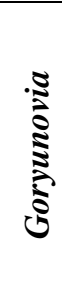 \\
\hline 1 & 2,3 & 1 & 1 & 3 & 2 & 1 & 3 & 3 & 2 & 3 & 2 & 2 & 0 \\
\hline 2 & 2 & 0 & 1 & 1 & 1 & 1 & 1 & 1 & 1 & 1 & 1 & 1 & 0 \\
\hline 3 & 0 & 0 & 1 & 1 & 1 & 1 & 1 & 0 & ? & ? & 1 & 1 & 0 \\
\hline 4 & 0 & 0 & 0 & 0 & 0 & 0 & 0 & 0 & 0 & 0 & 0 & 0 & 0 \\
\hline 5 & 1 & 0 & 0 & 3 & 0 & 0 & 3 & 3 & 1 & 2 & 1 & 0 & 0 \\
\hline 6 & 0 & 0 & 0 & 2 & 0 & 0 & 1 & 1 & 0 & 0 & 0 & 0 & 0 \\
\hline 7 & 0 & 0 & 0 & 1 & 0 & 0 & 1 & 1 & 0 & 0 & 0 & 0 & 0 \\
\hline 8 & 0 & 0 & 0 & 1 & 0 & 0 & 2 & 2 & 0 & 0 & 0 & 0 & 2 \\
\hline 9 & 0 & 0 & 0 & 0 & 0 & 0 & 2 & 2 & 0 & 0 & 0 & 0 & 0 \\
\hline 10 & 0 & 0 & 0 & 0 & 0 & 0 & 2 & 2 & 0 & 0 & 0 & 0 & 0 \\
\hline 11 & 0 & 0 & 0 & 0 & 0 & 0 & 0 & 0 & 0 & 0 & 0 & 0 & 0 \\
\hline 12 & 0 & 0 & 0 & 0 & 0 & 0 & 0 & 0 & 0 & 0 & 0 & 0 & 0 \\
\hline 13 & 2 & 2 & 2 & 2 & 2 & 2 & 2 & 1 & 2 & 2 & 2 & 2 & 2 \\
\hline 14 & 0 & 0 & 0 & 0 & 0 & 0 & 0 & 0 & 0 & 0 & 0 & 0 & 0 \\
\hline 15 & 0 & 0 & 0 & 0 & 0 & 0 & 0 & 0 & 0 & 0 & 0 & 0 & 0 \\
\hline 16 & 0 & 0 & 0 & 0 & 0 & 0 & 0 & 0 & 0 & 0 & 0 & 0 & 0 \\
\hline 17 & 0 & 0 & 0 & 0 & 0 & 0 & 0 & 0 & 0 & 0 & 0 & 0 & 0 \\
\hline 18 & 0 & 0 & 0 & 0 & 0 & 0 & 0 & 0 & 0 & 0 & 0 & 0 & 0 \\
\hline 19 & 0 & 0 & 0 & 0 & 0 & 0 & 0 & 0 & 0 & 0 & 0 & 0 & 0 \\
\hline 20 & 0 & 0 & 0 & 0 & 0 & 0 & 0 & 0 & 0 & 0 & 0 & 0 & 0 \\
\hline 21 & 0 & 0 & 0 & 0 & 0 & 0 & 0 & 0 & 0 & 0 & 0 & 0 & 0 \\
\hline 22 & 1 & 0 & 1 & 2 & 1 & 1 & 2 & 1 & 0 & 3 & 1 & 1 & 1 \\
\hline 23 & 0 & 0 & 0 & 0 & 0 & 0 & 0 & 0 & 0 & 1 & 0 & 0 & 0 \\
\hline 24 & 0 & 0 & 0 & 0 & 0 & 0 & 0 & 0 & 0 & 2 & 0 & 0 & 0 \\
\hline 25 & 0 & 0 & 1 & 0 & 0 & 0 & 0 & 0 & 0 & 0 & 0 & 1 & 0 \\
\hline 26 & 0 & 0 & 0 & 0 & 0 & 0 & 0 & 0 & 0 & 0 & 0 & 0 & 0 \\
\hline 27 & 0 & 0 & 0 & 0 & 0 & 0 & 0 & 0 & 0 & 2 & 0 & 0 & 0 \\
\hline 28 & 0 & 0 & 0 & 0 & 0 & 0 & 0 & 0 & 0 & 1 & 0 & 0 & 0 \\
\hline 29 & 0 & 0 & 0 & 0 & 0 & 0 & 0 & 0 & 0 & 2 & 0 & 0 & 0 \\
\hline 30 & 0 & 0 & 0 & 0 & 0 & 0 & 0 & 0 & 0 & 1 & 0 & 0 & 0 \\
\hline 31 & 0 & 0 & 0 & 0 & 0 & 2 & 0 & 0 & 2 & 0 & 0 & 2 & 0 \\
\hline 32 & 0 & 0 & 0 & 0 & 0 & 1 & 0 & 0 & 1 & 0 & 0 & 1 & 0 \\
\hline 33 & 2? & 1 & 1? & 2? & ? & 1? & $2 ?$ & 2 & ? & 1 & ? & ? & 1 \\
\hline 34 & 3? & 0 & 0 & 1 & ? & 0 & 0 & 0 & 0 & 1 & 0 & 0 & 0 \\
\hline 35 & 0 & 0 & 0 & 0 & 0 & 0 & 0 & 0 & 0 & 0 & 0 & 0 & 0 \\
\hline 36 & 0 & 0 & 0 & 0 & 0 & 0 & 0 & 0 & 1 & 0 & 0 & 0 & 0 \\
\hline
\end{tabular}




\begin{tabular}{|c|c|c|c|c|c|c|c|c|c|c|c|c|c|}
\hline 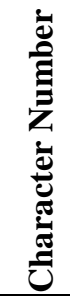 & 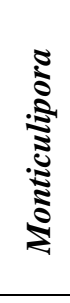 & 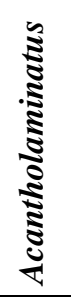 & 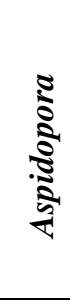 & 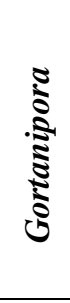 & 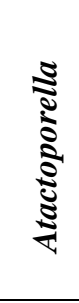 & $\begin{array}{l}0 \\
\overline{0} \\
0\end{array}$ & 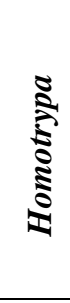 & 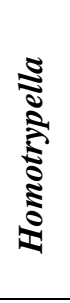 & 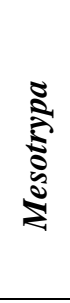 & 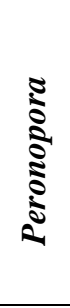 & $\begin{array}{l}0 \\
\vdots \\
\vdots \\
\vdots \\
\vdots \\
0\end{array}$ & 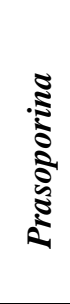 & 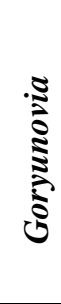 \\
\hline 37 & 3 & 0 & 1? & 1 & ? & 2? & 0 ? & 1 & 1 & 3 & 3 & ? & 3 \\
\hline 38 & 1 & 1 & 0 & 0 & 0 & 1 & 0 & 0 & 0 & 0 & 1 & 0 & 0 \\
\hline 39 & 1 & 0 & 0 & 1 & 1 & 0 & 0 & 1 & 1 & 1 & 0 & 0 & 0 \\
\hline 40 & 1 & 1 & 1 & 1 & 1 & 1 & 1 & 1 & 1 & 1 & 1 & 1 & 0 \\
\hline 41 & 2 & 2 & 2 & 2 & 2 & 3 & 1 & 1 & 1 & 2 & 2 & 3 & 3 \\
\hline 42 & 2 & 3 & 3 & 2 & 3 & 4 & 2 & 2 & 2 & 4 & 3 & 4 & 0 \\
\hline 43 & 0 & 1 & 2 & 1 & 2 & 2 & 0 & 1 & 0 & 2 & 0 & 0 & 0 \\
\hline 44 & 0 & 0 & 1 & 0 & 0 & 0 & 0 & 0 & 0 & 0 & 0 & 0 & 1 \\
\hline 45 & 0 & 0 & 0 & 0 & 0 & 0 & 0 & 0 & 0 & 0 & 0 & 0 & 0 \\
\hline 46 & 1 & 0 & 0 & 0 & 0 & 0 & 0 & 0 & 0 & 0 & 0 & 0 & 0 \\
\hline 47 & 2 & 0 & 0 & 2 & 0 & 0 & 2 & 1 & 1 & 0 & 0 & 0 & 0 \\
\hline 48 & 0 & 0 & 0 & 0 & 2 & 0 & 0 & 0 & 0 & 0 & 0 & 0 & 0 \\
\hline 49 & 0 & 0 & 0 & 0 & 0 & 0 & 0 & 0 & 0 & 0 & 0 & 0 & 0 \\
\hline 50 & 0 & 0 & 0 & 0 & 0 & 0 & 0 & 0 & 0 & 0 & 0 & 0 & 0 \\
\hline 51 & 0 & 0 & 0 & 0 & 0 & 0 & 0 & 0 & 0 & 0 & 0 & 0 & 0 \\
\hline 52 & 0 & 0 & 0 & 0 & 0 & 0 & 0 & 0 & 0 & 0 & 0 & 0 & 0 \\
\hline 53 & 0 & 0 & 0 & 0 & 0 & 0 & 0 & 0 & 0 & 0 & 0 & 0 & 0 \\
\hline 54 & 0 & 0 & 0 & 0 & 0 & 0 & 0 & 0 & 0 & 0 & 0 & 0 & 0 \\
\hline 55 & 0 & 0 & 0 & 0 & 0 & 0 & 2 & 0 & 0 & 1 & 0 & 0 & 0 \\
\hline 56 & 0 & 0 & 0 & 0 & 0 & 0 & 0 & 0 & 0 & 1 & 0 & 0 & 0 \\
\hline 57 & 0 & 0 & 0 & 0 & 0 & 0 & 0 & 0 & 0 & 0 & 0 & 0 & 0 \\
\hline 58 & 1 & 2 & 0 & 1 & 2 & 0 & 2 & 1 & 1 & 3 & 1 & 2 & 3 \\
\hline 59 & 0 & 0 & 0 & 0 & 0 & 0 & 0 & 0 & 0 & 0 & 0 & 0 & 1 \\
\hline 60 & 0 & 0 & 0 & 0 & 0 & 0 & 0 & 0 & 0 & 0 & 0 & 0 & 0 \\
\hline 61 & 0 & 0 & 0 & 0 & 0 & 0 & 0 & 0 & 0 & 1 & 0 & 0 & 0 \\
\hline 62 & 0 & 0 & 0 & 0 & 0 & 0 & 0 & 0 & 0 & 0 & 0 & 0 & 0 \\
\hline 63 & 0 & 0 & 0 & 0 & 0 & 0 & 0 & 0 & 0 & 0 & 0 & 0 & 0 \\
\hline 64 & 0 & 0 & 0 & 0 & 0 & 0 & 0 & 0 & 0 & 0 & 0 & 0 & 0 \\
\hline 65 & 0 & 0 & 0 & 0 & 0 & 0 & 0 & 0 & 0 & 0 & 0 & 0 & 0 \\
\hline 66 & 0 & 0 & 0 & 0 & 0 & 0 & 0 & 0 & 0 & 0 & 0 & 0 & 0 \\
\hline 67 & 1 & 1 & 1 & 1 & 1 & 2 & 0 & 1 & 1 & 1 & 0 & 1 & 0 \\
\hline 68 & 1 & 1 & 0 & 2 & 1 & 1 & 1 & 1 & 0 & 1 & 0 & 0 & 0 \\
\hline 69 & 2 & 1 & 1 & 2 & 1 & 1 & 2 & 2 & 0 & 2 & 0 & 0 & 0 \\
\hline 70 & 1 & 1 & 1 & 2 & 1 & 0 & 1 & 1 & 0 & 1 & 0 & 0 & 2 \\
\hline 71 & 1 & 1 & 1 & 1 & 1 & 0 & 1 & 1 & 0 & 2 & 2 & 0 & 0 \\
\hline 72 & 1 & 1 & 1 & 2 & 2? & 1 & 1 & 1 & 0 & 1 & 0 & 0 & 0 \\
\hline
\end{tabular}




\begin{tabular}{|c|c|c|c|c|c|c|c|c|c|c|c|c|c|}
\hline 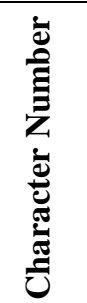 & 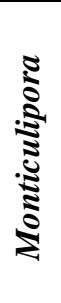 & 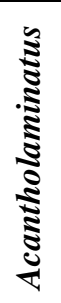 & 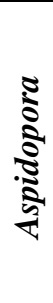 & 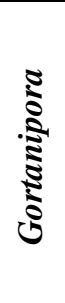 & 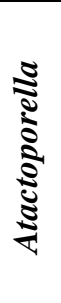 & 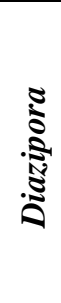 & 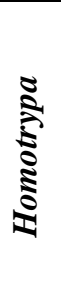 & 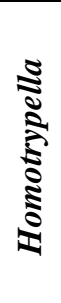 & 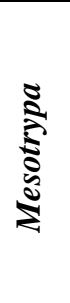 & 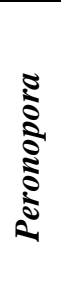 & 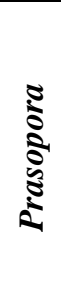 & 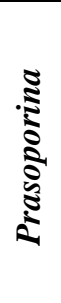 & 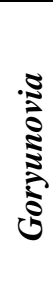 \\
\hline 73 & 1 & 1 & 2 & 1 & 1 & 1 & 1 & 1 & 1 & 1 & 0 & 0 & 0 \\
\hline 74 & 3 & 2 & 1 & 3 & 3 & 1 & 3 & 3 & 3 & 2 & 0 & 0 & 0 \\
\hline 75 & 1 & 2 & 2 & 2 & 1 & 0 & 3 & 2 & 0 & 1 & 0 & 0 & 0 \\
\hline 76 & 1 & 1 & 0 & 1 & 0 & 0 & 0 & 1 & 0 & 1 & 0 & 0 & 0 \\
\hline 77 & 2 & 0 & 1 & 1 & 2 & 0 & 0 & 1 & 0 & 0 & 0 & 0 & 0 \\
\hline 78 & 0 & 0 & 0 & 1 & 0 & 0 & 0 & 0 & 0 & 0 & 0 & 0 & 0 \\
\hline 79 & 2 & 1 & 1 & $2 ?$ & 1 & 0 & 0 & 0 & 0 & 0 & 0 & 0 & 1 \\
\hline 80 & 0 & 0 & 0 & 0 & 0 & 0 & 0 & 0 & 0 & 0 & 0 & 0 & 0 \\
\hline 81 & 0 & 0 & 0 & 1? & 0 & 0 & 0 & 0 & 0 & 1 & 0 & 0 & 0 \\
\hline 82 & 0 & 0 & 0 & 0 & 0 & 0 & 0 & 0 & 0 & 0 & 0 & 0 & 0 \\
\hline 83 & 0 & 0 & 2 & 1 & 2 & 0 & 0 & 0 & 1 & 0 & 0 & 0 & 0 \\
\hline 84 & 0 & 0 & 0 & ? & 0 & 0 & 0 & 0 & 0 & 0 & 0 & 0 & 0 \\
\hline 85 & 0 & 0 & 0 & 1 & 0 & 0 & 0 & 0 & 0 & 0 & 0 & 0 & 0 \\
\hline 86 & 0 & 0 & 0 & 1 & 0 & 0 & 0 & 0 & 0 & 0 & 0 & 0 & 0 \\
\hline 87 & 0 & 0 & 0 & 4 & 0 & 0 & 0 & 0 & 0 & 0 & 0 & 0 & 0 \\
\hline 88 & 0 & 0 & 0 & 1 & 0 & 0 & 0 & 0 & 0 & 0 & 0 & 0 & 0 \\
\hline 89 & 0 & 0 & 0 & 1 & 0 & 0 & 0 & 0 & 0 & 0 & 0 & 0 & 0 \\
\hline 90 & 0 & 0 & 0 & 1 & 0 & 0 & 0 & 0 & 0 & 0 & 0 & 0 & 0 \\
\hline 91 & 0 & 0 & 0 & ? & 0 & 0 & 0 & 0 & 0 & 0 & 0 & 0 & 0 \\
\hline 92 & 0 & 0 & 0 & 0 & 0 & 0 & 2 & 0 & 0 & 0 & 0 & 0 & 0 \\
\hline 93 & 1 & 0 & 1 & 0 & 0 & 0 & 0 & 0 & 0 & 1 & 0 & 0 & 0 \\
\hline 94 & 0 & 0 & 1 & 0 & 0 & 0 & 0 & 0 & 0 & 1 & 0 & 0 & 0 \\
\hline 95 & 0 & 0 & 1 & 0 & 0 & 0 & 0 & 0 & 0 & 1 & 0 & 0 & 0 \\
\hline 96 & 0 & 1 & 0 & 0 & 0 & 0 & 0 & 0 & 0 & 1 & 0 & 0 & 0 \\
\hline 97 & 0 & 1 & 1 & 0 & 0 & 0 & 0 & 0 & 0 & 2 & 0 & 0 & 0 \\
\hline 98 & 0 & 1 & 1 & 0 & 0 & 0 & 0 & 0 & 0 & 1 & 0 & 0 & 0 \\
\hline 99 & 0 & 0 & 0 & 0 & 0 & 1 & 0 & 2 & 0 & 0 & 0 & 0 & 2 \\
\hline 100 & 0 & 0 & 0 & 1 & 0 & 1 & 1 & 1 & 0 & 1 & 0 & 0 & 1 \\
\hline 101 & 0 & 0 & 0 & 0 & 0 & 0 & 1 & 0 & 0 & 0 & 0 & 0 & 0 \\
\hline 102 & 2 & 2 & 1 & 2 & 2 & 2 & 0 & 1 & 0 & 0 & 0 & 0 & 2 \\
\hline 103 & 0 & 0 & 0 & 1 & 0 & 0 & 1 & 1 & 1 & 0 & 0 & 0 & 0 \\
\hline 104 & 0 & 0 & 0 & 0 & 0 & 0 & 0 & 0 & 0 & 0 & 0 & 0 & 0 \\
\hline 105 & 1 & 1 & 0 & 2 & 0 & 0 & 0 & 2 & 1 & 0 & 1 & 0 & 1 \\
\hline 106 & 2 & 2 & 1 & 1 & 0 & 0 & 0 & 2 & 0 & 1 & 0 & 0 & 0 \\
\hline 107 & 0 & 0 & 0 & 1 & 0 & 0 & 0 & 0 & 0 & 0 & 0 & 0 & 0 \\
\hline 108 & 0 & 0 & 0 & 1 & 0 & 0 & 0 & 1 & 0 & 0 & 0 & 0 & 0 \\
\hline
\end{tabular}




\begin{tabular}{|c|c|c|c|c|c|c|c|c|c|c|c|c|c|}
\hline 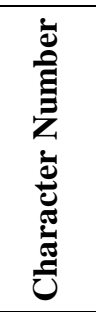 & 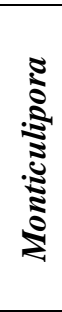 & 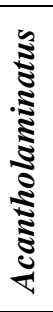 & 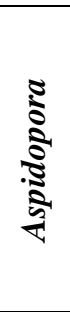 & ڤัँ & 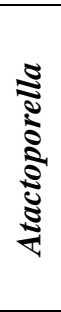 & 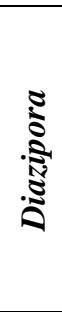 & 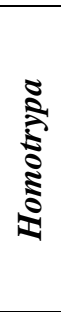 & 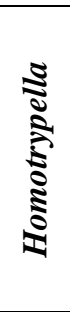 & 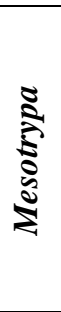 & 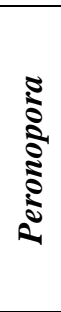 & 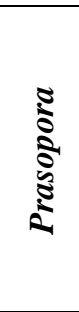 & 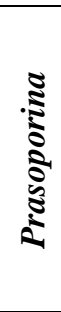 & 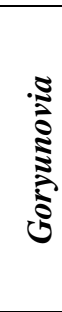 \\
\hline 109 & 2 & 1 & 2 & 1 & 2 & 2 & 0 & 2 & 2 & 2 & 2 & 2 & 0 \\
\hline 110 & 1 & 1 & 1 & 1 & 2 & 2 & 0 & 1 & 1 & 2 & 1 & 1 & 0 \\
\hline 111 & 1 & 1 & 2 & 1 & 3 & 2 & 0 & 1 & 2 & 2 & 2 & 2 & 0 \\
\hline 112 & 1 & 1 & 1 & 1 & 0 & 2 & 0 & 2 & 2 & 3 & 2 & 2 & 0 \\
\hline 113 & 1 & 1 & 1 & 1 & 2 & 2 & 0 & 1 & 1 & 1 & $1 / 2$ & 1 & 0 \\
\hline 114 & 1 & 1 & 2 & 1 & 3 & 3 & 0 & 1 & 1 & 1 & 2 & 2 & 0 \\
\hline 115 & 2 & ? & 1 & ? & 0 & 1 & 0 & 1 & 1 & 1 & 1 & 0 & 0 \\
\hline 116 & 3 & 1 & 3 & 2 & 1 & 0 & 0 & 1 & 0 & 1 & 0 & 0 & 0 \\
\hline 117 & 2 & 1 & 2 & 2 & 1 & 1 & 0 & 1 & 1 & 2 & 2 & 2 & 0 \\
\hline 118 & 1 & 1 & 2 & 1 & 1 & 1 & 0 & 1 & 1 & 1 & 1 & 1 & 0 \\
\hline 119 & 1 & 1 & 1 & 1 & 1 & 1 & 0 & 1 & 1 & 1 & 1 & 1 & 0 \\
\hline 120 & 1 & 1 & 1 & 1 & 1 & 1 & 0 & 1 & 1 & 3 & 1 & 1 & 0 \\
\hline 121 & 2 & 2 & 2 & 2 & 2 & 0 & 0 & 1 & 2 & 2 & 2 & 0 & 0 \\
\hline 122 & 2 & 1 & 1 & 3 & 1 & 0 & 0 & 2 & 2 & 2 & 3 & 0 & 0 \\
\hline 123 & 1 & 1 & 1 & 1 & 1 & 0 & 0 & 1 & 1 & 1 & 1 & 0 & 0 \\
\hline 124 & 1 & 1 & 1 & 1 & 1 & 0 & 0 & 1 & 1 & 1 & 1 & 1 & 0 \\
\hline 125 & 0 & 0 & 0 & 0 & 0 & 0 & 0 & 0 & 0 & 0 & 0 & 0 & 0 \\
\hline 126 & 0 & 0 & 0 & 0 & 0 & 0 & 0 & 0 & 0 & 0 & 0 & 0 & 0 \\
\hline 127 & 0 & 0 & 0 & 0 & 0 & 0 & 0 & 0 & 0 & 0 & 0 & 0 & 0 \\
\hline 128 & 0 & 0 & 0 & 0 & 0 & 0 & 0 & 0 & 0 & 0 & 0 & 0 & 0 \\
\hline 129 & 0 & 0 & 0 & 0 & 0 & 0 & 0 & 0 & 0 & 0 & 0 & 0 & 0 \\
\hline 130 & 0 & 0 & 0 & 0 & 0 & 0 & 0 & 0 & 0 & 0 & 0 & 0 & 0 \\
\hline 131 & 0 & 0 & 0 & 0 & 0 & 0 & 0 & 0 & 0 & 0 & 0 & 0 & 0 \\
\hline 132 & 0 & 0 & 0 & 0 & 0 & 0 & 0 & 0 & 0 & 0 & 0 & 0 & 0 \\
\hline 133 & 2 & 2 & 2 & 2 & 2 & 0 & 0 & 0 & 0 & 1 & 1 & 0 & 0 \\
\hline 134 & 1 & 1 & 1 & 1 & 1 & 0 & 0 & 0 & 0 & 1 & 1 & 0 & 0 \\
\hline 135 & 0 & 0 & 0 & 0 & 0 & 0 & 0 & 0 & 0 & 0 & 0 & 0 & 0 \\
\hline 136 & 0 & 0 & 0 & 0 & 0 & 0 & 0 & 0 & 0 & 0 & 0 & 0 & 0 \\
\hline 137 & 0 & 0 & 0 & 0 & 0 & 0 & 0 & 0 & 0 & 0 & 0 & 0 & 0 \\
\hline 138 & 0 & 0 & 0 & 0 & 0 & 0 & 0 & 0 & 0 & 0 & 0 & 0 & 0 \\
\hline 139 & 0 & 0 & 0 & 0 & 0 & 0 & 0 & 0 & 0 & 0 & 0 & 0 & 0 \\
\hline 140 & 0 & 0 & 0 & 0 & 0 & 0 & 0 & 0 & 0 & 0 & 0 & 0 & 0 \\
\hline 141 & 0 & 0 & 0 & 0 & 0 & 0 & 0 & 0 & 0 & 0 & 0 & 0 & 0 \\
\hline 142 & 0 & 0 & 0 & 0 & 0 & 0 & 0 & 0 & 0 & 0 & 0 & 0 & 0 \\
\hline 143 & 1 & 1 & 1 & 1 & 1 & 0 & 0 & 0 & 0 & 0 & 0 & 0 & 0 \\
\hline 144 & 0 & 0 & 0 & 0 & 0 & 0 & 0 & 0 & 0 & 0 & 0 & 0 & 0 \\
\hline
\end{tabular}




\begin{tabular}{|c|c|c|c|c|c|c|c|c|c|c|c|c|c|}
\hline 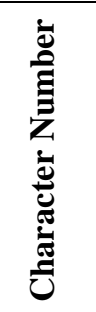 & 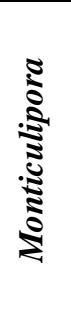 & 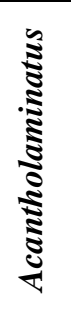 & $\begin{array}{l}\frac{0}{0} \\
\frac{0}{2} \\
\frac{0}{2} \\
\frac{0}{2}\end{array}$ & 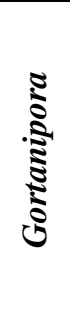 & 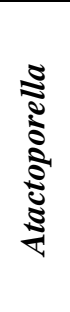 & 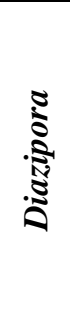 & 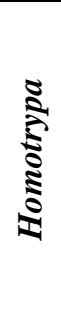 & 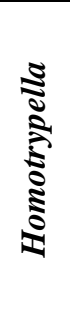 & 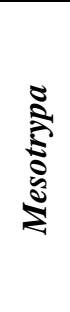 & 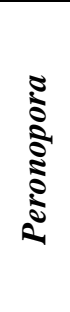 & 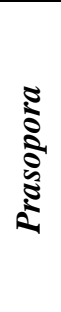 & 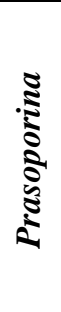 & 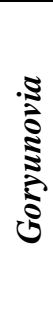 \\
\hline 145 & 0 & 0 & 1 & 0 & 0 & 0 & 0 & 0 & 0 & 1 & 0 & 0 & 0 \\
\hline 146 & 1 & 1 & 1 & 2 & 0 & 0 & 1 & 0 & 0 & 0 & 1 & 0 & 0 \\
\hline 147 & 1 & 1 & ? & ? & 0 & 0 & 0 & 0 & 0 & 0 & 1 & 0 & 0 \\
\hline 148 & 3 & 3 & 3 & 3 & 0 & 0 & 1 & 0 & 0 & 0 & 2 & 0 & 0 \\
\hline 149 & 0 & 0 & 0 & 0 & 0 & 0 & 0 & 0 & 0 & 0 & 0 & 0 & 0 \\
\hline 150 & 3 & 1 & 1 & 2 & 2 & 0 & 1 & 0 & 0 & 1 & 1 & 1 & 0 \\
\hline 151 & 1 & 0 & 0 & 0 & 1 & 0 & 0 & 0 & 0 & 0 & 0 & 0 & 0 \\
\hline 152 & 1 & 0 & 1 & 1 & 0 & 0 & 0 & 0 & 0 & 1 & 0 & 0 & 0 \\
\hline 153 & 1 & 0 & 1 & 2 & 1 & 0 & 0 & 0 & 0 & 2 & 0 & 0 & 0 \\
\hline 154 & 2 & ? & ? & 2 & 1 & 0 & 2 & 0 & 0 & 2 & 2 & 2 & 0 \\
\hline 155 & 1 & ? & 1 & 1 & 2 & 0 & 0 & 0 & 0 & 2 & 1 & 1 & 0 \\
\hline 156 & 2 & ? & ? & 2 & 1 & 0 & 1 & 0 & 0 & 0 & 1 & 0 & 0 \\
\hline 157 & 2 & 3 & 2 & 2 & 0 & 0 & 2 & 0 & 0 & 2 & 0 & 0 & 0 \\
\hline 158 & 1 & 2 & 2 & 1 & 0 & 0 & 2 & 0 & 0 & 2 & 0 & 0 & 0 \\
\hline 159 & 1 & 0 & 0 & 1 & 0 & 0 & 0 & 0 & 0 & 1 & 0 & 1 & 0 \\
\hline 160 & 0 & 0 & 0 & 0 & 0 & 0 & 0 & 0 & 0 & 0 & 0 & 0 & 0 \\
\hline 161 & 1 & 1 & 0 & 2 & 0 & 0 & 1 & 1 & 0 & 1 & 1 & 1 & 0 \\
\hline 162 & 1 & 0 & 0 & 3 & 0 & 0 & 0 & 2 & 0 & 2,3 & 0 & 1 & 0 \\
\hline 163 & 1 & 0 & 0 & 2 & 0 & 0 & 0 & 1 & 2 & 1 & 0 & 1 & 0 \\
\hline 164 & 0 & 0 & 0 & 1 & 0 & 0 & 0 & 1 & 0 & 2 & 0 & 0 & 0 \\
\hline 165 & 1 & 1 & 1 & 2 & 1 & 0 & 0 & 1 & 1 & 1 & 1 & 0 & 1 \\
\hline 166 & 0 & 0 & 0 & 0 & 0 & 0 & 0 & 0 & 0 & 0 & 0 & 0 & 0 \\
\hline 167 & 1 & 1 & 1 & 1 & 0 & 0 & 0 & 1 & 1 & 0 & 1 & 1 & 1 \\
\hline 168 & 0 & 0 & 0 & 0 & 0 & 0 & 0 & 0 & 0 & 0 & 0 & 0 & 0 \\
\hline 169 & 0 & 0 & 0 & 0 & 0 & 0 & 0 & 0 & 0 & 0 & 0 & 0 & 0 \\
\hline 170 & 0 & 0 & 0 & 0 & 0 & 0 & 0 & 0 & 0 & 0 & 0 & 0 & 0 \\
\hline 171 & 0 & 0 & 0 & 0 & 0 & 0 & 0 & 0 & 0 & 0 & 0 & 0 & 0 \\
\hline 172 & 0 & 0 & 0 & 0 & 0 & 0 & 0 & 0 & 0 & 0 & 0 & 0 & 0 \\
\hline 173 & 0 & 0 & 0 & 0 & 0 & 0 & 0 & 0 & 0 & 0 & 0 & 0 & 0 \\
\hline 174 & 0 & 0 & 0 & 0 & 0 & 0 & 0 & 0 & 0 & 0 & 0 & 0 & 0 \\
\hline 175 & 0 & 0 & 0 & 0 & 0 & 0 & 0 & 0 & 0 & 0 & 0 & 0 & 0 \\
\hline 176 & 0 & 0 & 0 & 0 & 0 & 0 & 0 & 0 & 0 & 0 & 0 & 0 & 0 \\
\hline 177 & 0 & 0 & 0 & 0 & 0 & 0 & 0 & 0 & 0 & 0 & 0 & 0 & 0 \\
\hline 178 & 0 & 0 & 0 & 0 & 0 & 0 & 0 & 0 & 0 & 0 & 0 & 0 & 0 \\
\hline 179 & 0 & 0 & 0 & 0 & 0 & 0 & 0 & 0 & 0 & 0 & 0 & 0 & 0 \\
\hline 180 & 0 & 0 & 0 & 0 & 0 & 0 & 0 & 0 & 0 & 0 & 0 & 0 & 0 \\
\hline
\end{tabular}




\begin{tabular}{|c|c|c|c|c|c|c|c|c|c|c|c|c|c|}
\hline 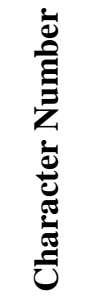 & 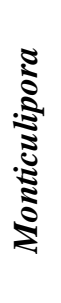 & 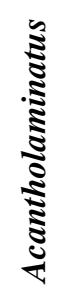 & $\begin{array}{l}\frac{0}{0} \\
\frac{0}{2} \\
\frac{0}{2} \\
\frac{5}{2}\end{array}$ & 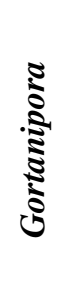 & 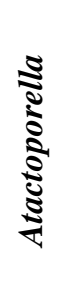 & 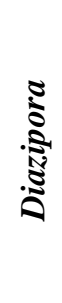 & 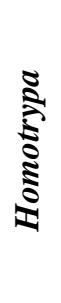 & 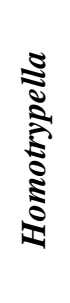 & 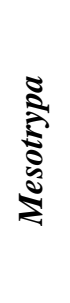 & 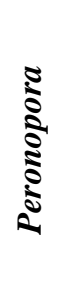 & 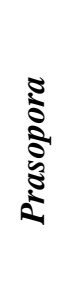 & 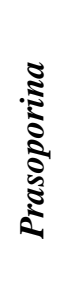 & 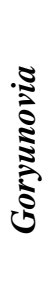 \\
\hline 181 & 0 & 0 & 0 & 0 & 0 & 0 & 0 & 0 & 0 & 0 & 0 & 0 & 0 \\
\hline 182 & 0 & 0 & 0 & 0 & 0 & 0 & 0 & 0 & 0 & 0 & 0 & 0 & 0 \\
\hline 183 & 1 & 2 & 2 & 2 & 2 & 0 & 1 & 2 & 1 & 1 & 1 & 0 & 0 \\
\hline 184 & 1 & 1 & 1 & 1 & 0 & 0 & 1 & 1 & 2 & 1 & 1 & 0 & 0 \\
\hline 185 & 1 & 2 & 2 & 1 & 0 & 0 & 2 & 2 & 2 & 2 & 1 & 0 & 0 \\
\hline 186 & 0 & 0 & 0 & 0 & 0 & 0 & 0 & 1 & 1 & 0 & 0 & 0 & 0 \\
\hline 187 & 1 & 1 & 1 & 1 & 0 & 0 & 0 & 1 & 1 & 0 & 1 & 0 & 0 \\
\hline 188 & 2 & 2 & 2 & 2 & 0 & 0 & 2 & 2 & 2 & 2 & 2 & 0 & 0 \\
\hline 189 & 2 & 2 & 2 & 2 & 0 & 0 & 1 & 3 & 0 & 2 & 1 & 0 & 0 \\
\hline 190 & 1 & 1 & 1 & 1 & 0 & 0 & 0 & 1 & 2 & 1 & 0 & 0 & 0 \\
\hline 191 & 0 & 2 & 1 & 0 & 3 & 0 & 0 & 2 & 1 & 2 & 0 & 0 & 0 \\
\hline 192 & 1 & 2 & 1 & 1 & 0 & 0 & 0 & 0 & 0 & 1 & 0 & 0 & 0 \\
\hline 193 & 2 & 3 & 2 & 2 & 3 & 0 & 1 & 3 & 2 & 2 & 1 & 0 & 0 \\
\hline 194 & 1 & 3 & 1 & 1 & 2 & 0 & 1 & 3 & 1 & 1 & 1 & 0 & 0 \\
\hline 195 & 1 & 1 & 1 & 1 & 0 & 0 & 0 & 1 & 1 & 1 & 1 & 0 & 0 \\
\hline 196 & 2 & 2 & 1 & 0 & 2 & 0 & 2 & 1 & 0 & 2 & 2 & 1 & 0 \\
\hline 197 & 2 & 2 & 1 & 0 & 2 & 0 & 0 & 2 & 0 & 1 & 0 & 0 & 0 \\
\hline 198 & 2 & 1 & 0 & 1 & 1 & 0 & 0 & 1 & 0 & 1 & 0 & 0 & 1 \\
\hline 199 & 2 & 2 & 0 & 0 & 2 & 0 & 2 & 2 & 0 & 2 & 0 & 0 & 0 \\
\hline 200 & 1 & 1 & 1 & 0 & 1 & 0 & 1 & 1 & 0 & 1 & 1 & 1 & 0 \\
\hline 201 & 2 & 2 & 0 & 2 & 2 & 2 & 2 & 2 & 2 & 2 & 2 & 0 & 2 \\
\hline 202 & 0 & 1 & 0 & 1 & 0 & 2 & 0 & 1 & 2 & 1 & 0 & 0 & 1 \\
\hline 203 & 0 & 0 & 0 & 2 & 0 & 0 & 0 & 0 & 2 & 0 & 0 & 0 & 1 \\
\hline 204 & 0 & 1 & 0 & 0 & 0 & 0 & 0 & 0 & 0 & 1 & 0 & 1 & 0 \\
\hline 205 & 1 & 1 & 1 & 1 & 1 & 0 & 1 & 1 & 2 & 1 & 1 & 1 & 1 \\
\hline 206 & 0 & 0 & 0 & 0 & 0 & 0 & 0 & 0 & 2 & 0 & 0 & 0 & 0 \\
\hline 207 & 0 & 0 & 0 & 0 & 0 & 0 & 0 & 0 & 1 & 0 & 0 & 0 & 0 \\
\hline 208 & 0 & 0 & 0 & 0 & 0 & 0 & 0 & 0 & 0 & 0 & 0 & 0 & 0 \\
\hline 209 & 2 & 2 & 2 & 2 & 2 & 0 & 2 & 2 & 0 & 2 & 2 & 2 & 0 \\
\hline 210 & 0 & 0 & 0 & 0 & 0 & 0 & 0 & 0 & 0 & 0 & 0 & 1 & 0 \\
\hline 211 & 1 & 1 & 1 & 2 & 1 & 0 & 2 & 1 & 0 & 1 & 1 & 1 & 0 \\
\hline 212 & 2 & 2 & 2 & 1 & 2 & 0 & 2 & 2 & 0 & 2 & 2 & 1 & 0 \\
\hline 213 & 2 & 2 & 2 & 2 & 2 & 0 & 2 & 2 & 0 & 2 & 2 & 2 & 0 \\
\hline 214 & 2 & 2 & 1 & 1 & 2 & 0 & 1 & 1 & 0 & 1 & 2 & 3 & 0 \\
\hline 215 & 1 & 1 & 1 & 1 & 1 & 0 & 1 & 1 & 0 & 1 & 1 & 1 & 0 \\
\hline 216 & 3 & 0 & 0 & 3 & 0 & 0 & 0 & 0 & 0 & 1 & 3 & 3 & 0 \\
\hline
\end{tabular}




\begin{tabular}{|c|c|c|c|c|c|c|c|c|c|c|c|c|c|}
\hline 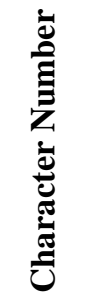 & 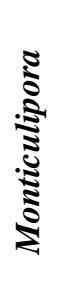 & 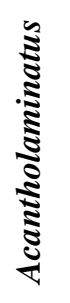 & 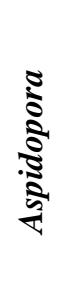 & 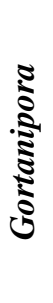 & 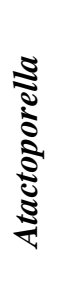 & 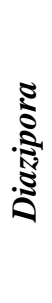 & 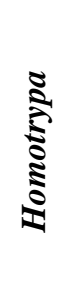 & 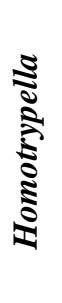 & 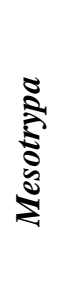 & 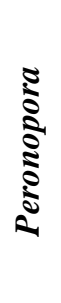 & 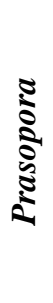 & 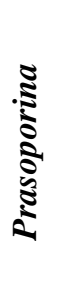 & 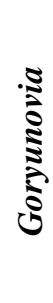 \\
\hline 217 & 1 & 0 & 0 & 2 & 0 & 0 & 0 & 0 & 0 & 1 & 2 & 2 & 0 \\
\hline 218 & 2 & 2 & 1 & 1 & 1 & 0 & 2 & 1 & 0 & 2 & 1 & 1 & 0 \\
\hline 219 & 1 & 1 & 1 & 1 & 0 & 0 & 0 & 1 & 0 & 1 & 1 & 1 & 0 \\
\hline 220 & 3 & 2 & 2 & 3 & 2 & 0 & 2 & 2 & 0 & 3 & 3 & 2 & 0 \\
\hline 221 & 2 & 1 & 1 & 1 & 2 & 0 & 1 & 2 & 0 & 2 & 1 & 1 & 0 \\
\hline 222 & 0 & 0 & 0 & 0 & 0 & 0 & 0 & 0 & 0 & 0 & 0 & 0 & 0 \\
\hline 223 & 0 & 0 & 0 & 0 & 0 & 0 & 0 & 0 & 0 & 0 & 0 & 0 & 3 \\
\hline 224 & 0 & 0 & 0 & 0 & 0 & 0 & 0 & 0 & 0 & 0 & 0 & 0 & 2 \\
\hline 225 & 0 & 0 & 0 & 0 & 0 & 0 & 0 & 0 & 0 & 0 & 0 & 0 & 2 \\
\hline 226 & 0 & 0 & 0 & 0 & 0 & 0 & 0 & 0 & 0 & 0 & 0 & 0 & 2 \\
\hline 227 & 0 & 0 & 0 & 0 & 0 & 0 & 0 & 0 & 0 & 0 & 0 & 0 & 1 \\
\hline 228 & 0 & 0 & 0 & 0 & 0 & 0 & 0 & 0 & 0 & 0 & 0 & 0 & 1 \\
\hline 229 & 0 & 0 & 0 & 0 & 0 & 0 & 0 & 0 & 0 & 0 & 0 & 0 & 0 \\
\hline 230 & 0 & 0 & 0 & 0 & 0 & 0 & 0 & 0 & 0 & 0 & 0 & 0 & 0 \\
\hline 231 & 0 & 0 & 0 & 0 & 0 & 0 & 0 & 0 & 0 & 0 & 0 & 0 & 0 \\
\hline 232 & 0 & 0 & 0 & 0 & 0 & 0 & 0 & 0 & 0 & 0 & 0 & 0 & 0 \\
\hline 233 & 0 & 0 & 0 & 0 & 0 & 0 & 0 & 0 & 0 & 0 & 0 & 0 & 1 \\
\hline 234 & 0 & 0 & 0 & 0 & 0 & 0 & 0 & 0 & 0 & 0 & 0 & 0 & 0 \\
\hline 235 & 0 & 0 & 0 & 0 & 0 & 0 & 0 & 0 & 0 & 0 & 0 & 0 & 2 \\
\hline 236 & 0 & 0 & 0 & 0 & 0 & 0 & 0 & 0 & 0 & 0 & 0 & 0 & 0 \\
\hline 237 & 0 & 0 & 0 & 0 & 0 & 0 & 0 & 0 & 0 & 0 & 1 & 0 & 0 \\
\hline 238 & 2 & 2 & 1 & 1 & 1 & 1 & 0 & 1 & 2 & 3 & 2 & 0 & 0 \\
\hline 239 & 0 & 0 & 0 & 0 & 0 & 0 & 0 & 0 & 0 & 0 & 0 & 0 & 0 \\
\hline 240 & 0 & 0 & 0 & 0 & 0 & 0 & 0 & 0 & 0 & 0 & 0 & 0 & 0 \\
\hline 241 & 0 & 0 & 0 & 0 & 0 & 0 & 0 & 0 & 0 & 0 & 0 & 0 & 0 \\
\hline 242 & 0 & 0 & 0 & 0 & 0 & 0 & 0 & 0 & 0 & 0 & 0 & 0 & 0 \\
\hline 243 & 0 & 0 & 0 & 0 & 0 & 0 & 0 & 0 & 0 & 0 & 0 & 0 & 0 \\
\hline 244 & 0 & 0 & 0 & 0 & 0 & 0 & 0 & 0 & 0 & 0 & 0 & 0 & 0 \\
\hline 245 & 0 & 0 & 0 & 0 & 0 & 0 & 0 & 0 & 0 & 0 & 0 & 0 & 0 \\
\hline 246 & 0 & 0 & 0 & 0 & 0 & 0 & 0 & 0 & 0 & 0 & 0 & 0 & 0 \\
\hline 247 & 0 & 0 & 0 & 0 & 0 & 0 & 0 & 0 & 0 & 0 & 0 & 0 & 0 \\
\hline 248 & 0 & 0 & 0 & 0 & 0 & 0 & 0 & 0 & 0 & 0 & 0 & 0 & 0 \\
\hline 249 & 0 & 0 & 0 & 0 & 0 & 0 & 0 & 0 & 0 & 0 & 0 & 0 & 0 \\
\hline 250 & 0 & 0 & 0 & 0 & 0 & 0 & 0 & 0 & 0 & 0 & 0 & 0 & 0 \\
\hline 251 & 0 & 0 & 0 & 0 & 0 & 0 & 0 & 0 & 0 & 0 & 0 & 0 & 0 \\
\hline 252 & 0 & 0 & 0 & 0 & 0 & 0 & 0 & 0 & 0 & 0 & 0 & 0 & 0 \\
\hline
\end{tabular}




\begin{tabular}{|c|c|c|c|c|c|c|c|c|c|c|c|c|c|}
\hline 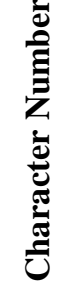 & 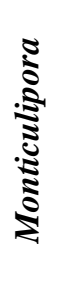 & 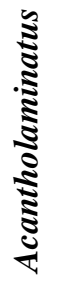 & 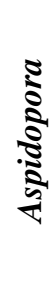 & 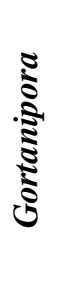 & 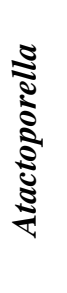 & 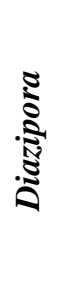 & 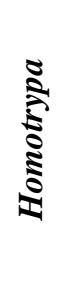 & 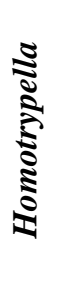 & 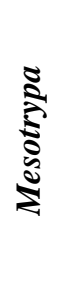 & 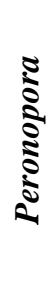 & 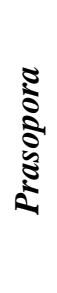 & 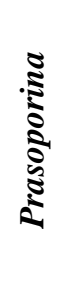 & 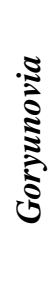 \\
\hline 253 & 0 & 0 & 0 & 0 & 0 & 0 & 0 & 0 & 0 & 0 & 0 & 0 & 0 \\
\hline 254 & 0 & 0 & 0 & 0 & 0 & 0 & 0 & 0 & 0 & 0 & 0 & 0 & 0 \\
\hline 255 & 1 & 0 & 1 & 0 & 0 & 0 & 0 & 1 & 0 & 1 & 1 & 0 & 0 \\
\hline 256 & 0 & 0 & 0 & 0 & 0 & 0 & 0 & 0 & 0 & 2 & 0 & 0 & 0 \\
\hline 257 & 0 & 0 & 0 & 0 & 0 & 0 & 0 & 0 & 1 & 0 & 0 & 0 & 0 \\
\hline 258 & 0 & 0 & 0 & 0 & 0 & 0 & 0 & 0 & 0 & 1 & 0 & 0 & 0 \\
\hline 259 & 0 & 0 & 0 & 0 & 0 & 0 & 0 & 0 & 0 & 1 & 0 & 0 & 0 \\
\hline 260 & 1 & 1 & 0 & 1 & 1 & 0 & 1 & 1 & 1 & 1 & 1 & 0 & 0 \\
\hline 261 & 0 & 0 & 0 & 0 & 0 & 0 & 0 & 0 & 0 & 0 & 0 & 0 & 0 \\
\hline 262 & 0 & 0 & 0 & 0 & 0 & 0 & 0 & 0 & 0 & 0 & 0 & 0 & 0 \\
\hline 263 & 0 & 0 & 0 & 0 & 0 & 0 & 0 & 0 & 0 & 1 & 0 & 0 & 0 \\
\hline 264 & 0 & 0 & 0 & 0 & 0 & 0 & 0 & 0 & 0 & 0 & 0 & 0 & 0 \\
\hline 265 & 0 & 0 & 0 & 0 & 0 & 0 & 0 & 0 & 0 & 0 & 0 & 0 & 0 \\
\hline 266 & 0 & 0 & 0 & 0 & 0 & 0 & 0 & 0 & 0 & 0 & 0 & 0 & 0 \\
\hline 267 & 0 & 0 & 0 & 0 & 0 & 0 & 0 & 0 & 0 & 0 & 0 & 0 & 0 \\
\hline
\end{tabular}




\section{REFERENCES}

Anstey, R. L. 1978. Taxonomic survivorship and morphologic complexity in Paleozoic bryozoan genera. Paleobiology, 4:407-418.

Anstey, R. L. 1981. Zooid orientation structures and water flow patterns in Paleozoic bryozoan colonies. Lethaia, 14:287-302.

Anstey, R. L. 1986. Colony patterning and functional morphology of water flow in Paleozoic stenolaemate bryozoans, p. 1-8. In J. R. P. Ross (ed.), Bryozoa: Present and Past. Western Washington University, Bellingham, 333p.

Anstey, R. L. 1987. Astogeny and Phylogeny: Evolutionary Heterochrony in Paleozoic Bryozoans. Paleobiology, 13:20-43.

Anstey, R. L. 1990. Bryozoans, p.232-252. In Evolutionary Trends. K. MacNamara: 232252.

Anstey, R. L. and J. F. Pachut. 1995. Phylogeny, Diversity History, and Speciation in Paleozoic Bryozoans, p. 239-284. In D. Erwin and R. L. Anstey (ed.), New Approaches to Speciation in the Fossil Record. Columbia University Press, New York.

Anstey, R. L. and J. F. Pachut. 2004. Cladistic and Phenetic Recognition of Species in the Ordovician Bryozoan Genus Peronopora. Journal of Paleontology, 78:651-674.

Anstey, R. L. and T. G. Perry. 1970. Biometric Procedures in Taxonomic Studies of Paleozoic Bryozoans. Journal of Paleontology, 44:383-398.

Anstey, R. L. and T. G. Perry. 1973. Eden Shale bryozoans: a numerical study (Ordovician, Ohio Valley). Publications of the Museum, Michigan State University, Paleontological Series 1:1-80.

Astrova, G. G. 1965. Morphologiya, istoriya razvitiya i sistema ordoviksikh i siluriyskikh mshanok. (Morphology, history of development, and systematics of Ordovician and Silurian Bryozoa.) Akademiya Nauk S.S.S.R., Trudy Paleontologischeskogo Instituta, 106: 1-432.

Astrova, G. G. 1978. Istoriya razvitiya, sistema i filogeniya mshanok. (Historical development, systematics and phylogeny of Bryozoa. Order Trepostomata.) Akademiya Nauk S.S.S.R., Trudy Paleontologischeskogo Instituta, 169:1-240.

Banta, W. C. and F. K. McKinney, et al. 1974. Bryozoan Monticules: Excurrent Water Outlets? Science, 185(4153):783-784. 
Bassler, R. S. 1911. The Early Paleozoic Bryozoa of the Baltic Provinces. US National Museum Bulletin 77. 382p.

Blake, D. and E. Snyder. 1987. Phenetic and cladistic analyses of the Rhabdomesina (Bryozoa) and similar taxa: a preliminary study. In J. Ross (ed.), Bryozoa: Past and Present. Western Washington University, Bellingham, p.33-40.

Boardman, R. S. 1983. General Features of the Class Stenolaemata, p.49-137. In R. S. Boardman et al. (eds.), Treatise on Invertebrate Paleontology, Part G, Bryozoa. Revised. Geological Society of America and the University of Kansas Press, Lawrence, 625p.

Boardman, R. S. and J. Utgaard. 1966. A Revision of the Ordovician Bryozoan Genera Monticulipora, Peronopora, Heterotrypa, and Dekayia. Journal of Paleontology, 40(5): 1082-1108.

Bock, Phil. 2010. Systematic List of Families of Bryozoa. www.bryozoa.net/famsys.html

Bork, K. B. and T. G. Perry. 1967. Bryozoa (Ectoprocta) of Champlainian Age (Middle Ordovician) from Northwestern Illinois and Adjacent Parts of Iowa and Wisconsin, Part I, Amplexopora, Monotrypella, Hallopora, and Batostoma. Journal of Paleontology, 41(6):1365-1392.

Bork, K. B. and T. G. Perry. 1968. Bryozoa (Ectoprocta) of Champlainian Age (Middle Ordovician) from Northwestern Illinois and Adjacent Parts of Iowa and Wisconsin, Part II, Bythotrypa, Diplotrypa, Hemiphragma, Heterotrypa, Stigmatella, Eridotrypa, and Nicholsonella. Journal of Paleontology, 42(2):337355.

Brown, G. D. and E. J. Daly. 1985. Trepostome Bryozoan Fauna from the Dillsboro Formation (Cincinnatian Series) of Southeastern Indiana. Indiana Department of Natural Resources, Geological Survey Special Report, 33:1-95.

Corneliussen, E.F. and T. G. Perry. 1973. Monotrypa, Hallopora, Amplexopora, and Hennigopora (Ectoprocta) from the Brownsport Formation (Niagaran), Western Tennessee. Journal of Paleontology, 47(2):151-220.

Cuffey, R. and D. Blake. 1991. Cladistic analysis of the Phylum Bryozoa, p. 97-108. In P. Bigey (ed.), Bryozoa living and fossil. Bull. Soc. Sci. Nat. Ouest Fr., Mem. HS 1.

Cumings. 1908. The stratigraphy and paleontology of the Cincinnatian series of Indiana. Indiana Department of Geology Annual Report, 32:605-1188.

Gradstein, F. M., Ogg, J. G., and A. G. Smith. 2004. A Geologic Time Scale 2004. Cambridge University Press, 589 p. 
Hageman, S.J. 1991. Approaches to systematic and evolutionary studies of perplexing groups: an example using fenestrate Bryozoa. Journal of Paleontology, 65:630647.

Hammer, O. 2003. PAST 1.15. http://folk.uio.no/ohammer/past.

Hickey, D. R. 1988. Bryozoan Astogeny and Evolutionary Novelties: Their Role in the Origin and Systematics of the Ordovician Monticuliporid Trepostome Genus Peronopora. Journal of Paleontology 62(2):180-203.

Key, M. M., Jr. 1990. A New Family of Trepostome Bryozoans from the Ordovician Simpson Group of Oklahoma. Journal of Paleontology 64(5):700-724.

Marintsch, E. 1998. Systematic paleontology, biostratigraphy, and paleoecology of Middle Ordovician Bryozoa (Trepostomata) from the Hermitage Formation. Bulletins of American Paleontology, 112(353):5-121.

McKinney, F. K. 1977. Autozooecial budding patterns in dendroid Paleozoic bryozoans. Journal of Paleontology, 51:303-329.

McKinney, F. K. 2000. Phylloporinids and the phylogeny of the Fenestrida. In Herrera Cubilla, Amalia \& Jackson, Jeremy B.C., (eds.), Proceedings of the 11th International Bryozoology Association Conference. Smithsonian Tropical Research Institute, Balboa, p.54-65.

Nicholson, H. A. 1881. On the structure and affinities of the genus Monticulipora and its subgenera, with critical descriptions of illustrative species. Edinburgh \& London, Willam Blackwood \& Sons.

Ogg, J. G., Ogg, G., and F. M. Gradstein. 2008. The Concise Geologic Time Scale: Cambridge University Press, 177 p.

Ogg, G. 2009. International Stratigraphic Chart. International Commission on Stratigraphy. http://www.stratigraphy.org/upload/ISChart2009.pdf

Pachut, J. F. and R. L. Anstey. 1984. The Relative Information Content of FourierStructural, Binary (Presence-Absence) and Combined Data Sets: A Test Using the H.A. Nicholson Collection of Paleozoic Stenolaemate Bryozoans. Journal of Paleontology, 58(5):1296-1311.

Pachut, J. F. and R. L. Anstey. 2002. Phylogeny, Systematics, and Biostratigraphy of the Ordovician Bryozoan Genus Peronopora. Journal of Paleontology, 76(4):607637. 
Pachut, J. F. and R. L. Anstey. 2007. Inferring Evolutionary Order and Durations Using Both Stratigraphy and Cladistics in a Fossil Lineage (Bryozoa: Peronopora). Palaios, 22:476-488.

Pachut, J. F., R. L. Anstey, and A. S. Horowitz. 1994. The H.A. Nicholson Collection of Paleozoic Stenolaemate Bryozoans: Comparisons of Cladistic and Phenetic Classifications. Journal of Paleontology, 68(5):978-994.

Paquette, L. M. 2008. Phylogenetic Analysis of the Bryozoan Suborder Rhabdomesina. Master's Thesis. Michigan State University.

Parks, W.A. and W.S. Dyer. 1922. The stratigraphy and paleontology of Tornot and vicinity; part 2, the Molluscoidea. Ontario Department of Mines Annual Report, 30:7, 43pp.

Prezbindowski, Dennis R. and R. L. Anstey. 1978. A Fourier-numerical study of a bryozoan fauna from the Threeforks Formation (Late Devonian) of Montana. Journal of Paleontology, 52:353-369.

Smith, A. B. 1994. Systematics and the Fossil Record: Documenting Evolutionary Patterns. Blackwell Scientific Publications, Oxford, 223 p.

Spearing, K. 1998. Phylogenetic Analysis of the Rhabdomesine Bryozoans. Master's Thesis. Michigan State University.

Swofford, D. L. 2007. PAUP*. Phylogenetic Analysis Using Parsimony (* and Other Methods). Version 4.0b4a. Sinauer Associates, Sunder- land, Massachusetts.

Tang, Su and R. J. Cuffey. 1998. Inconobotopora lichenoporoides a new genus and species of cystoporate bryozoan from the Silurian of Gotland, and its evolutionary implication. Journal of Paleontology, 72(2):256-264.

Taylor, P. D. 1979. The inference of extrazoodial feeding currents in fossil bryozoan colonies. Lethaia, 12(1):47-56.

Taylor, P. D. and S. Rozhnov. 1996. A new early cyclostome bryozoan from the Lower Ordovician (Volkhov Stage) of Russia. Palaont. Z., 70(1/2):171-180.

Taylor, P.D., and M. J. Weedon. 2000. Skeletal ultrastructure and phylogeny of cyclostome bryozoans. Zoological Journal of the Linnean Society, 128:337-399.

Ross, J. P. 1967. Evolution of Ectoproct Genus Prasopora in Trentonian Time (Middle Ordovician) in Northern and Central United States. Journal of Paleontology, 41(2):403-416. 
Utgaard, J. and T. G. Perry. 1964. Trepostomatous Bryozoan Fauna of the Upper Part of the Whitewater Formation (Cincinnatian) of Eastern Indiana and Western Ohio. Indiana Department of Conservation Geological Survey Bulletin, 33:111. 


\section{CURRICULUM VITAE}

\section{Amber Diane Adamczyk}

\section{Education}

2010 M.S. Geology

Indiana University - Purdue University Indianapolis

Thesis: Cladistic Analysis of the Paleozoic

Bryozoan Families Monticuliporidae and

3.9 GPA/ 4.0

Mesotrypidae.

2005 B.S. Biology

Hillsdale College, MI

Thesis: A Palaeoecological Reconstruction of a Northern Michigan Peatland with Special Emphasis on Local and Spatial Variability.

\section{English Hillsdale College, MI}

Thesis: The Waves: The Netted Fin in a Waste of Waters. (Virginia Woolf)

\section{$3.2 \mathrm{GPA} / 4.0$}

\section{Work Experience}

Fall 2007

$2005-2006$

$2004-2005$

$2004-2005$

Fall 2004

Fall 2003
Teaching Assistant

Fund. of Earth Hist. Lab

IUPUI, IN

Administrative Assistant

C.B. Clark Services, MI

Research Assistant / Lab Technician

for Dr. Anthony Swinehart

Hillsdale College, MI

Biology Night Tutor

Hillsdale College, MI

Lab Assistant, Bio 360 (Microbiology)

Hillsdale College, MI

Lab Assistant, Bio 200 (Biodiversity survey)

Hillsdale College, MI 
Volunteer Experience

2010 to present

The Indiana State Museum

- Naturalist Lab Host

- Collections Inventory and Database Entry

- Gallery Host for "Titanic: The Artifact Exhibition”

- Exhibit set up for "Titanic”

\section{Research Experience and Interests}

- Taxonomic studies using phylogenetic methods

- Identifying biological, botanical, and geological items

- Fieldwork Research at an isolated biological station in Northern Lower Michigan

- Scientific and Literary literature research

- Interests in ecological succession, biodiversity, and functional morphology; historical geology, botany, and natural history

\section{Awards}

$100 \%$ of graduate schooling paid for by fellowship

$2006 \quad$ Arthur Mirsky Fellowship

$43 \%$ of undergraduate schooling paid for with scholarships $(\$ 38,124)$

2004

2004

2004

2003-2004

2003

2003-2004

2002-2003

2002-2003

2001

2001

2001
The ALS Foundation Scolarship

John Millard Botts Scolarship

Jane S. Tate Memorial Scolarship

Mark Mason Memorial Scholarship

Raymond Mason Tradition Scolarship

Blay Endowed Scholarship

Hillsdale Tradition Award

Bainbridge-Cobb Scholarship

Thora Passekal Scholarship

Hillsdale Independence Grant

William E. Simon Scholarship

\section{Affiliations}

2008

2002-2005

2003-2005

2002-2004
Geological Society of America

Sigma Alpha Iota International Women's Music Honorary

Beta Beta Beta International Biology Honorary

Honors Program Hillsdale College 


\section{Skills}

- Computer skills

- MIMSY XG

- MS Word, Excel, PowerPoint

- Adobe Acrobat Pro, Illustrator, Photoshop

- ESRI ArcGIS

- PAUP

- TiliaGraph

- Digital photography

- Able to use a variety of laboratory equipment, including autoclaves, muffle furnaces, light microscopes, scanning electron microscopy, etc.

\section{Accomplishments}

- Had highest score of my peers on the ETS Major Field Test in 2005 (187/200)

- Spent one month on a college trip in Turkey - experience with history and culture

- Experience, talent, and love for textile arts: knitting, spinning, cross stitch, Japanese silk embroidery

- $\quad$ Performed in an orchestra at Carnegie Hall in 1999 